
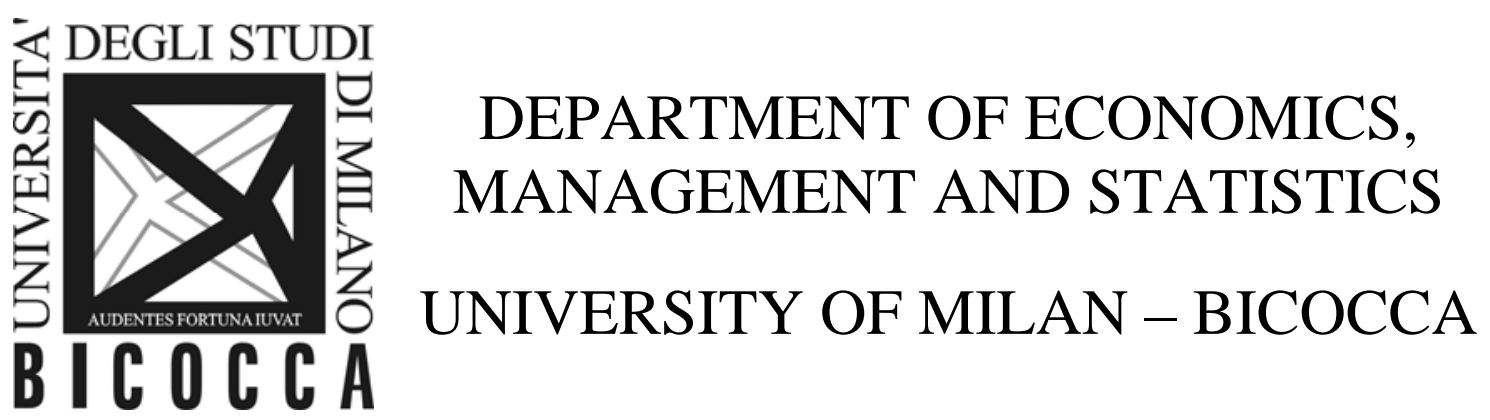

DEMS WORKING PAPER SERIES

\title{
Insights on the global macro-finance interface: Structural sources of risk factors fluctuations and the cross-section of expected stock returns
}

\author{
Claudio Morana
}

No. 264 - December 2013

Dipartimento di Economia, Metodi Quantitativi e Strategie di Impresa Università degli Studi di Milano - Bicocca 


\title{
Insights on the global macro-finance interface: Structural sources of risk factors fluctuations and the cross-section of expected stock returns
}

\author{
Claudio Morana, ${ }^{* \dagger}$ \\ Università di Milano Bicocca (Milano, Italy), \\ CeRP-Collegio Carlo Alberto (Moncalieri, Italy),
}

First draft May 2013; this draft December, 19, 2013

\begin{abstract}
This study contributes to the investigation of the macro-finance interface by assessing the economic content and risk based interpretation of widely employed risk factors in the specification of empirical asset pricing models, i.e., Fama-French size and value, and Carhart momentum factors, as well as the more recent Pastor-Stambaugh liquidity and Adrian-Etula-Muir leverage factors. Strong support for their risk based interpretation, encompassing evidence on causes, persistence and direction of the size, value and momentum effects, and new insights on the specification of systematic risk, are provided.

Keywords: macro-finance interface; risk factors; size, value, momentum, liquidity, and leverage effects; factor vector autoregressive model. JEL classification: G12, C22.
\end{abstract}

\footnotetext{
*Address for correspondence: Claudio Morana, Università di Milano-Bicocca, Dipartimento di Scienze Economiche, Metodi Quantitativi e Strategie d'Impresa, Piazza dell'Ateneo Nuovo 1, 20126, Milano, Italy. E-mail: claudio.morana@unimib.it.

${ }^{\dagger}$ A previous version of the paper was presented at the 8th BMRC-QASS Conference on Macro and Financial Economics, Brunel University, London, 24 May 2013. The author is greteful to conference participants, A. Beltratti and F.C. Bagliano for comments. Funding from EC7FP 3202782013-2015 is gratefully acknowledged.
} 


\section{Introduction}

Since the seminal contributions in the late 1980s, empirical evidence of predictability of stock prices by means of business cycle variables ${ }^{1}$ has stimulated the ongoing investigation of the macroeconomic determinants of asset prices $^{2}$, originally ensued from the empirical failure of the Capital Asset Pricing Model (CAPM; Sharpe, 1964; Lintner, 1965), as well as the ConsumptionCAPM (C-CAPM; Breeden, 1979). ${ }^{3}$

Two different lines of research can be noted in the empirical asset pricing literature, both related to the intertemporal CAPM model (ICAPM, Merton, 1973). As shown by Merton (1973), once shifts in the investment opportunity set are allowed for, the equilibrium equity premium is determined according to a multifactor model, measuring risk in terms of covariance with the market return, as well as with state variables related to unfavorable changes in the investment opportunity set, i.e., downward revisions in expectations of future returns on the market (Campbell, 1993), or in terms of covariance with cashflow and discount rates news (Campbell and Vuolteenaho, 2004) and news about future risk (Campbell et al., 2012).

Accordingly, a first strand of research attempts a more accurate measurement of systematic risk by augmenting the market model with additional factors. For instance, Fama and French (FF, 1993) propose a three-factor model considering, in addition to the market excess return $(M K T)$, size $(S M B)$ and value $(H M L)$ factors, while Carhart (1997) adds a fourth factor, i.e., momentum $(M O M)$, to the FF specification. Several other augmented market model specifications have been proposed in the literature, including risk factors related to sector investment growth, i.e., Cochrane (1996) and Li et al. (2006); human capital, i.e., Jagannathan and Wang (1996); consumption dispersion, i.e., Bansal and Yaron (2004); stock market liquidity, i.e., Pastor and Stambaugh (2003); default risk, i.e., Vassalou and Xing (2004), Kapadia (2011); gross-profitability, i.e., Novy-Marx (2013), Fama and French (2013); financial leverage, i.e., Adrian et al. (2012). ${ }^{4}$

Differently, a second strand of research proposes conditional reformulations of the CAPM and C-CAPM, following findings of Ferson and Harvey

\footnotetext{
${ }^{1}$ See Chen et al., 1986; Campbell and Shiller, 1988; Fama and French, 1988; Ferson and Harvey, 1991. More recently, Campbell and Yogo, 2006; Campbell an Diebold, 2009; Kasparis et al., 2012; Beber et al., 2013.

${ }^{2}$ See Cochrane (2007) for a survey on the macro-finance interface literature.

${ }^{3}$ See Fama and French (2004) and Campbell and Vuolteenaho (2004) for an account of the empirical literature.

${ }^{4}$ The list is by all means not exhaustive; see Goyal (2012) and Nagel (2013) for recent surveys.
} 
(1991) and Ferson and Korajczyck (1995), pointing to statistically significant time variation in the market beta and its price, i.e., in risk and risk premium. As shown by Jagannathan and Wang (1996), the unconditional version of the conditional CAPM (C-CAPM) model also has a multifactor structure, measuring priced risk in terms of covariance between the time-varying beta and the time-varying expected market risk premia (consumption growth), in addition to covariance with the market risk premium (consumption growth).

Empirical support for the two strands of multifactor models has in general been found in the literature, pointing to superior performance, along both the time series and cross-sectional dimensions, than the CAPM and C-CAPM. ${ }^{5}$

Yet, which of the two multifactor specifications is empirically validated is a controversial issue, as scaled CAPM/C-CAPM models have found to show similar explanatory power to the Fama-French three-factor model. Moreover, once scaling information is included in the specification, the Fama-French factors tend to loose explanatory power for the cross-section of expected returns. For instance, Ferson and Harvey (1999) find that when the market factor is scaled by business cycle variables, $H M L$ is not any longer statistically significant; similarly Li et al. (2006), Lettau and Ludvigson (2001), Petkova (2006) and Hahn and Lee (2006), showing the information contained in both $S M B$ and $H M L$ subsumed in four sector specific investment growth factors, the Lettau-Ludvigson cay factor, and the default $(S M B)$ and term $(H M L)$ premia, respectively. As the default and term spreads are determined by credit market conditions (asset distress risk) and the stance of monetary policy (asset duration risk), their innovations might measure revisions in market expectations about future credit supply and interest rates (Hahn and Lee, 2006; Petkova, 2005), and therefore business cycle conditions/risk (Campbell and Diebold, 2009).

Coherently, Ludvigson and $\mathrm{Ng}$ (2007) find $S M B, H M L$ and the return on the market portfolio $(M K T)$ strongly correlated with a common risk factor extracted from a broad cross-section of financial indicators (comprised of valuation ratios, interest rate spreads, industry returns and risk factors); Vassalou (2003) and Kapadia (2011) find the predictive ability of $S M B$ and $H M L$ for the cross-section of expected equity returns determined by their informational content concerning future GDP growth and that component of GDP growth correlated with aggregate distress risk, respectively.

The above results are however consistent with Merton's ICAPM, as $S M B$ and $H M L$ might mimic state variables related to firms' distress, measuring

\footnotetext{
${ }^{5}$ See for instance Fama and French (1993, 1996), Ferson and Harvey (1999), Davis et al. (2000), Lettau and Ludvigson (2001), Campbell and Vuolteenaho (2004), Petkova and Zhang (2005), Lustig and Van Nieuwerburgh (2005), Santos and Veronesi (2005), Kang et al. (2011), Campbell et al. (2012).
} 
revisions in expectations about the investment opportunity set (Fama and French, 1993, 1996; Davis et al., 2000), i.e., covariance with recession; as recessions are periods when risk and risk aversion are high, (procyclical) small and value stocks should pay a higher premium than (countercyclical) large and growth stocks.

Bai and Ng (2006b) provide support to the latter view, finding the information content of innovations in consumption and industrial production growth, inflation, and the corporate and term spreads actually subsumed in $S M B, H M L$ and $M K T{ }^{6}$

This paper contributes to the literature on the macro-finance interface under different perspectives, yielding insights on the economic content of risk factors, with particular reference to the Fama-French $S M B$ and $H M L$ factors, as well as Carhart momentum $(M O M)$, Pastor-Stambaugh stock market liquidity $(P S L)$ and Adrian-Etula-Muir financial leverage $(L E V)$; moreover, Bagliano-Morana financial fragility $(F R A)$, global stock marketwide returns $(M K T)$, and risk aversion/economic uncertainty are also assessed.

The originality of the study stems from its global economy perspective, as macro-financial conditions are assessed with reference to a broad cross-section of macroeconomic and financial variables for 50 countries, as well as for the depth of the investigation, yielding insights on $i$ ) the structural determinants of risk factors fluctuations; $i i)$ the source, persistence and direction of the size, value and momentum effects; $i i i)$ the specification of systematic risk. Both new findings, as well as encompassing evidence, concerning risk factors dynamics over the business cycle, are provided.

To anticipate the main results of the paper, we find strong support for a risk based interpretation of $S M B$ and $H M L, M O M$, as well as for the other risk factors.

Firstly, macro-financial shocks account for the bulk of risk factors fluctuations, with macroeconomic shocks contributing most sizably in the very short-term, financial shocks in the short-term, and oil market disturbances in the medium- to long-term term. Interestingly, different sources of macroeconomic and financial risk are reflected by the various risk factors; in particular, productivity and monetary policy stance shocks for $S M B$; labor market and term structure slope shocks for $H M L$; aggregate demand and US terms of trade shocks for $M O M$.

Secondly, procyclical size, value, momentum and market-wide effects, as

\footnotetext{
${ }^{6}$ Moreover, the exact factor null hypothesis is not rejected for $S M B, H M L$ and $M K T$, while it is strongly rejected for the innovations in any of the above macroeconomic variables.
} 
well as leverage and stock market liquidity effects, appear to be mostly generated by (demand-side) macroeconomic shocks, largely accounting for real activity and stock market fluctuations at business cycle frequencies; similarly for countercyclical volatility and credit risk effects. Differently, supply-side (productivity, oil reserves) shocks might generate opposite patterns for all the above effects, apart from credit risk.

Thirdly, concerning the specification of systematic risk, we find that not all the structural sources of risk factors fluctuations are priced by the market; hence, the performance of empirical asset pricing models can be sizably improved by filtering out non-priced components, i.e., observational noise; we also find risk aversion, fragility and leverage factors containing relevant information for the pricing of the Fama-French 25 size and value ordered portfolios, consistent with their business cycle state dependence reflecting covariance with recessions.

The rest of the paper is organized as follows. In Section 2 the econometric methodology is outlined, while in Section 3 the estimation of the econometric model and the identification of the structural shocks is performed. Then, in Section 4 and 5 the empirical results concerning macro-financial sources of risk factors fluctuations and their dynamic responses to key structural shocks are presented. Finally, in Section 6 results related to the specification of systematic risk are discussed, while conclusions are drawn in Section 8.

\section{The econometric model}

The econometric model is described by two blocks of equations. The first block refers to the observed $\left(\mathbf{F}_{2, t}\right)$ and unobserved $\left(\mathbf{F}_{1, t}\right)$ global macro-financial factors and oil market demand and supply side variables $\left(\mathbf{O}_{t}\right)$, collected in a

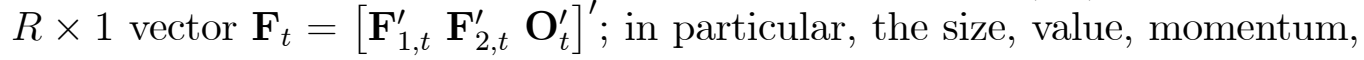
stock market volatility and liquidity, leverage and fragility factors are collected, among other variables, in the subvector $\mathbf{F}_{2, t}$. The second block refers to $Q$ macro-financial variables for $M$ countries, collected in a $N \times 1$ vector $\mathbf{Z}_{t}(N=M \times Q)$. The joint dynamics of the global and local macro-financial blocks are then modelled by means of the following reduced form dynamic factor model

$$
\begin{aligned}
(\mathbf{I}-\mathbf{P}(L))\left(\mathbf{F}_{t}-\boldsymbol{\kappa}\right) & =\boldsymbol{\eta}_{t} \\
(\mathbf{I}-\mathbf{C}(L))\left(\left(\mathbf{Z}_{t}-\boldsymbol{\mu}\right)-\boldsymbol{\Lambda}\left(\mathbf{F}_{t}-\boldsymbol{\kappa}\right)\right) & =\mathbf{v}_{t} .
\end{aligned}
$$


The model is cast in a weakly stationary representation, as $\left(\mathbf{F}_{t}-\boldsymbol{\kappa}\right),\left(\mathbf{Z}_{t}-\right.$ $\boldsymbol{\mu}) \sim I(0)$, where $\boldsymbol{\mu}$ and $\boldsymbol{\kappa}$ are $N \times 1$ and $R \times 1$ vectors of intercept components, respectively, with $R \leq N$.

Global dynamics are described by the stationary finite order polynomial matrix in the lag operator $\mathbf{P}(L), \mathbf{P}(L) \equiv \mathbf{P}_{1} L+\mathbf{P}_{2} L^{2}+\ldots+\mathbf{P}_{p} L^{p}$, where $\mathbf{P}_{j}$, $j=1, . ., p$, is a square matrix of coefficients of order $R$, and $\boldsymbol{\eta}_{t} \sim$ i.i.d.(0, $\left.\boldsymbol{\Sigma}_{\eta}\right)$ is a $R \times 1$ vector of i.i.d. reduced form shocks driving the $\mathbf{F}_{t}$ factors. The contemporaneous effects of the global factors on each country's variables in $\mathbf{Z}_{t}$ are measured by the loading coefficients collected in the $N \times R$ matrix $\boldsymbol{\Lambda}=\left[\begin{array}{lll}\boldsymbol{\Lambda}_{F_{1}}^{\prime} & \boldsymbol{\Lambda}_{F_{2}}^{\prime} & \boldsymbol{\Lambda}_{O}^{\prime}\end{array}\right]^{\prime}$.

Local dynamics are described by the stationary finite order block (own country) diagonal polynomial matrix in the lag operator $\mathbf{C}(L) \equiv \mathbf{C}_{1} L+$ $\mathbf{C}_{2} L^{2}+\ldots+\mathbf{C}_{c} L^{c}$, where $\mathbf{C}_{j}, j=0, . ., c$, is a square matrix of coefficients of order $N$, partitioned as

$$
\underset{N \times N}{\mathbf{C}_{j}}=\left[\begin{array}{cccc}
\mathbf{C}_{j, 11} & \mathbf{0} & \ldots & \mathbf{0} \\
Q \times Q & & & \mathbf{0} \\
\mathbf{0} & \mathbf{C}_{j, 22} & \ldots & \\
& Q \times Q & & \vdots \\
\vdots & \ldots & \ddots & \vdots \\
\mathbf{0} & \mathbf{0} & \ldots & \mathbf{C}_{j, M M}
\end{array}\right]
$$

Finally, $\mathbf{v}_{t} \sim$ i.i.d. $\left(\mathbf{0}, \boldsymbol{\Sigma}_{v}\right)$ is the $N \times 1$ vector of reduced-form idiosyncratic (i.e., country-specific) disturbances, with $E\left[\eta_{j t} v_{i s}\right]=0$ for all $i, j, t, s$.

The specification of the model in (1)-(2) embeds a set of important assumptions on the structure of global and local linkages: $(i)$ global shocks $\left(\boldsymbol{\eta}_{t}\right)$ affect both the global and local economies through the polynomial matrix $\mathbf{P}(L)$ and the factor loading matrix $\boldsymbol{\Lambda} ;(i i)$ country-specific disturbances $\left(\mathbf{v}_{t}\right)$ do not affect the global economy, limiting their impact only to the country of origin $(\mathbf{C}(L)$ is assumed to be block (own-country) diagonal).

By substituting (1) into (2), the reduced form vector autoregressive (VAR) representation of the dynamic factor model can be written as

$$
(\mathbf{I}-\mathbf{A}(L))\left(\mathbf{Y}_{t}-\gamma\right)=\varepsilon_{t},
$$

where $\mathbf{Y}_{t}=\left[\begin{array}{ll}\mathbf{F}_{t}^{\prime} & \mathbf{Z}_{t}^{\prime}\end{array}\right]^{\prime}, \boldsymbol{\gamma}=\left[\begin{array}{ll}\boldsymbol{\kappa}^{\prime} & \boldsymbol{\mu}^{\prime}\end{array}\right]^{\prime}$,

$$
\begin{gathered}
\mathbf{A}(L)=\left(\begin{array}{cc}
\mathbf{P}(L) & \mathbf{0} \\
{[\boldsymbol{\Lambda} \mathbf{P}(L)-\mathbf{C}(L) \boldsymbol{\Lambda}]} & \mathbf{C}(L)
\end{array}\right), \\
\boldsymbol{\varepsilon}_{t} \equiv\left[\begin{array}{c}
\boldsymbol{\varepsilon}_{1, t} \\
\boldsymbol{\varepsilon}_{2, t}
\end{array}\right]=\left[\begin{array}{c}
\mathbf{I} \\
\boldsymbol{\Lambda}
\end{array}\right]\left[\boldsymbol{\eta}_{t}\right]+\left[\begin{array}{c}
\mathbf{0} \\
\mathbf{v}_{t}
\end{array}\right],
\end{gathered}
$$


with variance-covariance matrix

$$
E\left[\varepsilon_{t} \varepsilon_{t}^{\prime}\right]=\Sigma_{\varepsilon}=\left(\begin{array}{cc}
\Sigma_{\eta} & \Sigma_{\eta} \Lambda^{\prime} \\
\Lambda \Sigma_{\eta} & \Lambda \Sigma_{\eta} \Lambda^{\prime}+\Sigma_{v}
\end{array}\right)
$$

The structural vector moving average representation for the global model in (1) can then be written as

$$
\left(\mathbf{F}_{t}-\boldsymbol{\kappa}\right)=\mathbf{H}_{F}(L) \mathbf{K}^{-1} \boldsymbol{\xi}_{t},
$$

where $\boldsymbol{\xi}_{t}$ is the vector of the $R$ structural shocks driving the common factors in $\mathbf{F}_{t}$, i.e., $\boldsymbol{\xi}_{t}=\mathbf{K} \boldsymbol{\eta}_{t}, \mathbf{K}$ is a $R \times R$ invertible matrix, and

$$
\mathbf{H}(L) \equiv\left(\begin{array}{cc}
\mathbf{H}_{F}(L) & \mathbf{0} \\
\mathbf{H}_{F Z}(L) & \mathbf{H}_{Z}(L)
\end{array}\right) \equiv(\mathbf{I}-\mathbf{A}(L))^{-1} .
$$

By assumption, the structural factor shocks are orthogonal and have unit variance, so that $E\left[\boldsymbol{\xi}_{t} \boldsymbol{\xi}_{t}^{\prime}\right]=\mathbf{K} \boldsymbol{\Sigma}_{\eta} \mathbf{K}^{\prime}=\mathbf{I}_{R}$. To achieve exact identification of the structural disturbances, additional $R(R-1) / 2$ restrictions need to be imposed. Since $\boldsymbol{\eta}_{t}=\mathbf{K}^{-1} \boldsymbol{\xi}_{t}$, imposing exclusion restrictions on the contemporaneous impact matrix amounts to imposing zero restrictions on the elements of $\mathbf{K}^{-1}$, for which a lower-triangular structure is assumed. Operationally, $\mathbf{K}^{-1}$ (with the $R(R-1) / 2$ zero restrictions necessary for exact identification imposed) is estimated by the Choleski decomposition of the factor innovation variance-covariance matrix $\boldsymbol{\Sigma}_{\eta}$, i.e., $\hat{\mathbf{K}}^{-1}=\operatorname{chol}\left(\hat{\boldsymbol{\Sigma}}_{\eta}\right)$. Impulse responses, forecast error variance and historical decompositions can then be obtained by means of standard formulas.

\subsection{Estimation}

Consistent and asymptotically normal estimation of the two-block specification in (1) and (2) is obtained by means of the procedures proposed in Morana $(2011,2012)$, shown to yield accurate estimation also in small samples (see the Monte Carlo results reported in Morana, 2011, 2012). Following the thick modelling strategy of Granger and Jeon (2004), median estimates of the parameters of interest, impulse responses, forecast error variance and historical decompositions, as well as their confidence intervals, are obtained by means of simulation.

\subsubsection{Estimation of the unobserved factors and the local block}

Iterative estimation of the unobserved global factors and the local model in (2) is performed through the following steps. 


\section{- Step 1: initialization.}

An initial estimate of the $R_{1}$ unobserved common factors in $\mathbf{F}_{1, t}$ can be obtained through the application of Principal Components Analysis (PCA) to subsets of homogeneous cross-country data $\mathbf{Z}_{i}=\left\{\mathbf{Z}_{i, 1}, \ldots, \mathbf{Z}_{i, T}\right\}, i=1, \ldots, R_{1}$, $R_{1} \leq Q$; for instance, a GDP growth global factor can be estimated by means of the first PC extracted from cross-country GDP growth data, a stock return global factor by means of the first PC extracted from cross-country stock return data, and so on.

Then, conditional on the estimate of the unobserved stochastic factors, a preliminary estimate of the polynomial matrix $\mathbf{C}(L)$ and the factor loading matrix $\Lambda$ is obtained by means of OLS estimation of the equation system in (2). This can be performed by first regressing $\mathbf{Z}_{t}$ on $\boldsymbol{\mu}$ and the demeaned factors $\left(\hat{\mathbf{F}}_{t}-\hat{\boldsymbol{\kappa}}\right)$ to obtain $\hat{\boldsymbol{\mu}}$ and $\hat{\boldsymbol{\Lambda}}$; then, the gap variables $\mathbf{Z}_{t}-$ $\hat{\boldsymbol{\mu}}-\hat{\boldsymbol{\Lambda}}\left(\hat{\mathbf{F}}_{t}-\hat{\boldsymbol{\kappa}}\right)$ can be constructed and $\hat{\mathbf{C}}(L)$ obtained by means of $O L S$ estimation of the VAR model in (2).

- Step 2: the iterative procedure.

Next, a new estimate of the unobserved common factors in $\mathbf{F}_{1, t}$ can be obtained by means of PCA applied to the filtered variables $\mathbf{Z}_{t}^{*}=\mathbf{Z}_{t}-$ $\hat{\boldsymbol{\Lambda}}_{*}\left(\hat{\mathbf{F}}_{*, t}-\hat{\boldsymbol{\kappa}}_{*}\right)-\hat{\mathbf{C}}(L)\left[\mathbf{Z}_{t}-\hat{\boldsymbol{\Lambda}}_{*}\left(\hat{\mathbf{F}}_{*, t}-\hat{\boldsymbol{\kappa}}_{*}\right)\right]$, with $\hat{\mathbf{F}}_{*, t}=\left[\mathbf{F}_{2, t}^{\prime} \mathbf{O}_{t}^{\prime}\right]^{\prime}, \hat{\boldsymbol{\Lambda}}_{*}=$ $\left[\hat{\boldsymbol{\Lambda}}_{F_{2}}^{\prime} \hat{\boldsymbol{\Lambda}}_{O}^{\prime}\right]^{\prime}$ and $\hat{\boldsymbol{\kappa}}_{*}=\left[\hat{\boldsymbol{\kappa}}_{F_{2}}^{\prime} \hat{\boldsymbol{\kappa}}_{O}^{\prime}\right]^{\prime}$. Then, conditional on the new unobserved common factors, a new estimate of the polynomial matrix $\mathbf{C}(L)$ and the factor loading matrix $\boldsymbol{\Lambda}$ is attained as above described. The procedure is then iterated until convergence.

Note that the proposed iterative procedure bears the interpretation of $Q M L$ estimation performed by means of the EM algorithm, using a Gaussian likelihood function. In the $E$-step the unobserved factors are estimated, given the observed data and the current estimate of model parameters, by means of $P C A$; in the $M$-step the likelihood function is maximized (OLS estimation of the $C(L)$ matrix is performed) under the assumption that the unobserved factors are known, conditioning on their $E$-step consistent estimate. Consistent and asymptotically normal estimation of unobserved $\mathrm{I}(0)$ factors by means of PCA is proved in Bai (2003) under general conditions ${ }^{7}$; moreover, as proved by Bai and $\mathrm{Ng}$ (2006a), when the unobserved factors are estimated

\footnotetext{
${ }^{7}$ In particular, under some general conditions, given any invertible matrix $\Xi$ and the vector of unobserved $\mathrm{I}(0)$ factors $f_{t}, \sqrt{N}$ consistency and asymptotic normality of PCA for $\Xi f_{t}$, at each point in time, is established for $N, T \rightarrow \infty$ and $\sqrt{N} / T \rightarrow 0$ and the case of $\mathrm{I}(0)$ idiosyncratic components, the latter also displaying limited heteroskedasticity in both their time-series and cross-sectional dimensions (Bai, 2003). Moreover, $\sqrt{T}$ consistency and asymptotic normality of PCA for $\Lambda_{f} \Xi^{-1}$ is established under the same conditions, as
} 
by means of PCA in the $E$-step, the generated regressors problem is not an issue for consistent estimation in the $M$-step, due to faster vanishing of the estimation error, provided $\sqrt{T} / N \rightarrow 0$; the factors estimated by means of PCA can then be considered as they were actually observed, therefore not requiring Kalman smoothing at the $E$-step, i.e., the computation of their conditional expectation. Convergence to the one-step $Q M L$ estimate is ensured, as the value of the likelihood function is increased at each step. See Morana (2011) for additional details and Monte Carlo results, validating the use of the iterative estimation procedure in small samples.

\subsubsection{Estimation of the global model}

- Step 3: restricted estimation of the reduced form VAR model. Consistent and asymptotically normal estimation of the polynomial matrix $\mathbf{P}(L)$ in the VAR model in (1), still relying on Bai and $\mathrm{Ng}$ (2006a), can be obtained by means of OLS (Morana, 2011) or PC-VAR (Morana, 2012) estimation, by holding the latent factors $\mathbf{F}_{1, t}$ as they were observed; then, by employing $\hat{\mathbf{P}}(L)$ and the final estimate of the $\mathbf{C}(L)$ and $\boldsymbol{\Lambda}$ matrices, the $\boldsymbol{\Phi}^{*}(L)$ polynomial matrix is estimated as $\hat{\mathbf{\Phi}}^{*}(L)=[\hat{\mathbf{\Lambda}} \hat{\mathbf{P}}(L)-\hat{\mathbf{C}}(L) \hat{\mathbf{\Lambda}}]$.

PC-VAR estimation Given the $R \times 1$ vector $\mathbf{x}_{t} \equiv \hat{\mathbf{F}}_{t}-\hat{\boldsymbol{\kappa}}$, consider the vector autoregressive (VAR) model in (1); PC-VAR estimation relies on the following algebraic identity

$$
\mathbf{x}_{t} \equiv \hat{\Xi} \hat{\mathbf{f}}_{t}
$$

where $\hat{\mathbf{f}}_{t}=\hat{\boldsymbol{\Xi}}^{\prime} \mathbf{x}_{t}$ is the $R \times 1$ vector of estimated principal components of $\mathbf{x}_{t}, \hat{\boldsymbol{\Xi}}$ is the $R \times R$ matrix of orthogonal eigenvectors associated with the $R$ (ordered) eigenvalues of $\hat{\boldsymbol{\Sigma}}\left(\boldsymbol{\Sigma}=E\left[\mathbf{x}_{t} \mathbf{x}_{t}^{\prime}\right]\right)$. This follows from the eigenvalueeigenvector decomposition of $\hat{\boldsymbol{\Sigma}}$, i.e., $\hat{\boldsymbol{\Xi}}^{-1} \hat{\boldsymbol{\Sigma}} \hat{\boldsymbol{\Xi}}=\hat{\boldsymbol{\Gamma}}$, where $\hat{\boldsymbol{\Gamma}}=\operatorname{diag}\left(\hat{\gamma}_{1}, \ldots, \hat{\gamma}_{R}\right)$ is the $R \times R$ diagonal matrix containing the (ordered) eigenvalues of $\hat{\boldsymbol{\Sigma}}$.

PC-VAR estimation of $\mathbf{P}(L)$ is then implemented as follows:

- apply PCA to $\mathbf{x}_{t}$ and compute $\hat{\mathbf{f}}_{t}=\hat{\mathbf{\Xi}}^{\prime} \mathbf{x}_{t}$;

- obtain $\hat{\mathbf{D}}(L)$ by means of OLS estimation of the stationary dynamic vector regression model

$$
\begin{aligned}
& \mathbf{x}_{t}=\mathbf{D}(L) \hat{\mathbf{f}}_{t}+\boldsymbol{\varepsilon}_{t} \\
& \boldsymbol{\varepsilon}_{t} \sim \text { i.i.d. }\left(\mathbf{0}, \boldsymbol{\Sigma}_{\varepsilon}\right),
\end{aligned}
$$

well as $\min \{\sqrt{N}, \sqrt{T}\}$ consistency and asymptotic normality of PCA for the unobserved common components $\Lambda_{f} f_{t}$, at each point in time, for $N, T \rightarrow \infty$. 
where $\mathbf{D}(L) \equiv \mathbf{D}_{1} L+\mathbf{D}_{2} L^{2}+\ldots+\mathbf{D}_{p} L^{p}$ has all the roots outside the unit circle;

- recover the (implied OLS) estimate of the actual parameters yield by the unrestricted VAR model in (1) by solving the linear constraints

$$
\hat{\mathbf{P}}(L)_{P C V A R}=\hat{\mathbf{D}}(L) \hat{\mathbf{\Xi}}^{\prime}
$$

in the actual implementation only the first $Q<R$ ordered PCs are employed, yielding

$$
\hat{\mathbf{P}}(L)_{P C V A R}=\hat{\mathbf{D}}(L) \hat{\mathbf{\Xi}}_{Q}^{\prime},
$$

where $\underset{(R \times R)}{\hat{\boldsymbol{\Xi}}}=\left[\begin{array}{cc}\hat{\boldsymbol{\Xi}}_{Q} & \hat{\boldsymbol{\Xi}}_{R-Q} \\ (R \times Q) & (R \times R-Q)\end{array}\right]$.

See Morana (2012) for further details on PC-VAR estimation, its asymptotic properties and Monte Carlo results.

\section{Estimation of the global model}

The global model in (1) counts 33 endogenous variables, collected in the vector $\mathbf{F}_{t}=\left[\begin{array}{lll}\mathbf{F}_{1, t}^{\prime} & \mathbf{F}_{2, t}^{\prime} & \mathbf{O}_{t}^{\prime}\end{array}\right]^{\prime}$, over the period 1985:1 through 2010:3.

$\mathbf{F}_{1, t}$ contains 12 unobserved global factors estimated by means of the local country block (2), using a first order own country diagonal dynamic structure, as suggested by the BIC information criterion. ${ }^{8}$ The local block counts over 800 equations and contains macroeconomic and financial data for 50 countries. $^{9}$ The unobserved global macro-financial factors, estimated using subsets of homogeneous variables are as follows: real activity growth $(Y)$; excess public consumption growth $(G$, fiscal stance); US\$ exchange rate return index $(X)$; core inflation $(N)$; excess liquidity growth $(L)$; employment growth $(E)$; unemployment rate change $(U)$; real wage growth $(W)$; real stock market returns $(F)$; real housing returns $(H)$; real short term rate $(S R)$; term spread $(T S) .{ }^{10}$

$\mathbf{F}_{2, t}$ contains 11 observed global (or US) factors, i.e., the Bagliano-Morana financial fragility index $(F R A)$ in differences, the Fama-French size and

\footnotetext{
${ }^{8} \hat{\mathbf{F}}_{1, t}$ has been obtained by conditioning with respect to $\mathbf{F}_{2, t}$ and only a subset of the variables considered in $\mathbf{O}_{t}$, i.e., the real oil price and the real non-energy commodities price index, which are available since 1980:1. The other oil market variables are available only since $1986: 1$.

${ }^{9}$ See Appendix A for details.

${ }^{10}$ Detailed results on PCA and unit root testing are not included for reasons of space, but are available from the author upon request.
} 
value factors $(S M B, H M L)$, the Carhart momentum factor $(M O M)$, the Pastor-Stambaugh stock market liquidity factor $(P S L)$, the Adrian-EtulaMuir leverage factor $(L E V)$, a risk aversion index $(F V)$, real gold price returns $(G D)$, real non-energy commodities price index returns $(M)$, US fiscal $(F d)$ and trade $(T d)$ deficit to GDP ratios in differences. ${ }^{11}$

$\mathbf{O}_{t}$ contains 10 global oil market variables, i.e., world oil reserves growth $(R)$, net world oil production changes (increase: $P p$, decrease: Pm), OECD oil refineries margins growth $(R M)$, world oil consumption growth $(C), O E C D$ oil inventories growth $(I N V)$, real WTI oil price returns $(O P)$, nominal WTI oil price volatility in differences $(O V)$, the 12-month futures basis $(F B)$, and Working-T index growth rate $(W T) .{ }^{12}$

PC-VAR estimation of the global model in (1) involves the first 12 principal components of $\mathbf{F}_{t}{ }^{13}$, jointly accounting for $80 \%$ of total variance, and three lags, as selected according to Monte Carlo results (Morana, 2012) and specification tests. Hence, 36 parameters are estimated for each of the 33 equations in the model. Note that, given the sample size available, the estimation of an unrestricted $\operatorname{VAR}(3)$ model would have been unfeasible, counting 99 parameters for each equations.

\subsection{Identification of the structural shocks}

The identification of the structural shocks is grounded on the following rationale concerning global macro-financial interactions:

- the oil market supply side is constrained by geophysical conditions, and therefore relatively exogenous to macro-financial conditions;

- oil consumption is contemporaneously determined by the state of the world business cycle, while oil inventories by oil market supply-side and (flow and financial) demand-side conditions;

- real oil price and nominal oil price volatility are contemporaneously determined by oil supply and demand interactions.

Moreover, it is assumed that:

- real activity, over the business cycle, is determined by labor market conditions, through a short-run production function;

- the fiscal/trade stance contemporaneously adjust to business cycle conditions;

- aggregate demand feedbacks with delay to aggregate supply, and prices adjust according to their interaction;

\footnotetext{
${ }^{11}$ See Appendix A for details.

${ }^{12}$ See Appendix A for details.

${ }^{13}$ Net oil production variables excluded.
} 
- real wages contemporaneously react to prices and aggregate demand/supply developments;

- the liquidity stance, set (by central banks) according to the state of the business cycle, contemporaneously determines the real short-term interest rate, also impacting on asset prices and financial risk;

- liquidity, consistent with a leaning-against-the-wind strategy followed by central banks, may then respond to asset prices and financial risk developments only with (at least one-quarter) delay;

- risk factors contemporaneously react to oil market, macroeconomic/liquidity, real estate and exchange rate market conditions;

- asset prices contemporaneously react to oil market and business cycle conditions, the monetary policy stance and changing expectations on the investment opportunity set (risk factors), assuming housing prices slower moving than commodities prices, and stock prices faster moving relatively to any other asset class.

As the identification of the structural shocks is performed by means of the Choleski decomposition approach, the recursive ordering implied by the above assumptions is as follows:

- oil supply conditions: reserves $(R)$, oil production changes $(P p ; P m)$, refineries margins $(R M)$;

- macroeconomic conditions: employment $(E)$, unemployment $(U)$, real activity $(Y)$, fiscal stance $(G)$, US fiscal and trade deficits $(F d, T d)$, core inflation $(N)$; real wages $(W)$;

- flow oil demand conditions: oil consumption $(C)$;

- monetary policy stance: excess liquidity $(L)$, real short term rate $(S R)$ and term spread $(T S)$;

- financial conditions $I$ : real housing prices $(H)$, US\$ exchange rate index $(X)$, risk aversion index $(F V)$, Fama-French size and value factors $(S M B$, $H M L)$, Carhart momentum factor $(M O M)$, Pastor-Stambaugh stock market liquidity factor $(P S L)$, Adrian-Etula-Muir leverage factor $(L E V)$;

- oil futures and spot market conditions: Working-T index $(W T)$, futures market basis $(F B)$, oil inventories $(I N V)$, oil price $(O P)$, oil price volatility $(O V)$;

- financial conditions $I I$ : real non-energy commodities price index $(M)$, real stock $(F)$ and gold $(G D)$ prices, Bagliano-Morana fragility index $(F R A)$.

As the implied recursive structural model is exactly identified, the assumed contemporaneous exclusion restrictions cannot be tested. Yet, a joint test, based on the Bonferroni bounds principle, carried out using the 528 possible bivariate tests implied by the recursive structure involving the 33 variables, does not reject, even at the $20 \%$ significance level, the weak exo- 
geneity null hypothesis (the value of the test is 0.005 to be compared with a $20 \%$ critical value equal to 0.0004 ). While this result cannot be taken as a validation for the set of restrictions at the system level, it however suggests that the implied pair wise recursive structure is coherent with the data. We then expect the identified shocks be robust to the ordering of the variables.

Three main sets of structural disturbances are then identified by means of the assumed recursive structure, i.e., oil market, macroeconomic and financial shocks. Insights on the theoretical properties of the identified structural disturbances are reported in Appendix $\mathrm{B}^{14}$, where the congruence of empirical and expected theoretical properties is assessed by means of impulse response analysis as well (Table A1-A3). Given the scope of the analysis, insights for selected shocks of interest only are reported below; the latter are those contributing most to risk factors fluctuations (see the forecast error variance decomposition section).

\subsubsection{Oil market structural shocks}

The oil market structural disturbances are: oil market supply side shocks (oil reserves $(O R)$, flow oil supply (positive, $O S P$; negative, $O S N$ ), oil production mix $(O X)$ ); oil market demand side shocks (oil consumption and inventories preferences $(O C, O I)$ ); oil futures market speculative shocks (oil futures market-pressure $(O F P)$, residual oil futures market $(O F R))$; other oil price (other real oil price $(O R P)$ and nominal oil price volatility $(O N V)$ ) shocks.

In particular:

- A positive oil reserves $(O R$ ) shock (signaling a future downward shift in the flow oil supply schedule) drives the futures and the spot oil prices downward.

- A negative $(O S N)$ (positive, $O S P$ ) flow oil supply shock (upward (downward) shift in the flow oil supply schedule) causes a negative (positive) correlation between oil production and the real oil price.

\subsubsection{Macroeconomic structural shocks}

The macroeconomic structural disturbances are labor market shocks (labor demand $(L D)$ and supply $(L S))$; aggregate demand shocks $(A D)$; productivity shocks $(P R)$; core inflation shocks $(C I)$; global imbalance shocks (global (GFI), US (GDI) and ex-US global (GTI) saving rate).

In particular:

\footnotetext{
${ }^{14}$ Appendix B will be made permanently availabe online from SSRN.
} 
- A positive labor supply shock ( $L S$, upward shift in the labor supply schedule) causes a negative correlation between employment and the real wage. The latter can also be understood in terms of a (positive labor) factor shares shock, causing a negative correlation between real stock prices and real wages, as in Lettau and Ludvigson (2011).

- A positive aggregate demand shock ( $A D$, upward shift in the aggregate demand schedule) induces a positive correlation between output and the price level.

- A positive productivity shock $(P R$, rightward shift in the long-run aggregate supply schedule) causes a permanent increase in output and contraction in aggregate stock prices (through Shumpeterian's creative destruction effects or through pricing kernels effects), negatively affecting, or without impacting, the price level.

- A positive global fiscal imbalance shock is a negative global saving rate shock (GFI); as predicted by the neoclassical growth model, the shock leads to a downward shift in gross investment and to a contraction in the steadystate real capital and output levels, which decline over the transition process as well.

- Similarly, a positive US fiscal imbalance shock is a negative US saving rate shock $(G D I)$; due to the driving role of the US for the global economy, the contraction in the US steady-state real capital and output levels determined by $G D I$ leads to a contraction in the world steady-state real capital and output levels as well.

- A positive US trade imbalance shock $(G T I)$ is a positive saving glut shock, which can be associated with the ongoing capital flows from emerging countries to the US, since early 1980s. Consistent with Bernanke (2005), the shock leads to the diversion of savings from countries with relative higher productivity (fast growing emerging countries) to the US, driving down the global real interest rate.

\subsubsection{Financial structural shocks}

The financial structural disturbances are monetary policy stance shocks (MPS); term structure level $(T L)$ and slope (TS) shocks; US terms of trade shocks $(T T)$; portfolio allocation/preferences shocks (stocks (PF), housing $(P H)$, non-energy commodities $(P M)$ and gold $(P G))$; revisions in expectations about the state of the investment opportunity set (size $(S Z)$, value $(V L)$, momentum $(M M)$, stock market liquidity $(S L)$ and financial leverage $(L V)$ ), risk aversion and risk appetite $(R A V, R A P)$ shocks.

In particular:

- A positive monetary policy stance/excess liquidity shock (MPS) induces 
a negative correlation between overall liquidity and interest rates; through interest rate, asset prices, and credit channels, the shock is then transmitted to real activity.

- A positive term structure level shock (TL) shifts upward the whole term structure of interest rates; differently, a positive term structure slope shock $(T S)$ tilts upward the term structure of interest rates.

- A negative US terms of trade shock (TT) causes a depreciation of the US\$ exchange rate.

- Positive stocks $(P F)$, housing $(P H)$, non-energy commodities $(P M)$ and gold $(P G)$ portfolio allocation/preference shocks lead to an increase in the demand of the corresponding asset and its price, unrelated to global macro-financial and oil market developments, triggering portfolio reallocation across assets classes and impacting, through wealth, Tobin's $Q$ and financial accelerator effects, on real activity as well.

\section{Forecast error variance decomposition}

Figures 1-3 report the results for the median forecast error variance decomposition (FEVD), computed up to a horizon of ten years (40 quarters), for selected horizons: very short-term (within 2 quarters, VST), short-term (between 1 and 2 years, ST), medium-term (three to five years, MT), and longterm (10-year horizon, LT).

Given the scope of the analysis, results are reported only for the variables of interest, i.e., real activity $(Y)$, real stock prices $(F)$, stock market volatility $(F V)$ and risk factors, i.e., Fama-French size $(S M B)$ and value $(H M L)$, Carhart momentum $(M O M)$, Pastor-Stambaugh stock market liquidity $(P S L)$, Adrian-Etula-Muir leverage $(L E V)$ and Bagliano-Morana fragility $(F R A)$. The latter exercise is useful to gauge insights on the macro-financial information content of risk factors, measured on average over the period investigated, i.e., 1986:1 through 2010:3.

For expository purposes, in Figure 1 results are displayed with reference to the joint effect of various categories of shocks, distinguishing among oil market supply side shocks (SUP: OR, OSP, OSN, OX), other oil market shocks (OOS: OC, OI, OFP, OFR, ORP, ONV), macroeconomic shocks (MAC:LS,LD, AD, PR, CI, GFI, GDI, GTI), financial shocks (FIN: $M P S, T L, T S, T T, P F, P H, P M, P G)$, revisions in expectations about the investment opportunity set and risk aversion/appetite shocks (RF:SZ,VL, $M M, S L, L V, R A V, R A P)$.

Results are also displayed with reference to the contribution of the own/idiosyncratic shock $(O W N)$, i.e., $A D$ for $Y, P F$ for $F, R A V$ for $F V, S Z$ for $S M B, V L$ 
for $H M L, M M$ for $M O M, S L$ for $P S L, L V$ for $L E V$, and $R A P$ for $F R A$.

For instance, in the left top plot of Figure 1 the contribution to fluctuations yield by the $O W N$ shock to each of the corresponding variable of interest is displayed at various horizons, from the very short- to long-term. Results net of the contribution of the own shock are reported in all the other plots; for instance, with reference to real stock market prices $(F)$, results displayed for the FIN category (left bottom plot) do not include the contribution of the real stock prices own shock (i.e., $P F$ ).

Differently, in Figures 2-3 results are displayed with reference to subcategories or single shocks, i.e., labor supply $(L S)$, aggregate demand $(A D)$, productivity $(P R)$, core inflation $(C I)$, global imbalance/saving rates (FT: GFI, GDI, GTI), monetary policy stance (MPS), term structure level (TL) and slope (TS), US terms of trade (TT), portfolio allocation/preferences ( $P A$ : PF, $P H, P M, P G)$. Again, the contribution of the own/idiosyncratic shock $(O W N)$ is isolated from the overall contribution when applicable, i.e., in displaying the results for the contribution of portfolio allocation shocks to real stock prices fluctuations (Figure 3, right top plot). ${ }^{15}$

\subsection{Determinants of real activity fluctuations}

As shown in Figure 1 (left top plot), real activity is fairly endogenous already in the very short-term, as the aggregate demand (OWN, $A D)$ shock accounts for $58 \%$ of fluctuations within 2 quarters ( $80 \%$, within 1 quarter). $A D$ still sizably contributes in the short-term (14\% ST; $5 \%$ LT), albeit other macroeconomic ( $M A C$, net of the $A D$ /own shock; left center plot) and financial (FIN; left bottom plot) shocks are dominating in the short- to long-term (MAC: 44\% ST; 40\% LT; FIN: 19\% ST; 22\% LT); among macroeconomic shocks (Figure 2), labor supply ( $L M$, Figure 2, left top plot), global imbalance (FT, Figure 2, left bottom plot; global saving rate $(G F I)$, in particular) and productivity $(P R$, Figure 2 , right center plot) shocks stand out, accounting for up to $21 \%(L S), 14 \%$ (GFI, not reported) and $19 \%$ of real activity fluctuations in the short-term, short- to long-term, and medium- to longterm, respectively; among financial shocks (Figure 3), term structure level ( $T L$, Figure 3, right top plot; up to $6 \% \mathrm{ST}$ ), housing preference ( $H P$; up to $5 \%$ ST; not reported), and US terms of trade shocks (TT, Figure 3, left top plot; up to 10\%, MT and LT) are most relevant. Smaller, yet non negligible, is the overall contribution of risk factors shocks in the short- to long-term (14\% ST; $12 \%$ LT; Figure 1, right top plot), SZ in particular (up to $9 \%$ ST;

\footnotetext{
${ }^{15} \mathrm{~A}$ full set of results is available upon request from the author. More detailed results are also reported in Tables A4-A5 in Appendix B.
} 
not reported), as well as of oil market shocks in the long-term (8\% to $12 \%$; Figure 1, right center and bottom plots), negative flow oil supply shocks especially ( $O S N ; 7 \% \mathrm{LT}$; not reported).

The overall picture is then consistent with the neoclassical framework grounding the identification of the structural shocks, as real activity fluctuations at business cycle frequencies are accounted for not only by aggregate demand shocks, but also labor supply and productivity disturbances, the latter being more relevant in the long- than in the short-term; also consistent is the sizable contribution yield by the global saving rate shock in the mediumto long-term.

Moreover, the contribution of $S Z$ to short-term real activity fluctuations provides empirical support to the view that small firms do contribute to business cycle fluctuations, as well as to the relevance of the financial accelerator mechanism, being the external finance premium countercyclical. ${ }^{16}$ In so far as $S Z$ measures revisions in expectations on the investment opportunity set, changes in expected fundamentals, by impacting on firms' investment, as well as on households' labor supply, might actually even affect business cycle conditions directly, consistent with news-driven business cycle theories (see Beaudry and Portier, 2013).

\subsection{Determinants of risk factors fluctuations}

As shown in Figure 1, strong endogeneity can also be noted for all the financial factors already in the very short-term (Figure 1, left top plot); in fact, the own (idiosyncratic) shock only accounts for $13 \%$ to $16 \%$ of fluctuations for real stock prices $(F)$ and the fragility index $(F R A)$ within 2 quarters; $28 \%$ for momentum $(M O M)$ and leverage ( $L E V) ; 43 \%$ to $49 \%$ for size $(S M B)$, value $(H M L)$, stock market volatility $(F V)$ and stock market liquidity $(P S L)$. Figures are even smaller at longer horizons; short-term: $11 \%$ to $24 \%$ for $F, M O M, L E V$ and $F R A ; 31 \%$ to $46 \%$ for $F V, S M B$, $H M L$ and PSL; long-term: $8 \%$ to $12 \%$ for F, SMB, MOM and FRA; $21 \%$ to $23 \%$ for $F V$ and $L E V ; 32 \%$ to $39 \%$ for $H M L$ and $P S L$.

In terms of macro-financial and oil market determinants, similarities across factors can be noted. Firstly, for $F, F V, L E V, F R A$ and $H M L$ the contri-

\footnotetext{
${ }^{16}$ External finance is in general more expensive than internal finance and the external finance premium depends inversely on the strength of borrower's financial position, as given by net worth, liquidity, and current and future expected cash flows (Bernanke and Gertler, 1989). Small firms, being poorly collaterized, have limited access to external capital markets, paying a higher external finance premium. Then, a positive (negative) shock to borrower's creditworthiness turns into a lower (higher) external finance premium and to higher (lower) investment, creating a financial accelerator effect.
} 
bution of macroeconomic shocks ( $M A C$; Figure 1, left center plot) is larger in the very short-term (25\% to $35 \%$ ) than in the short- (21\% to $31 \%)$ to longterm (15\% to $30 \%)$; differently, the contribution of $M A C$ is monotonically increasing with the forecasting horizon for SMB (28\% VST; $31 \% \mathrm{ST} ; 44 \%$ LT) and PSL (12\% VST; $19 \%$ ST; $20 \%$ LT), and largest in the short-term $(38 \%)$ than at any other horizon (24\%) for MOM.

Overall, the sizable contribution of $M A C$ to $F$ ( $28 \%$ to $35 \%$ ), SMB (24\% to $40 \%$ ), HML (20\% to $27 \%$ ), and $M O M$ (24\% (VST) to $39 \%$ ) fluctuations (Figure 1, left center plot) is consistent with their risk based interpretation, in terms of mimicking factors for state variables related to the investment opportunity set; similarly for $F V$ (22\% to $33 \%)$ and $L E V$ (30\% (VST) to $33 \%$ ), while a smaller contribution of $M A C$ can be noted for $P S L$ (7\% to $20 \%$ ) and FRA (15\% to $25 \%$ ).

Secondly, the contribution of financial shocks ( $F I N$; Figure 1, left bottom plot) to risk factors fluctuations is in general larger in the short-term than at any other horizon (long-term): $8 \%$ to $10 \%$ (3\% to 10\%) for F, LEV, PSL and $16 \%$ to $23 \%$ (13\% to $22 \%$ ) for $F R A, S M B$; differently, the contribution of FIN is stable across horizons for $H M L$ (7\% to $9 \%)$, while monotonically increasing with the forecasting horizon for MOM (9\% VST; $17 \%$ ST; $35 \%$ LT).

Thirdly, the contribution of oil market supply side shocks (SUP; Figure 1 , right center plot) is in general larger in the long-term than at any other horizon (short-term): $23 \%$ to $31 \%$ (13\% to $15 \%$ ) for $F, F V, F R A$ and $12 \%$ to $18 \%(11 \%$ to $14 \%)$ for $P S L, L E V$ and $H M L$; differently, the contribution of $S U P$ is largest in the very short-term for $M O M(7 \% ; 4 \% \mathrm{LT})$ and in the medium-term for $S M B(9 \% ; 7 \%$ LT). Similarly for the other oil market shocks $(O O S$; Figure 1, right bottom plot), albeit their contribution is smaller: $7 \%$ to $9 \%$ for $F V, M O M, H M L$ and $S M B ; 2 \%$ to $6 \%$ for $F, L E V$, $P S L$ in the long-term; differently, up to $15 \%$ of very short-term fluctuations in FRA are accounted for by $O O S$.

Fourthly, the contribution of the (other) risk factors (own) shocks ( $R F$; Figure 1, right top plot) to risk factors fluctuations is in general larger in the very short-term than at longer horizons (long-term): $23 \%$ to $35 \%$ (19\% to $25 \%$ LT) for F, FRA, LEV , PSL, MOM; $8 \%$ to $10 \%$ for $F V, H M L$ and $S M B$ in the short-term ( $6 \%$ to $7 \% \mathrm{LT})$.

\subsection{Additional insights on macro-financial determinants}

As shown in Figure 2 and 3, additional insights concerning structural sources of comovement between risk factors, real activity and stock prices can be gauged by a more detailed decomposition of the macroeconomic $(M A C)$ and 
financial $(F I N)$ shocks categories.

Concerning the effects of macroeconomic disturbances (Figure 2), all shocks, apart from core inflation ( $C I$, Figure 2, right top plot), are generator of common fluctuations in real activity, stock prices and risk factors; yet, not all macroeconomic shocks are equally relevant across variables. Moreover, while financial disturbances (Figure 3) also generate comovement in real activity and risk factors, their contribution is weaker.

The latter findings are consistent with Fama (1981), pointing to a spurious linkage between unexpected inflation and stock prices, as well as with Lettau and Ludvigson (2011), finding the bulk of real stock prices variability being accounted for by a risk aversion shock, rather then productivity and labor share shocks; in this respect, the more detailed decomposition achieved in the current study allows for disentangling other sources of macro-financial risk, presumably subsumed in the risk aversion shock of Lettau and Ludvigson (2011).

Overall, the following findings are noteworthy.

Firstly, labor supply $(L S)$ and aggregate demand $(A D)$ shocks, as well as term structure level $(T L)$ shocks, are a source of common fluctuations in real activity and stock prices at short horizons.

In particular, $L M$ (Figure 2, left top plot) accounts for $21 \%, 9 \%$ and $5 \%$ of real activity $(Y)$, stock prices $(F)$ and stock market volatility $(F V)$ fluctuations in the very short-term, as well as for $15 \%$ for $H M L$. Also sizable is its contribution in the short-term $(17 \%, 11 \%, 6 \%, 9 \%$, for $Y, F, F V$ and $H M L$, respectively), while weaker in the long-term $(6 \%, 11 \%, 5 \%, 4 \%$, for $Y, F, F V$ and $H M L$, respectively); $L M$ also accounts for up to $7 \%$ of fluctuations for $P S L, L E V, F R A$ in the short- to long-term.

Moreover, $A D$ (Figure 2, left center plot ${ }^{17}$ ) accounts for $58 \%$ of fluctuations in $Y$ and $7 \%$ in $F$ and $F V$ in the very short-term, as well as for $9 \%$ for $F R A$. The contribution of $A D$ to common fluctuations at longer horizons is weaker (ST: $14 \%, 2 \%, 7 \%$ for $Y, F, F V$, respectively; LT: $5 \%, 1 \%, 7 \%$, respectively). Also, $A D$ accounts for a sizable proportion of fluctuations for $M O M$ in the short-term ( $8 \% \mathrm{ST} ; 4 \% \mathrm{VST}$ and LT), and for $S M B$ and $H M L$ in the medium- to long-term (5\%; ST 3\%-4\%).

Finally, $T L$ (Figure 3, right top plot) is a source of common fluctuations in $Y(2 \%$ to $6 \%), F(4 \%$ to $5 \%)$ and FRA (3\% to $5 \%)$ in the short-term.

Secondly, productivity $(P R)$ and global imbalance/saving rates shocks $(F T)$, as well as monetary policy stance $(M P S)$, term structure slope $(T S)$ and portfolio allocation $(P A)$ shocks (mostly housing market preference shocks,

\footnotetext{
${ }^{17}$ Due to very different magnitude, FEVD results concerning AD are reported using a different scale for real activity and the other variables.
} 
PH; not reported), are sources of common fluctuations in the short- to longterm.

In particular, $P R$ (Figure 2, right center plot) accounts for $15 \%$ to $19 \%$, $7 \%$ to $9 \%, 4 \%$ to $2 \%$ of medium- to long-term fluctuations in $Y, F, F V$, as well as for $28 \%$ to $32 \%$ for $S M B$ and $6 \%$ for $L E V$. PR sizably contributes to fluctuations at shorter horizons as well (VST to ST: $0 \%$ to $9 \%, 8 \%$ to $3 \%, 12 \%$ to $8 \%, 16 \%$ to $19 \%$, and $7 \%$, for $Y, F, F V, S M B$, and $L E V$, respectively).

Also, FT (Figure 2, left bottom panel) accounts for $17 \%$ to $15 \%, 9 \%$ to $8 \%$, and $8 \%$ to $7 \%$ of fluctuations in $Y, F, F V$ in the medium- to long-term, as well as for $14 \%, 21 \%$ to $17 \%, 7 \%$ to $6 \%$ for $L E V, M O M$ and $H M L$, respectively. The contribution of $F T$ to common fluctuations is also sizable at shorter horizons ( $8 \%$ to $17 \%, 13 \%$ to $10 \%, 7 \%, 16 \%$ to $14 \%, 12 \%$ to $23 \%$ and $16 \%$ to $7 \%$ for $Y, F, F V, L E V, M O M$ and $H M L$, respectively); $F T$ finally accounts for $6 \%$ to $8 \%$ of fluctuations for FRA, SMB and PSL in the very short- to long-term.

Moreover, MPS (Figure 3, left center plot) accounts for common fluctuations in $F V$ (5\% to $9 \%)$ and $S M B(15 \%$ to $10 \%)$ in the short- to long-term; similarly TS (Figure 3, right center plot) for $Y(3 \%$ to $4 \%)$ and $H M L(3 \%$ to $5 \%$ ); $P A$ (Figure 3, left bottom plot) for $Y$ (6\% to $3 \%$ ), $F V$ (4\% to $6 \%$ ), FRA (11\% to $10 \%)$ and $M O M(3 \%$ to $10 \%)$.

Thirdly, TT (Figure 3, left top plot) is a source of common fluctuations in $Y$ (6\% to $10 \%$ ), SMB (6\% to $7 \%$ ) and $M O M$ (7\% to $21 \%$ ) in the medium-to long-term.

Overall, the results are clear-cut, providing strong support for a risk based interpretation of $S M B$ and $H M L$, as well as for $M O M, F, F V, L E V, P S L$ and FRA. While broadly consistent with available evidence on the linkages between $S M B$ and $H M L$ and business cycle and interest rates shocks (Li et al., 2006; Lettau and Ludvigson, 2001; Ludvigson and Ng, 2007; Petkova, 2006; Hahn and Lee, 2006; Vassalou, 2003; Kapadia, 2011), as well as between MOM and the state of the business cycle (Chordia and Shivakumar, 2002; Cooper et al., 2004; Liu and Zhang, 2008), the findings yield deeper insights on their structural drivers.

In particular, different sources of macroeconomic risk appear to be reflected by the various risk factors: labor market (and saving rates) shocks for $H M L$, aggregate demand (and saving rates) shocks for $M O M$, productivity shocks for $S M B$, global imbalance shocks for $L E V$; differently, $F, F V, P S L$ and FRA cannot be associated with a specific source of macroeconomic risk, being affected by all macroeconomic shocks, at various extent.

Similarly concerning the sources of financial risk: monetary policy stance (and US terms of trade) shocks for $S M B$; term structure slope shocks for 
$H M L$; portfolio allocation (and term structure level) shocks for $F R A$ and $F$; US terms of trade (and portfolio allocation) shocks for $M O M$; monetary policy stance (and portfolio allocation) shocks for $F V$.

Finally, oil market supply side shocks are a common source of fluctuations for all risk factors, affecting $F, F V, F R A, P S L, L E V$ and $H M L$ more than $S M B$ and $M O M$.

\section{Dynamic response of risk factors to struc- tural shocks}

The dynamic response of risk factors to structural disturbances of interest is assessed by means of impulse response analysis, carried out over selected time horizons, i.e., very short-term (VST; within 2 quarters), short-term (ST; between 1 and 2 years), medium-term (MT; 3 to 5 years), and long-term (LT, 10-year horizon).

The exercise is useful to gauge further insights on the risk based interpretation of risk factors, as it allows to compare their empirical dynamic responses to shocks causing favorable/adverse changes in the investment opportunity set with theoretical predictions.

Based on FEVD findings, the dynamic response of risk factors to structural disturbances is assessed with reference to labor supply $(L S)$, aggregate demand $(A D)$, productivity $(P R)$, global imbalance/saving rates $(G F I$, $G D I, G T I)$, US terms of trade $(T T)$, monetary policy stance $(M P S)$, term structure level $(T L)$ and slope $(T S)$, flow oil supply $(O S N, O S P)$ and oil reserves $(O R)$ shocks. The latter shocks have been found to generate comovement in real activity, stock prices and risk factors at various horizons and of different degrees.

The empirical results are displayed in Table 1, Panel A-I. In each Panel, impulse response functions for a given variable to the various structural shocks of interest are reported. For instance, Panel A in Table 1 reports the dynamic response of real activity to the various structural shocks; hence, the column indexed by $A D$ in Panel $\mathrm{A}$ reports impulse responses for real activity to a 1 standard deviation (positive) aggregate demand disturbance $(A D)$. Similarly for real stock prices in Panel $\mathrm{B}$, stock market volatility in Panel C, and so on. Apart from $L E V$ and $P S L$, cumulated impulse response functions are reported in all cases. 


\subsection{Responses to aggregate demand shocks}

A positive (favorable) aggregate demand $(A D)$ shock leads to a permanent increase in real activity (0.67\% VST; $0.59 \% \mathrm{ST} ; 0.29 \% \mathrm{LT})$ and stock prices (0.23\% VST; $0.13 \%$ ST and LT), strongest in the short- than in the long-term.

Procyclical stock market liquidity and leverage, and countercyclical stock market volatility and credit risk are triggered by the shock, most sizably in the very short-term: consistent with the improved macroeconomic outlook, LEV (0.59\% VST; $0.19 \% \mathrm{ST})$ and PSL (0.11\% VST, not significant; $0.59 \%$ $\mathrm{ST})$ increase temporarily, while $F V(-0.27 \% \mathrm{VST} ;-0.20 \% \mathrm{ST}$ and LT) and FRA (-3 b.p. VST; 2 b.p. ST; -1 b.p. LT) contract.

Procyclical size, value and momentum effects can also be noted, as $S M B$ (0.91\% VST; $1.08 \%$ ST; $1.12 \%$ LT), HML (0.32\% VST; $1.65 \%$ ST, $1.49 \%$ LT) and MOM (1.97\% VST; $1.49 \% \mathrm{ST} ; 1.26 \% \mathrm{LT})$ permanently increase.

\subsection{Responses to global saving rate shocks}

Similarly, a positive (adverse) global saving rate (GFI) shock leads to a permanent contraction in real activity $(-0.25 \%$ VST; $-0.7 \%$ ST; $-0.5 \%$ LT) and stock prices $(-0.29 \%$ VST; $-0.34 \% \mathrm{ST} ;-0.26 \% \mathrm{LT})$, strongest in the shortthan in the long-term.

Procyclical leverage and stock market liquidity and countercyclical stock market volatility and credit risk can be noted at short horizons; in fact, consistent with the worsened macroeconomic outlook, $L E V$ contracts $(-0.53 \%$ VST; $-0.16 \% \mathrm{ST}$ ) and $F V$ increases (up to $0.08 \%$ between 2 and 6 quarters) in the short-term; PSL contracts $(-0.79 \%)$ and FRA increases (1 b.p.) in the very short-term.

Procyclical size and value effects are also generated by the shock, as both $S M B(-0.43 \%$ VST; $-0.34 \% \mathrm{ST})$ and $H M L(-1.51 \% \mathrm{VST} ;-0.81 \% \mathrm{ST} ;-0.55 \%$ LT) contract, most strongly in the very short-term; procyclical momentum can finally be noted in the short- to long-term, as profitability of momentum strategies persists in the very short-term only (0.91\% VST), MOM turning negative in the short-to long-term (-1.39\% ST; $-1.09 \%$ LT).

\subsection{Responses to US saving rate and global saving glut shocks}

Positive (adverse) US saving rate (GDI) and saving glut (GTI) shocks trigger similar macro-financial effects. In fact, $G D I$ leads to a permanent contraction in real activity $(-0.31 \% \mathrm{VST},-0.25 \% \mathrm{ST},-0.43 \% \mathrm{LT})$ and stock prices 
(-0.31\% VST, $-0.25 \%$ ST, $-0.43 \%$ LT); GTI leads to a permanent contraction in real activity $(-0.03 \% \mathrm{VST},-0.30 \% \mathrm{ST},-0.37 \% \mathrm{LT})$ and a transitory contraction in real stock prices (-0.05\% VST; $-1.13 \% \mathrm{ST})$.

Countercyclical credit risk and procyclical leverage and stock market liquidity are generated by both $G D I$ and $G T I$ at short horizons, determining a transitory increase in FRA (GDI: 2 b.p. VST; GTI: 2 b.p. ST) and a transitory contraction in $L E V(G D I:-1.44 \%$ VST; GTI: $-1.14 \%$ VST) and PSL (GDI: $-1.08 \%$ VST; GTI: $-0.71 \% \mathrm{ST}$ ), consistent with a worsened macroeconomic outlook. Yet, countercyclical stock market volatility is triggered by GDI only, in the very short-term (GDI: $0.16 \%$ VST; GTI: $-0.23 \%$ VST).

Differently, procyclical size and value effects are generated by GTI in the very short-term only ( $S M B$ : $-0.99 \% \mathrm{VST} ; H M L:-0.41 \% \mathrm{VST}$ ), as both $S M B$ and $H M L$ increase in the short- to long-term ( $S M B: 1.12 \% \mathrm{ST} ; 1.25 \%$ LT; $H M L: 0.59 \% \mathrm{ST} ; 0.88 \% \mathrm{LT})$; the latter pattern is however consistent with the permanent contraction in the real short-term rate triggered by GTI (-11 b.p. VST; -4 b.p. ST and LT; not reported), and the ensuing mitigation of the financial burden afflicting distressed (small and value) firms; on the other hand, countercyclical size and value effects are generated by GDI in the short-term only ( $S M B: 0.65 \% \mathrm{ST}$ ) and at any horizon ( $H M L: 1.45 \%$ VST; $1.55 \%$ ST; $1.06 \%$ LT), respectively.

Finally, countercyclical momentum (MOM: $2.01 \%$ VST; $2.18 \%$ ST; $2.06 \%$ $\mathrm{LT})$ is triggered by GTI, while procyclical momentum by $G D I(-1.25 \%$ VST; $-2.25 \% \mathrm{ST} ;-1.48 \% \mathrm{LT})$.

\subsection{Responses to productivity and labor supply shocks}

Both similarities and differences can be noted in the macro-financial dynamic pattern generated by supply-side macroeconomic shocks. For instance, a positive (favorable) labor supply $(L S)$ shock leads to an increase in real activity $(0.43 \%$ VST; $0.60 \% \mathrm{ST} ; 0.18 \% \mathrm{MT})$ and stock prices $(0.37 \%$ VST; $0.34 \% \mathrm{ST} ; 0.47 \% \mathrm{LT}$ ); differently, a positive (favorable) productivity $(P R)$ shock leads to an increase in real activity (0.04\% VST; $0.67 \%$ ST; $0.85 \%$ LT) and in housing prices $(0.28 \%$, VST; $0.63 \%$, ST; $0.96 \%, \mathrm{LT})$, as well as to a contraction in real stock prices $\left(-0.27 \%\right.$ VST, ST; $-0.63 \%$ LT).$^{18}$

Both shocks generate countercyclical credit risk at short horizons, as $L S$ triggers a contraction in FRA in the very short-term only (-3 b.p. VST) and $P R$ in the short- to long-term (-3 b.p. ST; -2 b.p. LT).

\footnotetext{
${ }^{18}$ The negative response of the real stock price index to productivity shocks is consistent with empirical findings in Kogan et al. (2012), Chun et al. (2013) and Canova and De Nicolò (1995) as well.
} 
Also consistent with the improved macroeconomic outlook, procyclical leverage and stock market liquidity and countercyclical stock market volatility are generated by $L S$ at short-horizons: in fact, following the shock, $L E V$ $(0.98 \% \mathrm{VST})$ and PSL (1.39\% VST) increase in the very short-term, while $F V$ contracts transitorily $(-0.25 \%$ VST; $-0.18 \% \mathrm{ST})$.

Differently, $P R$ generates procyclical leverage and stock market liquidity, and countercyclical stock market volatility, at short horizons, relatively to stock market-wide movements only; in fact, $L E V$ (-1.14\% VST) and PSL ($0.29 \% \mathrm{VST})$ contract in the very short-term, while $F V$ increases transitorily (0.39\% VST; $0.06 \%$ ST; $0.07 \%$ MT).

Procyclical size and value effects, relatively to stock market-wide movements only, are generated by $P R$, leading to a permanent contraction in $S M B(-1.91 \%$ VST; $-2.42 \% \mathrm{ST})$ and $H M L(-0.31 \% \mathrm{VST} ;-1.46 \% \mathrm{ST}$ and LT); differently, procyclical value effects ( $H M L: 2.39 \%$ VST; $0.56 \% \mathrm{ST}$ ), yet countercyclical size effects ( $S M B:-0.18 \%$ VST; $-0.98 \%$ ST; $-0.77 \% \mathrm{LT}$ ), are triggered by $L S$. The latter pattern is consistent with Kogan and Panikolau (2012), as growth firms, having richer growth opportunities, also have a stronger investment demand; hence, $P R$, by being embodied in physical capital, yields a larger positive impact on the profitability of growth firms, triggering a contraction in $H M L$; it is also consistent with Kogan et al. (2012), showing few large firms being responsible for a large proportion of the aggregate rate of innovation for the US; hence, $P R$ might be expected to enhance more the profitability of large than small firms, causing a contraction in $S M B$.

Moreover, both $L S$ and $P R$ generate countercyclical momentum at shorthorizons (MOM: LS, $-0.95 \%$ VST; $P R,-1.55 \%$ VST, $-1.93 \%$ ST), turning procyclical at longer horizons (MOM: LS, 1.01\% ST; PR, 1.19\% LT). The latter finding may be consistent with supply-side improvements spreading slowly at the economy-wide level; the benefits of technical progress are in fact earned by innovative firms only at the outset, while labor intensive firms/sectors benefit most of lower labor costs.

\subsection{Responses to US terms of trade shocks}

A negative (adverse) US terms of trade shock (TT) leads to a short- to longterm contraction in real activity $(-0.45 \% \mathrm{VST} ;-0.56 \% \mathrm{LT})$ and stock prices (-0.09\% VST; $-0.12 \%$ ST).

Procyclical leverage and stock market liquidity are generated by $T T$ at short horizons, as, consistent with the worsened macroeconomic outlook, $L E V$ (up to $-0.32 \%, 2$ to 6 quarters) and PSL (-1.31\% VST) transitorily contract; differently, stock market volatility is unaffected in the short- to long- 
term $(-0.04 \% \mathrm{VST})$, while the response of credit risk is procyclical (FRA: -1 b.p. VST; -2 b.p. ST; -1 b.p. MT); the latter effect might be related to the permanent contraction in the US trade deficit to GDP ratio $(-0.10 \% \mathrm{ST}$ ad LT) triggered by $T T$, and therefore in the global trade imbalance.

Procyclical value effects ( $H M L:-1.38 \%$ VST; $-0.54 \%$ ST) and countercyclical size effects ( $S M B: 0.71 \%$ VST; $1.35 \% \mathrm{ST}, \mathrm{LT}$ ) can finally be noted, consistent with the lower international dimension of small than large firms, the former being therefore less adversely affected by the contraction in international trade triggered by $T T$. Moreover, consistent with persistence in fundamentals, countercyclical momentum is generated in the very short-term, as $M O M$ increases within 1 quarter $(0.64 \%)$, turning procyclical already in the short-term (-0.37\% within 2 quarters; $-3.11 \mathrm{ST} ;-4.02 \% \mathrm{LT})$.

\subsection{Responses to monetary policy stance shocks}

A positive monetary policy stance/excess liquidity shock (MPS), consistent with boom-bust cyclical dynamics, leads to a very short-term increase in real activity and stock prices $(0.02 \%$ and $0.03 \%$, respectively, VST), turning into a contraction in the short- to long-term $(Y:-0.09 \% \mathrm{ST} ;-0.14 \% \mathrm{LT} ; F$ : $-0.09 \% \mathrm{ST})$.

Procyclical leverage ( $L E V: 0.24 \%$ VST; $-0.48 \% \mathrm{ST})$ and stock market liquidity (PSL: $-0.39 \%$ VST; $-0.65 \% \mathrm{ST}$ ), as well as countercyclical credit risk (FRA: 2 b.p. ST; 1 b.p. LT) and stock market volatility $(F V: 0.12 \%$ VST; $0.23 \%$ ST; $0.28 \%$ LT), are triggered by the shock. The latter effects, i.e., higher uncertainty and credit risk, and deleveraging of financial institutions, are all consistent with a short- to long-term boost scenario (see Borio and Zhu, 2008; Adrian and Shin, 2008).

$M P S$ also generates procyclical size effects in the short- to long-term and procyclical value and momentum effects at any horizon: in fact, $S M B$ (-1.69\% ST; $-1.51 \%$ LT; $-1.64 \%$ VST), HML (-0.94\% ST; $-0.84 \%$ LT) and $\operatorname{MOM}(-0.62 \%$ within 2 quarters; $-1.10 \% \mathrm{ST} ;-1.36 \% \mathrm{LT})$ contract in the short- to long-term, while $H M L(0.52 \% \mathrm{VST})$ and $M O M(0.39 \%$ within 1 quarter) increase in the very short-term.

\subsection{Responses to term structure shocks}

Positive (favorable) term structure level (TL) and slope (TS) shocks trigger similar macro-financial effects; in fact, both $T L$ and $T S$ lead to a permanent increase in real activity (TL: $0.06 \%$ VST; $0.51 \%$ ST; $0.37 \%$ LT; TS: $0.07 \%$ VST; $0.36 \%$ ST; $0.31 \%$ LT) and stock prices (TL: 0.23 VST; $0.31 \% \mathrm{ST}$; 
0.21\% LT; TS: $0.04 \%$ VST; $0.16 \%$ ST; $0.12 \%$ LT), strongest in the shortthan in the long-term.

Consistent with the improved macroeconomic outlook, at short horizons, countercyclical stock market volatility is generated by both shocks, while procyclical stock market liquidity and leverage is triggered by $T S$, and countercyclical credit risk by $T L$ only; in fact, $F V$ contracts in the short-term following both shocks (TL: $-0.04 \%$; TS: -0.05\%); differently, PSL (TS: $0.48 \%$; TL: $-1.44 \%$; VST) and $L E V$ (TS: $0.26 \%$; TL: $-0.19 \%$; ST) increase in the short-term following $T S$; FRA contracts following $T L$ (TL: -3 b.p.; TS: 1 b.p.; VST).

Also, procyclical size and value effects can be noted in the very shortterm only, as $S M B$ increases following both shocks (TL: $0.48 \%$; TS: $0.26 \%$; VST) and $H M L$ following $T L$ (TL: $0.34 \%$; TS; $-1.08 \%$; VST); coherent with higher sensitivity of small and distressed firms to interest rate changes and overall credit conditions, both $S M B$ (TL: $-0.83 \%$ VST; $-0.91 \%$ LT; TS: $-0.41 \%$ VST; $-0.51 \%$ LT) and $H M L$ (TL: $-0.71 \%$ VST; $-0.86 \%$ ST; $T S$ : $-1.05 \%$ ST; $-1.44 \%$ LT) then contract in the short- to long-term.

Still consistent with the impact of changing interest rates on firms' financial conditions, countercyclical momentum is finally generated by both shocks, as MOM contracts at any horizon (TL: $-1.31 \%$ VST; $-0.47 \%$ ST; $-0.89 \%$ LT; TS: $-1.30 \%$ VST; $-0.62 \%$ ST; $-0.50 \%$ LT).

\subsection{Responses to oil market shocks}

Negative (adverse) (OSN) and positive (favorable) (OSP) flow oil supply shocks trigger fairly symmetric macro-financial effects. In fact, $O S N$ leads to a very short-term contraction in real activity $(-0.11 \% \mathrm{VST})$ and stock prices (-0.13\% VST; $-0.45 \%$ ST; $-0.92 \%$ LT); yet, due to lower oil price uncertainty (not reported), real activity increases in the medium- to long-term $(0.44 \%$ MT; $0.62 \% \mathrm{LT}$ ); a portfolio shift favoring the housing market can also be noted, as housing prices increase $(0.20 \%$ VST; $0.81 \%$ ST; $1.38 \%$ LT; not reported).

Conversely, $O S P$ does not significantly affect real activity in the shortto medium-term; yet, due to increased oil price uncertainty (not reported), some negative effects can be noted in the long-term (-0.19\%); an increase in stock prices (0.14\% VST; $0.38 \% \mathrm{ST} ; 0.50 \% \mathrm{LT})$ and a contraction in housing prices (-0.23\% VST; $-0.21 \% \mathrm{ST} ;-0.55 \% \mathrm{LT}$; not reported) can also be noted.

Moreover, a positive (favorable) oil reserves $(O R)$ shock leads to a shortto long-term increase in real activity $(0.23 \% \mathrm{ST} ; 0.44 \% \mathrm{LT})$; a portfolio shift favoring housing can then be noted, as housing prices increase $(0.20 \%$ VST; $0.56 \%$ ST; $0.79 \%$ LT), while stock prices contract (-0.18\% VST; $-0.23 \%$ ST; 
$-0.54 \%$ LT $).{ }^{19}$

Procyclical leverage and stock market liquidity, relatively to market return dynamics, in the very short-term, as well as countercyclical stock market volatility and credit risk, in the short- to long-term, are generated by oil market supply side shocks as well. In fact, $L E V$ contracts following both $O S N$ $(-0.43 \% \mathrm{VST})$ and $O R(-1 \% \mathrm{VST})$, while increasing following $O S P(0.95 \%$ VST); similarly PSL (OSN: $-0.63 \%, O R$ : $-2.13 \%, O S P$ : $0.68 \%$; VST) and FRA (OSN: -6b.p., OR: -1 to -2b.p.; OSP: 1 to 2 b.p.; ST and LT); $F V$ increases in the short-term following $O S N(0.34 \% \mathrm{ST} ;-0.29 \% \mathrm{LT})$ and in the medium- to long-term following $\operatorname{OSP}(0.16 \% \mathrm{MT} ; 0.19 \% \mathrm{LT})$, while contracting in the very short-term following $O R(-2.13 \% \mathrm{VST})$.

Moreover, procyclical size and value effects are generated by the flow oil supply shocks in the medium- to long-term, as an increase in both $S M B$ $(0.68 \% \mathrm{MT})$ and $H M L(1.84 \% \mathrm{LT})$ is triggered by $O S N$, while a contraction is caused by $O S P(S M B:-0.72 \%$ LT; HML: $-1.43 \%$ LT); countercyclical size effects are however triggered by $O S N$ in the very short-term $(S M B$ : $0.15 \%$, VST; $0.95 \%$ ). Procyclical value effects (HML: $0.40 \%$ VST; $1.35 \%$ ST and LT), yet countercyclical size effects ( $S M B:-0.74 \%$ VST; $-0.33 \%$ ST; $-1.09 \% \mathrm{LT})$, are generated also by $O R$.

Finally, $O S P$ and $O S N$ generate procyclical momentum in the mediumto long-term (OSP: $-0.79 \% \mathrm{LT}$; $O S N$ : $1.61 \% \mathrm{LT})$, while both $O S N$ and $O R$ generates countercyclical effects at short horizons (0.66\% VST, and $-1.04 \%$ ST, respectively).

\subsection{Summary of the results}

Concerning the dynamic response of risk factors to structural disturbances, the following stylized facts can then be noted.

Firstly, strong empirical support is found for a risk based interpretation of the size and value effects, as well as for the momentum effect, i.e., for a direct linkage of $S M B, H M L$ and $M O M$ with business cycle fluctuations; similarly for market-wide stock return dynamics $(F)$.

Procyclical size, value, momentum and market-wide dynamics appear to be originated by common structural causes, most notably macroeconomic demand-side shocks, largely accounting for real activity fluctuations at business cycle frequencies, i.e., aggregate demand $(A D)$ and global saving rate

\footnotetext{
${ }^{19} \mathrm{~A}$ decline in the real oil price might favor energy intensive more than energy saving sectors; then shareholder wealth would increase at the energy intensive firms, while declining at energy saving firms. As the aggregate market return is a weighted average of individual firm's stock returns, if wealth destruction dominates wealth creation, a negative linkage between $O R$ and aggregate stock returns arises.
} 
$(G F I)$ shocks, as well as other structural shocks at selected horizons, i.e., monetary policy stance $(M P S)$, term structure level $(T L)$, saving glut $(G T I)$, and flow oil supply $(O S N, O S P)$ shocks. Moreover, while labor supply $(L S)$ shocks contribute to procyclical market-wide dynamics, likewise productivity $(P R)$ and oil reserves $(O R)$ shocks, they generate countercyclically size, value and momentum effects.

The above findings, while in general consistent with the evidence that the information contained in both $S M B$ and $H M L$ might be subsumed in business cycle predictors, i.e., sector-specific investment growth factors ( $\mathrm{Li}$ et al., 2006) and default and term premia (Petkova, 2006; Hahn and Lee, 2006; Vassalou, 2003; Vassalou and Xing, 2004; Kapadia, 2011), yield additional insights on the structural causes of the size and value effects.

Similarly for the linkage of momentum with the state of the business cycle and market-wide dynamics (Chordia and Shivakumar, 2002; Cooper et al., 2004), as well as between business cycle and market-wide dynamics themselves (Fama and French, 1989), and therefore the generation of the momentum effect and the procyclical behavior of market-wide stock returns. Hence, while in general $S M B, H M L, M O M$, and $F$ might be expected to be on average positive during expansions and negative during recessions, an opposite scenario may arise if supply-side, rather than demand-side, disturbances generate the bulk of business cycle fluctuations.

Secondly, strong empirical support is found for a risk based interpretation for the volatility $(F V)$, credit risk/fragility $(F R A)$, leverage $(L E V)$, and stock market liquidity $(P S L)$ factors as well, still grounded on their linkage with business cycle dynamics, i.e., on generators of common fluctuations in real activity and stock prices.

Countercyclical stock market volatility is in fact generated by macroeconomic demand-side shocks, i.e., $A D$ and GFI (short-term), and by negative flow oil supply shocks $(O S N)$, as well as by other structural shocks at selected horizons: $G D I$ in the very short-term; $T S, T L$ and $L S$ in the short-term; $M P S$ in the short- to long-term. Differently, $P R$ and $O R$ generate procyclical stock market volatility relatively to the level of economic activity, yet countercyclical relatively to stock prices.

Similarly, countercyclical credit/fragility risk is determined by the macroeconomic shocks which contribute mostly to real activity fluctuations, i.e., $A D, P R$ and $L S$, as well as by $M P S$ and $T L$; by GFI, GDI and GTI in the very short-term and oil market supply side shocks $(O S P, O S N, O R)$ in the long-term.

Finally, procyclical financial leverage and stock market liquidity, albeit more transitory features, are similarly generated by macroeconomic shocks which contribute mostly to real activity fluctuations in the short-term, i.e., 
GFI and TS, as well as AD, LS, TT, MPS, GDI, GTI, and $O S N$ at various horizons. Differently, procyclical financial leverage and stock market liquidity effects are generated by $P R$ and $O R$ shocks.

Hence, the findings are consistent with available evidence on countercyclical US stock market volatility (Schwert, 1989a,b; Beltratti and Morana, 2006) and credit risk (Bernanke and Gertler, 1989), and procyclical financial intermediaries' leverage (Adrian et al., 2012; Adrian and Shin, 2010) and stock market liquidity (Pastor and Stambaugh, 2003). Yet, as for the size, value and momentum effects, the analysis yields additional insights on their structural causes. Therefore, while $F V$ and $F R A$ should be expected on average lower during expansions than recessions, and the other way around for $L E V$ and $P S L$, countercyclical leverage and liquidity effects, as well as procyclical volatility effects, might arise in the case supply side (productivity) disturbances dominate demand-side shocks in the generation of business cycle dynamics.

\section{The cross-section of expected equity returns}

Through historical decomposition, each risk factor can be dissected in up to 33 components, each one associated with a given structural shock; yet, not all of them might be relevant for asset pricing purposes. As a non-priced risk factor component might negatively affect the performance of an empirical asset pricing model, by acting as observational noise, assessing the impact of filtering on the explanation of the cross-section of expected returns is thus clearly of interest.

Filtering can be implemented factor by factor by running, for each test asset, a time series regression of risk premia on the 33 risk factor components obtained through the historical decomposition, and then reaggregating by retaining only the statistically significant ones.

Hence, considering the (standardized) risk premium for the generic $i$ th test asset $\left(r_{i, t}-r_{f, t}\right)$ and $k$ th risk factor $\left(x_{k, t} \equiv \sum_{j=1}^{33} x_{k, j, t}\right)$, the OLS time series regression

$$
\begin{aligned}
r_{i, t}-r_{f, t} & =\sum_{j=1}^{33} \beta_{i, k, j} x_{k, j, t}+\varepsilon_{i, t}, \\
\varepsilon_{i, t} & \sim \operatorname{mds}\left(0, \sigma^{2}\right)
\end{aligned}
$$

is run, where $i=1 \ldots, k=1 \ldots, t=1, \ldots, T$; the statistical significance of the various components is then assessed by means of $t$-ratio tests, and the 
filtered factor $x_{k, t}^{+}$obtained by aggregating the $m \leq 33$ priced/statistically significant components, i.e., $x_{k, t}^{+}=\sum_{s=1}^{m} x_{k, s, t}$.

Alternatively, the selection of the priced components can be implemented within a bivariate framework, i.e., by running the regressions

$$
r_{i, t}-r_{f, t}=\beta_{i, k, j} x_{k, j, t}+\varepsilon_{i, t},
$$

involving only one component $(j)$ of the $k$ th risk factor at the time.

Filtered factors are then employed in the place of the actual factors in the estimation of time series and cross-sectional regressions.

In the current application, the Fama-French 25 size/value ordered porftolios, over the period 1986-3 through 2010:3, are employed as test assets. Despite being short, the sample investigated is highly informative, covering several episodes of economic and financial distress, i.e., the 1987(4) stock market crash, the 1990(4) first Persian Gulf War and associated oil price shock, the 1998(4) East Asia crisis, the 2000(2) burst of the dot-com bubble, the 2003(2) second Persian Gulf War, the 2007-2009 financial crisis and the 2008 (third) oil price shock. Moreover, according to NBER chronology, over the period investigated, three main recessionary episodes have affected the US, as well as the global economy, i.e. 1990:3 through 1991:1, 2001:1 through 2001:4, and 2007:4 through 2009:2.

As the Fama-MacBeth approach is likely to perform better than GMM estimation in small samples (Khan and Zhou, 1999), the former is then implemented. In the investigation we compare several specifications, estimated using both filtered and non-filtered factors; in particular, we consider the CAPM (CAPM), the 3-factor Fama-French model (FF), the 4-factor FamaFrench model augmented with $M O M$ (FF-M), an 8-factor model obtained by augmenting the 3-factor Fama-French model with all the available factors, i.e., $M O M, P S L, L E V, F R A$ and $F V$ (FF-A). Various 4-factor models are also considered, augmenting the 3-factor Fama-French model with each of the other available factors, i.e., PSL (FF-P), LEV (FF-L), FRA (FF$\mathrm{F}), F V(\mathrm{FF}-\mathrm{V})$. Similarly, various augmented CAPM models are considered, by including $M O M$ (CAPM-M), PSL (CAPM-P), LEV (CAPM-L), FRA (CAPM-F) and $F V$ (CAPM-V).

For each of the above models, either a US or a global market risk factor is considered; while the former is measured by the (nominal) US S\&P500 stock market return, the latter is yield by the (real) global stock market return factor $F$. In both cases the risk premium is computed by subtracting the (nominal/real) 3-month US Treasury bills interest rate.

In Table 2 a summary of results is reported; in particular, Table 2 reports the results for the Fama-MacBeth second step, i.e., the OLS estimated para- 
meters for the Fama-French 25 size and value portfolios cross-sectional betarepresentation, with Shanken's standard errors; actual $\left(R^{2}\right)$ and adjusted $\left(\bar{R}^{2}\right)$ coefficient of determination are also reported. ${ }^{20}$

Moreover, Panel A and $\mathrm{C}$ report results for the non-filtered specifications, i.e., using actual factors, for US standard models, where the market return is measured by the nominal US S\&P 500 return (Panel A), as well as for their global versions, conditioned on the global stock market factor (Panel C). Differently, in Panel B and D results for the filtered versions of the US and global specifications are reported. ${ }^{21}$

Hence, comparing results reported in Panel A and B (C and D) yields a relative assessment of the impact of filtering for the US (global) specifications. Differently, comparing results reported in Panel A and C (B and D) yields a relative assessment of the US and global specifications without (with) filtering.

In the current application both multivariate and univariate filtering has been implemented, using HCSE and OLS standard errors and cut-off significance levels in the range $1 \%$ to $10 \%$; the results reported are for the filtered specifications which show the highest explanatory power $\left(R^{2}\right.$ and $\left.\bar{R}^{2}\right)$. As shown in Table 2, the following findings are noteworthy.

Firstly, by comparing the $R^{2}$ and $\bar{R}^{2}$ results reported in Panel A and B (the US non-filtered and filtered models), it can be noted that filtering yields a $15 \%(20 \%)$ average increase (across models) in the $R^{2}\left(\bar{R}^{2}\right)$ statistic; the increase in explanatory power is particularly high for the CAPM-P, CAPM-V and FF-P models (30\% to $40 \%$ ); in only two cases out of twelve (CAPM$\mathrm{M}$ and CAPM-L) filtering yields a loss in explanatory power for the US models. For the global models the improvement yield by filtering is even more dramatic, i.e., $90 \%\left(R^{2} ; 110 \%, \bar{R}^{2}\right)$ on average across models, apart from FF-A (10\%).

Secondly, the 3-factor Fama-French model is not the best specification for the selected sample. In particular, the FF model shows an $R^{2}\left(\bar{R}^{2}\right)$ of about 0.52 (0.45) for the US specification, rising up to $0.58(0.52)$ when $S M B$ and $H M L$ are filtered; the global versions of the model are less performing, showing an $R^{2}\left(\bar{R}^{2}\right)$ of $0.36(0.27)$ and $0.54(0.47)$ for the non-filtered and filtered versions of the model, respectively.

While filtering improves the performance of both US and global FF specifications, a superior performance, in terms of both $R^{2}$ and $\bar{R}^{2}$, is yield by various 4-factor models, obtained by augmenting $\mathrm{FF}$ with the other avail-

\footnotetext{
${ }^{20}$ Estimation has been performed also by means of GLS; results are qualitatively similar, not reported for reasons of space, yet available from the author upon request.

${ }^{21}$ The US market factor is not filtered as the latter variable is not included in the global model in (1); hence, its historical decomposition is not available.
} 
able factors, i.e., $M O M, P S L, L E V, F R A, F V$. In this respect, the best 4 -factor specifications are obtained from the filtered global FF model (Panel D), augmented with $L E V$ (FF-L) or $F V(\mathrm{FF}-\mathrm{V})$, showing an $R^{2}\left(\bar{R}^{2}\right)$ of about $0.70(0.63)$, getting very close to the upper bound attained by the 8 factor model (FF-A: $\left.R^{2}, 0.78 ; \bar{R}^{2}, 0.67\right)$; slightly inferior, yet still noticeable, is the performance of the FF model augmented with $F R A$, i.e., $0.60(0.52)$.

Thirdly, also impressive is the impact of filtering on the performance of the augmented US CAPM models, yielding $R^{2}\left(\bar{R}^{2}\right)$ of about $0.64(0.60)$ and 0.55 (0.51) for the $F V$ and $F R A$ augmented models, respectively (Panel B; CAPM-V and CAPM-F).

Finally, in terms of average mispricing errors, filtering in general yields a sizable contraction in the value of the Jensen's alpha (intercept) parameter, larger for the global (30\% on average across models) than for the US (13\%) models; in only 3 cases out of 25 a larger mispricing error is induced by filtering (global CAPM-M; US and global CAPM-V).

Overall, the results are promising, corroborating the intuition that not all risk factors components might be priced and therefore filtering improves the performance of empirical asset pricing models. Further investigations are clearly demanded, in order to identify regularities in non priced components, according to the size and value metric, as well as other metrics, by extending the set of test assets to include size/momentum, industry and bonds portfolios. This is left for future research.

The noteworthy performance of the US CAPM model augmented with the filtered volatility or fragility factors is also a very interesting result, given the highly debated issue concerning the specification of systematic risk. As shown by Merton (1973), when the investment opportunity set is time-varying, systematic risk is not only yield by covariance with the market-wide return, but also with recession; given the countercyclical behavior of risk aversion and credit risk, the relevance of $F V$ and $F R A$ for the explanation of the cross-section of expected stock returns is then not surprising.

\section{Conclusions}

This study contributes to the understanding of the macro-finance interface by assessing the economic content of risk factors widely employed in the specification of empirical asset pricing models, i.e., Fama-French size $(S M B)$ and value $(H M L)$, Carhart momentum $(M O M)$, as well as other factors more recently proposed in the literature, i.e., Pastor-Stambaugh stock market liquidity $(P S L)$ and Adrian-Etula-Muir financial leverage $(L E V)$; moreover, the Bagliano-Morana fragility $(F R A)$ index, global stock market-wide re- 
turns $(M K T)$, and a risk aversion/uncertainty factor $(F V)$, as measured by US stock market volatility, are also assessed.

Consistent with Merton's ICAPM, once time-varying risk is allowed for, systematic risk is not only described by covariance with the market return, but also with recession. A risk based interpretation of $S M B, H M L, M O M$, as well as for the other factors, might then be grounded on their mimicking state variables measuring downward revisions in expectations about the investment opportunity set. As recessions are periods when risk aversion, as well as earnings and default risk are high, procyclical stocks, that do well in booms and bad during recessions, should pay a higher premium than countercyclical stocks, to compensate risk averse investors.

Relatively to the available literature, we provide novel, as well as encompassing empirical evidence. The investigation is in fact set within the framework of a large scale global dynamic econometric model, where the conditioning macro-financial information set span over 800 variables and 50 countries, including industrialized and emerging economies. The evidence provided thus concerns also the global economy information content of US risk factors.

The empirical results are clear-cut. Firstly, macro-financial shocks account for the bulk of risk factors fluctuations, with macroeconomic shocks contributing most sizably in the very short-term, financial shocks in the shortterm, and oil market disturbances in the medium- to long-term term. Interestingly, different sources of macroeconomic and financial risk are reflected by the various risk factors; in particular, productivity and monetary policy stance shocks for $S M B$; labor market and term structure slope shocks for $H M L$; aggregate demand and US terms of trade shocks for $M O M$.

Secondly, procyclical size, value, momentum and market-wide effects, as well as leverage and stock market liquidity effects, appear to be mostly generated by (demand-side) macroeconomic shocks, largely accounting for real activity and stock market fluctuations at business cycle frequencies; similarly for countercyclical volatility and credit risk effects. Differently, supply-side (productivity, oil reserves) shocks might generate opposite patterns for all the above effects, apart from credit risk.

Thirdly, concerning the specification of systematic risk, we find that not all the structural sources of risk factors fluctuations are priced by the market; hence, the performance of empirical asset pricing models can be sizably improved by filtering out non-priced components, i.e., observational noise; we also find risk aversion, fragility and leverage factors containing relevant information for the pricing of the Fama-French 25 size and value ordered portfolios, consistent with their business cycle state dependence reflecting covariance with recessions. 
In the light of the results of the study, at least two main issues should be considered in future research.

Firstly, given the improvement in explanatory power of empirical asset pricing models yield by filtering out non-priced risk factors components, further investigation is demanded in order to identify regularities in the nonpriced components, according to the size/value metric, as well as other metrics, by extending the set of test assets to size/momentum, industry and bonds portfolios. The noteworthy performance of the US CAPM model, augmented with filtered volatility or fragility factors, is clearly of utmost interest in this respect, given the still open debate concerning the specification of systematic risk, and its implications for the testing of asset pricing theories.

Secondly, it would be worthwhile investigating the signalling properties of risk factor shocks for the economic outlook, also in the perspective of constructing an early warning index of macro-financial risk. As pointed out by the forecast error variance decomposition, risk factors shocks contribute to real activity and stock prices fluctuations at various extent: by accounting for up to $9 \%$ and $23 \%$ of short- to medium term real activity and stock prices fluctuations, the size $(S M B)$ shock clearly stands out as a likely candidate indicator of incoming changes in the global economic outlook, also within an early warning system of macro-financial risk.

\section{Appendix A: The data}

The dataset contains macroeconomic and financial data for 50 countries, i.e., 31 advanced economies (Australia, Austria, Belgium, Canada, Czech Republic, Denmark, Finland, France, Germany, Greece, Hong Kong, Iceland, Ireland, Israel, Italy, Japan, Luxembourg, Netherlands, New Zealand, Norway, Portugal, Singapore, Slovakia, Slovenia, South Korea, Spain, Sweden, Switzerland, Taiwan, United Kingdom), 5 advanced emerging economies (Brazil, Hungary, Mexico, Poland, South Africa), and 14 secondary emerging economies (Argentina, Chile, China, Colombia, India, Indonesia, Malaysia, Morocco, Pakistan, Peru, Philippines, Russia, Thailand, Turkey), for a total of 50 countries.

For each of the 50 countries, apart from some exceptions, 17 macroeconomic variables are employed, namely real GDP, private consumption and investment growth, public expenditure to GDP ratio growth, nominal bilateral US\$ exchange rate (value of 1 US\$ in units of country currency) returns, CPI inflation rate, M2 or M3 to GDP ratio growth, nominal M2/M3 growth, civilian employment growth, unemployment rate changes, real wages growth, 
real stock prices returns, real housing prices returns, real short and long term interest rates, real effective exchange rate returns, bank loans to the private sector to GDP ratio growth. A total of over 800 equations is then considered in block (2). For OECD countries the macro-financial sample extends from 1980:1 through 2010:3, while for non OECD countries only from 1995:1 through 2010:3; macroeconomic data are seasonally adjusted. The (main) data source is IMF International Financial Statistics ${ }^{22}$.

Twelve unobserved global macro-financial factors are estimated using (2), from homogeneous subsets of the above variable, i.e., a real activity growth factor $(Y)$ is extracted from real GDP, private consumption and investment growth series; an excess public consumption growth ( $G$, fiscal stance) from the public expenditure to GDP ratio growth series; a US\$ exchange rate return index from the various bilateral exchange rates against the US $\$$ returns $(X)$; a core inflation (nominal) factor $(N)$ from the inflation rate and the nominal money growth, short and long term interest rate series; an excess liquidity growth index $(L)$ from the M3 (M2) to GDP ratio and the private loans to GDP ratio growth series; an employment growth factor $(E)$ from the civilian employment growth series; an unemployment rate change factor $(U)$ from the unemployment rate in changes series; a real wage growth factor $(W)$ from the real wage growth series; a real stock market return factor $(F)$ from the real stock market price index return series; a real housing return factor $(H)$ from the real housing price index return series; a real short term rate factor $(S R)$ from the real short term interest rate series; a term spread factor $(T S)$ from the term spread series. This yields the vector of (global) unobserved factors $\mathbf{F}_{1, t}$.

Then, eleven variables are included in the vector of (global) observed factors $\mathbf{F}_{2, t}$, i.e., the Bagliano and Morana (2011) US economic/financial fragility index $(F R A)$ in differences ${ }^{23}$, the Fama and French (1993) size

\footnotetext{
${ }^{22}$ Other data sources employed are FRED2 (Federal Reserve Bank of St. Louis); OECD and BIS (unofficial) house price data sets, and International Energy Agency (IEA-OECD) data sets.

${ }^{23}$ The Bagliano-Morana fragility index is the common component in the TED, agency and corporate spreads. The TED spread, i.e., the spread between the 3 -month LIBOR rate (Euro dollar deposit rate) and the yield on 3-month Treasury bills, being the difference between an unsecured deposit rate and a risk-free rate, yields a measure of credit and liquidity risk; differently, the spread between $B A A$-rated and $A A A$-rated corporate bonds $(B A A-A A A)$ yields a measure of corporate default risk, as well as a measure of investors' risk-taking attitude, a contraction in the corporate spread signalling an increase in the demand for riskier bonds relative to safer ones; moreover, the agency spread is the spread between the 30-year Fannie Mae/Freddie Mac bonds yield and the 30-year Treasury bonds yield, measuring stress in the mortgage market. The fragility index therefore summarizes overall credit conditions, with reference to corporate, interbank and mortgage markets.
} 
and value factors $(S M B, H M L)$, the Carhart (1997) momentum factor $(M O M)^{24}$, the Pastor and Stambaugh (1997) stock market liquidity factor $(P S L)^{25}$, the S\&P 500 stock return volatility in differences $(F V)$, computed from an asymmetric GARCH model, the real gold price $(G D)$ return, real IMF non-energy commodities price index returns $(M)$, the US fiscal $(F d)$ and trade deficit $(T d)$ to GDP ratios in differences, the Adrian, Etula and Muir (2011) leverage factor $(L E V)^{26}$. The sample for the observed macrofinancial factors extends from 1980:1 through 2010:3.

Finally, ten additional variables, concerning global oil demand and supply conditions, are included in the vector $\mathbf{O}_{t}$, i.e., world oil reserves growth $(R)$, net world oil production changes (increase: $P p$, decrease: $P m)^{27}, O E C D$ oil refineries margins growth $(R M)$, world oil consumption growth $(C)$, OECD oil inventories growth $(I N V)$, real WTI oil price return $(O P)$, nominal WTI oil price volatility in differences $(O V)$, computed from a GARCH model, the 12-month futures basis, i.e., the ratio of the nominal 12-month futures-spot spread over the nominal spot oil price $(F B)$, computed using Crude Oil (Light-Sweet, Cushing, Oklahoma) 12th Contract settle futures prices, and the oil futures market Working (1960)-T index growth rate (WT), computed using US Commodity Futures Trading Commission (CFTC) Commitment of Trades (COT) data. ${ }^{28}$ The sample for the latter variables extends from

\footnotetext{
${ }^{24}$ The size factor is the return differential between small and big size portfolios; the value factor is the return differential between high and low bookto-market-ratio portfolios; the momentum factor is the difference between the returns on the high and low past perfomance portfolios, measured over the previous four quarters. SMB, HML and MOM data are available at http://mba.tuck.dartmouth.edu/pages/faculty/ken.french/data_library.html\#Developed.

${ }^{25}$ The stocks' liquidity factor is measured by the innovations in aggregate liquidity (nontraded liquidity factor; equation (8) in Pastor and Stambaugh, 2003). Data are available at http://faculty.chicagobooth.edu/lubos.pastor/research/liq_data_1962_2011.txt. The Pastor-Stambaugh liquidity factor is computed as the a cross-sectional weighted average of individual-stock liquidity measures, the latter being the effect of the transaction volume in one month on next month individual return.

${ }^{26}$ The leverage factor is computed as the ratio of total financial assets over the difference between total financial assets and total financial liabilities of security brokers-delears as reported in Table L.129 of the US Federal Reserve Flow of Funds. It may be considered as a proxy for financial instability, i.e., the higher the ratio, the higher the fragility of the financial sector. The author is grateful to T. Muir for providing the data.

${ }^{27}$ See Hamilton (1996) for details concerning the construction of the net change variables, albeit for an application to the oil price.

${ }^{28}$ The Working's $\mathrm{T}$ index is calculated as the ratio of speculative open interest to total open interest resulting from hedging activity, i.e., as $1+\mathrm{SS} /(\mathrm{HS}+\mathrm{HL})$ if HS HL and $1+\mathrm{SL} /(\mathrm{HS}+\mathrm{HL})$ if $\mathrm{HS}<\mathrm{HL}$, where open interest held by speculators (non-commercials) and hedgers (commercials) is denoted as follows: SS = Speculation, Short; HL = Hedging, Long; SL = Speculation, Long; HS = Hedging, Short.
} 
1986:1 through 2010:3.

The global model in (1) then counts 33 endogenous variables, collected in the vector $\mathbf{F}_{t}=\left[\mathbf{F}_{1, t}^{\prime} \mathbf{F}_{2, t}^{\prime} \mathbf{O}_{t}^{\prime}\right]^{\prime}$, over the period 1985:1 through 2010:3.

\section{References}

[1] Adrian, T., Etula, E., Muir, T., 2012. Financial intermediaries and the cross-section of asset returns. Federal Reserve Bank of New York Staff Report, no. 464, July 2010, revised (The Journal of Finance, forthcoming).

[2] Adrian, T., Shin, H.S., 2008. Liquidity, monetary policy and financial cycles. Federal Reserve of New York: Current Issues 14, 1-7.

[3] Adrian, T., Shin, H.S., 2010. Liquidity and leverage. Journal of Financial Intermediation 19, 418-437.

[4] Bai, J., 2003. Inferential theory for factor models of large dimensions. Econometrica 71, 135-171.

[5] Bai, J. and S. Ng, 2006a. Confidence intervals for diffusion index forecasts and inference with factor-augmented regressions. Econometrica 74, 1133-1150.

[6] Bai., J., Ng, S., 2006b. Evaluating latent and observed factors in macroeconomics and finance. Journal of Econometrics 131, 507-537.

[7] Bagliano, F.C., Morana, C., 2012. The Great Recession: US dynamics and spillovers to the world economy. Journal of Banking and Finance $36,1-13$.

[8] Bansal, R., Yaron, A., 2004. Risks for the long run: A potential resolution of asset pricing puzzles. The Journal of Finance 59, 1481-1509.

[9] Beber, A., Brandt, M.W., Luisi, M., 2013. Economic cycles and expected stock returns. Duke University. Mimeo.

[10] Beltratti, A., Morana, C., 2006. Breaks and persistency: Macroeconomic causes of stock market volatility. Journal of Econometrics 131, 151-177.

[11] Bernanke, B.S., Gertler, M., 1989. Agency costs, net worth, and business fluctuations. American Economic Review 79, 14-31. 
[12] Bernanke, B.S., 2005. The global saving glut and the U.S. current account deficit. Remarks by Governor Ben S. Bernanke at the Sandridge Lecture, Virginia Association of Economists, Richmond, Virginia, March, 10, 2005.

[13] Beaudry, P., Portier, F., 2013. News driven business cycles: Insights and Challenges. University of British Columbia. Mimeo.

[14] Borio, C., Zhu, H., 2008. Capital regulation, risk-taking and monetary policy: A missing link in the transmission mechanism? BIS Working Papers, no. 268.

[15] Breeden, D.T., 1979. An intertemporal asset pricing model with stochastic consumption and investment opportunities. Journal of Financial Economics 7, 265-296.

[16] Campbell, J.Y., Shiller, R.J, 1988. Stock prices, earnings and expected dividends. The Journal of Finance XLIII, 661-676.

[17] Campbell, J.Y., 1993. Intertemporal asset pricing without consumption data. American Economic Review 83, 487-512.

[18] Campbell, J.Y., Vuolteenaho, T., 2004. Bad beta, good beta. American Economic Review 94, 1249-1275.

[19] Campbell, J. Y., Yogo, M., 2006. Efficient tests of stock return predictability. Journal of Financial Economics 81, 27-60.

[20] Campbell, S.D., Diebold, F.X., 2009. Stock returns and expected business conditions: Half a century of direct evidence. Journal of Business and Economic Statistics 27, 266-278.

[21] Campbell, J.Y., Giglio, S., Polk, C., Turley, R., 2012. An intertemporal CAPM with stochastic volatility. NBER Working Paper Series, no.18411.

[22] Canova, F., De Nicolò, G., 1995. Stock returns and real activity: A structural approach. European Economic Review 39, 981-1015.

[23] Carhart, M.M., 1997. On persistence in mutual fund performance, The Journal of Finance 52, 57-82.

[24] Chen, N.-F., Roll, R., Ross, S.A., 1986, Economic forces and the stock market. The Journal of Business 59, 383-403. 
[25] Chordia, T, Shivakumar, L., 2002. Momentum, business cycle and time varying expected returns. Journal of Finance 57, 985-1019.

[26] Chun, H., Kim, J.-W., Morck, R., 2013. Productivity growth and stock returns: Firm- and aggregate-level analyses. NBER Working Paper, no. 19462.

[27] Cochrane, J.H., 1996. A cross-sectional test of an investment based asset pricing model. Journal of Political Economy 104, 572-621.

[28] Cochrane, J.H., 2007. Financial markets and the real economy. In Mehra, R. (Ed.), Handbook of the Equity Premium. Elsevier, UK, 237-325.

[29] Cooper, M.J., Gutierrez JR., R.C., Hamed, A., 2004. Market states and momentum. The Journal of Finance LIX, 1345-1365.

[30] Davis, J.L., Fama, E.J. and French, K.R., 2000, Characteristics, covariances and average returns: 1929-1997, The Journal of Finance, LV, 389-406.

[31] Fama, E.F., 1981. Stock returns, real activity, inflation and money, The American Economic Review,71, 545-565.

[32] Fama, E.F., French, K.R., 1988. Permanent and temporary components of stock prices. The Journal of Political Economy 96, 246-273.

[33] Fama, E.F., French, K.R., 1989. Business conditions and expected returns on stocks and bonds. Journal of Financial Economics 25, 23-49.

[34] Fama, E.F., French, K.R., 1993. Common risk factors in the returns on stocks and bonds. Journal of Financial Econonomics 33, 3-56.

[35] Fama, E.F., French, K.R., 1996. Multifactor explanations of asset pricing anomalies. Journal of Finance 51, 55-87.

[36] Fama, E.F., French, K.R., 2004. The capital asset pricing model: Theory and evidence. The Journal of Economic Perspectives 18, 25-47.

[37] Fama, E.F., French, K.R., 2013. A four-factor model for the size, value, and profitability patterns in stock returns. Fama-Miller Working Paper Series, July 2013.

[38] Fama, E.F., MacBeth, J., 1973. Risk, return and equilibrium: empirical tests. Journal of Political Economy 81, 607-36. 
[39] Ferson, W.E., Harvey, C., 1991. Time variation of economic risk premiums. Journal of Political Economy 99, 385-415.

[40] Ferson, W.E., Harvey, C., 1999. Conditioning variables and the crosssection of stock returns. The Journal of Finance LIV, 1325-1360.

[41] Ferson, W.E., Korajczyk, R.A., 1995. Do arbitrage pricing models explain the predictability of stock returns? The Journal of Business 68, 309-349.

[42] Goyal, A., 2012. Empirical cross-sectional asset pricing: A survey, Financial Markets Porfolio Management 26, 3-38.

[43] Griffin, J.M., Ji, X., Spencer Martin, J., 2003. Momentum investing and business cycle risk: Evidence from pole to pole. The Journal of Finance LVIII, 2515-2547.

[44] Hahn, J., Lee, H., 1996. Yield spreads as alternative risk factors for size and book-to-market. The Journal of Financial and Quantitative Analysis 41, 245-269.

[45] Hamilton, J., 1996. This is what happened to the oil pricemacroeconomy relationship. Journal of Monetary Economics 38, 215-20.

[46] Hamilton, J.D., 2011. Historical Oil Shocks. In Parker, R., Whaples, R., eds., Handbook of Major Events in Economic History, Abingdon: Routledge, forthcoming.

[47] Jagannathan, R., Wang, Z., 1996. The conditional CAPM and the crosssection of expected returns. Journal of Finance 51, 3-53.

[48] Kasparis, I., Andreou, E., Phillips, P.C.B, 2006, Non parametric predictive regression. Cowles Foundation Discussion Paper, no. 1878.

[49] Kan, R., Zhou, G. 1999. A critique of stochastic discount factor methodology. Journal of Finance LIV, 1221-1248.

[50] Kang, J., Kim, T.S., Lee, C., Min, B.-K., 2011. Macroeconomic risk and the cross-section of stock returns. Journal of Banking and Finance 35, 3158-3173.

[51] Kapadia, N., 2011, Tracking down distress risk. Journal of Financial Economics, 102, 167-182. 
[52] Kogan, L., Papanikolaou, D., 2012. Growth opportunities, technology shocks, and asset prices. Journal of Finance, forthcoming.

[53] Kogan, L., Papanikolaou, D., Seru, A., Stoffman, N., 2012. Technological innovation, resource allocation, and growth. NBER Working Paper, no. 17769 .

[54] Li, Q., Vassalou, M., Xing, Y., 2006. Sector investments growth rates and the cross-section of expected returns. The Journal of Business 79, $1637-1665$.

[55] Lintner, J., 1965. The valuation of risky assets and the selection of risky investments in stock portfolios and capital budgets. Review of Economics and Statistics 47, 13-37.

[56] Liu, X.L., Zhang, L., 2008. Momentum profits, factor pricing, and macroeconomic risk. The Review of Financial Studies 21, 2417-2448.

[57] Lettau, M., Ludvigson, S., 2001. Resurrecting the (C)CAPM: A crosssectional test when risk premia are time-varying. Journal of Political Economy 109, 1238-1287.

[58] Lettau, M., Ludvigson, S., 2011. Shocks and crashes. NBER Working Paper Series, no. 16966.

[59] Ludvigson, S.C., Ng, S., 2007. The empirical risk-return relation: A factor analysis approach. Journal of Financial Economics 83, 171-222.

[60] Lustig, H., Van Nieuwerburgh, S., 2005. Housing collateral, consumption insurance and risk premia: An empirical perspective. The Journal of Finance 9, 1167-1219.

[61] Merton, R., 1973. An Intertemporal Capital Asset Pricing Model. Econometrica 41, 867-887.

[62] Morana, C., 2011. Factor vector autoregressive estimation of heteroskedastic persistent and non persistent processes subject to structural breaks. University of Milano-Bicocca, mimeo, available at SSRN: http://ssrn.com/abstract=1756376 (revised version October 2013).

[63] Morana, C., 2012. PC-VAR estimation of vector autoregressive models. Open Journal of Statistics 2, 251-259.

[64] Nagel, S., 2013. Empirical cross-sectional asset pricing. Annual Review of Financial Economics 5, 167-199. 
[65] Novy-Marx, R., 2013, The other side of value: The gross profitability premium. Journal of Financial Economics 108, 2013, 1-28.

[66] Pastor, L., Stambaugh, R.F., 2003. Liquidity risk and expected stock returns. Journal of Political Economy 11, 642-685.

[67] Petkova, R. and Zhang, L., 2005. Is value riskier than growth? Journal of Financial Economics 78, 187-202.

[68] Petkova, R., 2006. Do the Fama-French factors proxy for innovations in predictive variables? Journal of Finance 61, 581-612.

[69] Ross, S. A., 1976. The arbitrage theory of capital asset pricing, Journal of Economics Theory 13. 341-360.

[70] Santos, T., Veronesi,P., 2006. Labor income and predictable stock returns. Review of Financial Studies 19, 1-44.

[71] Schwert, G.W., 1989a. Why does stock market volatility change over time? The Journal of Finance XLIV, 1115-1153.

[72] Schwert, G.W., 1989b. Business cycles, financial crises and stock volatility. Carnegie-Rochester Conference Series on Public Policy 31, 83-125.

[73] Sharpe, W., 1964. Capital asset prices: a theory of market equilibrium under conditions of risk. Journal of Finance 19, 425-42.

[74] Vassalou, M., 2003. News related to future GDP growth as a risk factor in equity returns. Journal of Financial Economics 68, 47-73.

[75] Vassalou, M., Xing, Y., 2004. Default risk in equity returns. The Journal of Finance LIX, 831-868.

[76] Working, H., 1960. Speculation on hedging markets. Stanford University Food Research Institute Studies 1, 185-220. 
Table 1: Dynamic responses of real activity and risk factors to structural shocks

\begin{tabular}{|c|c|c|c|c|c|c|c|c|c|c|c|c|c|}
\hline \multicolumn{14}{|c|}{ Panel A: Real activity } \\
\hline & OR & OSN & OSP & LS & AD & GFI & GDI & GTI & PR & MPS & TL & TS & TT \\
\hline 0 & -0.03 & -0.11 & -0.05 & 0.13 & 0.41 & 0.00 & 0.00 & 0.00 & 0.00 & 0.00 & 0.00 & 0.00 & 0.00 \\
\hline 2 & 0.01 & 0.00 & 0.00 & 0.43 & 0.67 & -0.25 & -0.23 & -0.03 & 0.04 & 0.02 & 0.06 & 0.07 & 0.02 \\
\hline 4 & 0.12 & 0.04 & -0.05 & 0.62 & 0.59 & -0.49 & -0.13 & -0.17 & 0.26 & -0.06 & 0.28 & 0.22 & -0.17 \\
\hline 6 & 0.22 & 0.04 & 0.07 & 0.64 & 0.39 & -0.63 & -0.03 & -0.30 & 0.56 & -0.09 & 0.44 & 0.34 & -0.34 \\
\hline 8 & 0.23 & 0.11 & 0.10 & 0.60 & 0.32 & -0.70 & 0.01 & -0.30 & 0.67 & -0.07 & 0.51 & 0.36 & -0.45 \\
\hline 12 & 0.22 & 0.28 & -0.01 & 0.43 & 0.29 & -0.65 & 0.08 & -0.32 & 0.66 & -0.11 & 0.49 & 0.40 & -0.54 \\
\hline 20 & 0.29 & 0.44 & -0.13 & 0.18 & 0.28 & -0.47 & 0.13 & -0.29 & 0.70 & -0.10 & 0.34 & 0.30 & -0.54 \\
\hline 40 & 0.44 & 0.62 & -0.19 & 0.14 & 0.29 & -0.50 & 0.21 & -0.37 & 0.85 & -0.14 & 0.37 & 0.31 & -0.56 \\
\hline \multicolumn{14}{|c|}{ Panel B: Real stock prices } \\
\hline & OR & OSN & OSP & LS & $A D$ & GFI & GDI & GTI & PR & MPS & TL & TS & TT \\
\hline 0 & -0.17 & -0.01 & -0.02 & 0.09 & 0.23 & -0.15 & -0.12 & -0.05 & -0.22 & 0.03 & 0.12 & 0.04 & -0.05 \\
\hline 2 & -0.18 & -0.13 & 0.14 & 0.37 & 0.23 & -0.29 & -0.31 & -0.06 & -0.27 & 0.02 & 0.23 & 0.04 & -0.09 \\
\hline 4 & -0.12 & -0.39 & 0.26 & 0.32 & 0.12 & -0.34 & -0.19 & -0.13 & -0.17 & -0.09 & 0.30 & 0.18 & -0.15 \\
\hline 6 & -0.13 & -0.46 & 0.37 & 0.35 & 0.07 & -0.33 & -0.20 & -0.09 & -0.14 & -0.04 & 0.31 & 0.14 & -0.12 \\
\hline 8 & -0.23 & -0.45 & 0.38 & 0.34 & 0.13 & -0.34 & -0.25 & 0.01 & -0.27 & -0.03 & 0.28 & 0.16 & -0.08 \\
\hline 12 & -0.34 & -0.55 & 0.34 & 0.33 & 0.12 & -0.30 & -0.28 & 0.05 & -0.40 & -0.04 & 0.24 & 0.16 & -0.08 \\
\hline 20 & -0.46 & -0.75 & 0.41 & 0.37 & 0.13 & -0.22 & -0.38 & 0.12 & -0.55 & 0.02 & 0.19 & 0.10 & -0.02 \\
\hline 40 & -0.54 & -0.92 & 0.50 & 0.47 & 0.13 & -0.26 & -0.43 & 0.15 & -0.63 & 0.04 & 0.21 & 0.12 & 0.02 \\
\hline \multicolumn{14}{|c|}{ Panel C: Stock market volatility } \\
\hline & OR & OSN & OSP & LS & AD & GFI & GDI & GTI & PR & MPS & $\mathrm{TL}$ & TS & TT \\
\hline 0 & 0.19 & 0.07 & 0.00 & -0.09 & -0.15 & -0.07 & 0.05 & -0.23 & 0.20 & 0.01 & 0.03 & 0.04 & -0.04 \\
\hline 2 & 0.30 & 0.06 & -0.09 & -0.25 & $\begin{array}{l}-0.27 \\
\end{array}$ & 0.06 & 0.16 & -0.23 & 0.39 & 0.12 & -0.04 & 0.00 & 0.00 \\
\hline 4 & 0.10 & 0.34 & -0.04 & -0.18 & -0.23 & 0.08 & $\begin{array}{l}-0.03 \\
\end{array}$ & -0.13 & 0.21 & 0.18 & -0.02 & -0.09 & 0.01 \\
\hline 6 & -0.11 & 0.13 & -0.08 & -0.04 & -0.14 & 0.05 & -0.06 & -0.09 & 0.01 & 0.25 & -0.04 & -0.06 & 0.03 \\
\hline 8 & -0.06 & -0.04 & -0.03 & 0.03 & -0.20 & 0.04 & -0.13 & -0.20 & 0.06 & 0.23 & 0.00 & -0.05 & 0.01 \\
\hline 12 & -0.08 & -0.12 & 0.12 & 0.11 & -0.23 & 0.00 & $\begin{array}{l}-0.12 \\
\end{array}$ & -0.19 & 0.07 & 0.27 & 0.04 & -0.02 & 0.00 \\
\hline 20 & -0.11 & -0.20 & 0.16 & 0.18 & -0.22 & -0.05 & -0.14 & -0.19 & 0.05 & 0.26 & 0.08 & 0.02 & 0.02 \\
\hline 40 & -0.17 & -0.29 & 0.19 & 0.21 & -0.22 & -0.04 & -0.18 & -0.16 & -0.04 & 0.28 & 0.07 & 0.02 & 0.04 \\
\hline \multicolumn{14}{|c|}{ Panel D: Size factor } \\
\hline & OR & OSN & OSP & LS & AD & GFI & GDI & GTI & PR & MPS & TL & TS & TT \\
\hline 0 & -0.74 & 0.15 & -0.42 & -0.18 & 0.42 & -0.35 & 0.00 & -0.99 & -1.64 & -1.57 & 0.48 & 0.25 & 0.49 \\
\hline 2 & -0.48 & 0.81 & -0.57 & -0.08 & 0.91 & -0.43 & 0.28 & -0.48 & -1.91 & -1.64 & -0.08 & 0.26 & 0.71 \\
\hline 4 & 0.04 & 0.41 & -0.69 & -0.28 & 0.91 & -0.34 & 0.56 & 0.01 & -1.79 & -1.79 & -0.37 & -0.08 & 0.94 \\
\hline 6 & 0.09 & 0.88 & -0.85 & -0.76 & 0.71 & 0.00 & 0.65 & 0.37 & -1.76 & -1.66 & -0.46 & -0.33 & 1.17 \\
\hline 8 & -0.33 & 0.95 & -1.16 & -0.98 & 1.08 & 0.26 & 0.46 & 0.77 & -2.42 & -1.69 & -0.83 & -0.41 & 1.35 \\
\hline 12 & -0.63 & 0.68 & -1.31 & -0.77 & 1.17 & 0.27 & 0.11 & 1.12 & -2.85 & -1.69 & -1.00 & -0.55 & 1.33 \\
\hline 20 & -0.88 & -0.01 & -0.89 & -0.37 & 1.18 & 0.20 & -0.15 & 1.17 & -3.03 & -1.58 & -0.95 & -0.55 & 1.30 \\
\hline 40 & -1.09 & -0.38 & -0.72 & -0.20 & 1.12 & 0.15 & -0.26 & 1.25 & -3.22 & -1.51 & -0.91 & -0.51 & 1.34 \\
\hline \multicolumn{14}{|c|}{ Panel E: Value factor } \\
\hline & OR & OSN & OSP & LS & AD & GFI & GDI & GTI & PR & MPS & $\mathrm{TL}$ & TS & TT \\
\hline 0 & 0.25 & 0.16 & -0.63 & 1.29 & -0.04 & -1.36 & 1.45 & -0.25 & 0.00 & 0.30 & 0.16 & -0.13 & -1.38 \\
\hline 2 & 0.40 & -0.58 & 0.18 & 2.39 & 0.32 & -1.51 & 0.12 & -0.41 & -0.31 & 0.52 & 0.34 & -1.08 & -0.63 \\
\hline 4 & 0.68 & -0.07 & -0.33 & 1.06 & 0.20 & -0.97 & 1.11 & -0.43 & -0.84 & -0.28 & 0.36 & -0.98 & -0.54 \\
\hline 6 & 0.97 & 1.43 & -0.51 & 0.76 & 1.58 & -0.78 & 1.04 & -0.17 & -1.54 & -0.91 & -0.36 & -0.97 & -0.18 \\
\hline 8 & 1.38 & 1.98 & -1.08 & 0.56 & 1.65 & -0.81 & 1.55 & 0.59 & -1.47 & -0.94 & -0.71 & -1.05 & -0.07 \\
\hline 12 & 1.45 & 2.22 & -1.57 & 0.11 & 1.41 & -0.49 & 1.34 & 0.83 & -1.21 & -0.83 & -0.82 & -1.42 & 0.06 \\
\hline 20 & 1.14 & 1.86 & -1.48 & 0.30 & 1.44 & -0.52 & 1.03 & 0.94 & -1.52 & -0.83 & -0.88 & -1.48 & -0.23 \\
\hline 40 & 1.13 & 1.84 & -1.43 & 0.34 & 1.49 & -0.55 & 1.06 & 0.88 & -1.46 & -0.84 & -0.86 & -1.44 & -0.21 \\
\hline \multicolumn{14}{|c|}{ Panel F: Momentum factor } \\
\hline & OR & OSN & OSP & LS & AD & GFI & GDI & GTI & PR & MPS & TL & TS & TT \\
\hline 0 & 0.72 & 0.63 & -0.40 & -0.95 & -0.01 & 0.91 & -1.07 & 1.22 & 0.07 & 0.39 & -0.64 & -1.30 & 0.64 \\
\hline 2 & -0.61 & 0.66 & -1.62 & -0.93 & 1.97 & 0.54 & -1.25 & 2.01 & -1.75 & -0.62 & -1.31 & -0.99 & -0.37 \\
\hline 4 & -1.04 & 0.83 & -1.17 & 1.39 & 2.92 & $\begin{array}{r}-0.81 \\
\end{array}$ & -2.76 & 2.74 & -1.93 & -0.22 & -1.22 & -1.21 & -1.22 \\
\hline 6 & -0.26 & -0.33 & -0.89 & 1.01 & 1.83 & -1.21 & -2.51 & 2.36 & -1.01 & -1.07 & -0.67 & -0.59 & -2.48 \\
\hline 8 & 0.23 & -0.28 & 0.04 & 1.01 & 1.49 & -1.39 & -2.25 & 2.18 & 0.04 & -1.10 & -0.47 & $\begin{array}{l}-0.62 \\
\end{array}$ & -3.11 \\
\hline 12 & 0.09 & 0.14 & $\begin{array}{l}-0.04 \\
\end{array}$ & 0.61 & 1.58 & -1.54 & -2.08 & 2.37 & 0.19 & -1.17 & -0.53 & -0.33 & -3.55 \\
\hline 20 & 0.38 & 0.78 & -0.47 & -0.48 & 1.18 & -1.06 & $\begin{array}{l}-1.84 \\
\end{array}$ & 2.35 & 0.63 & -1.17 & -0.86 & -0.47 & -3.97 \\
\hline 40 & 1.02 & 1.61 & -0.79 & -0.77 & 1.26 & -1.03 & -1.48 & 2.06 & 1.19 & -1.36 & -0.89 & -0.50 & -4.02 \\
\hline \multicolumn{14}{|c|}{ Panel G: Stock market liquidity factor } \\
\hline & OR & OSN & OSP & LS & AD & GFI & GDI & GTI & PR & MPS & TL & TS & TT \\
\hline 0 & -2.13 & 1.20 & -1.02 & 1.39 & 0.11 & 0.40 & -1.08 & 1.36 & -0.29 & -0.39 & -1.44 & 0.48 & -1.31 \\
\hline 2 & -0.03 & -0.63 & 0.68 & 0.81 & -0.33 & -0.79 & -0.55 & 0.24 & 0.67 & 0.15 & 0.33 & -0.28 & -0.73 \\
\hline 4 & 0.54 & -0.95 & 0.41 & 0.02 & -0.38 & -0.07 & -0.33 & -0.71 & 0.53 & -0.65 & 0.51 & -0.40 & -0.15 \\
\hline 6 & 0.36 & 0.38 & 0.20 & -0.64 & -0.18 & 0.62 & 0.30 & -0.56 & 0.13 & 0.03 & -0.02 & -0.13 & 0.09 \\
\hline 8 & 0.16 & 0.75 & -0.19 & -0.37 & 0.59 & 0.10 & 0.06 & 0.14 & -0.19 & -0.16 & -0.43 & 0.15 & 0.23 \\
\hline 12 & 0.21 & 0.28 & -0.16 & -0.43 & -0.13 & 0.19 & -0.03 & 0.02 & 0.15 & -0.09 & -0.11 & -0.01 & 0.01 \\
\hline 20 & 0.08 & 0.03 & 0.02 & 0.01 & 0.02 & 0.00 & 0.03 & -0.05 & 0.07 & -0.02 & 0.00 & -0.01 & -0.02 \\
\hline 40 & 0.01 & 0.01 & -0.01 & -0.01 & 0.00 & 0.01 & 0.00 & 0.00 & 0.01 & 0.00 & -0.01 & $\begin{array}{r}-0.01 \\
\end{array}$ & 0.00 \\
\hline
\end{tabular}


Table 1 (ctd): Dynamic responses of real activity and risk factors to structural shocks

\begin{tabular}{|c|c|c|c|c|c|c|c|c|c|c|c|c|c|}
\hline \multicolumn{14}{|c|}{ Leverage factor } \\
\hline & OR & OSN & OSP & LS & AD & GFI & GDI & GTI & PR & MPS & TL & TS & TT \\
\hline 0 & -1.00 & -0.17 & -0.75 & 0.98 & 0.01 & 0.10 & -0.56 & -1.14 & -0.94 & 0.24 & -0.50 & -0.37 & 0.27 \\
\hline 2 & -0.43 & 0.30 & 0.95 & 0.96 & 0.59 & -0.53 & -1.44 & 0.50 & -1.14 & 0.24 & -0.21 & 0.03 & -0.32 \\
\hline 4 & -0.26 & -0.48 & 0.25 & 0.20 & -0.08 & 0.12 & 0.05 & -0.14 & -0.29 & -0.24 & 0.21 & -0.09 & -0.06 \\
\hline 6 & 0.66 & -0.18 & 0.53 & -0.25 & -0.01 & -0.02 & 0.12 & -0.14 & 0.18 & -0.48 & -0.19 & 0.26 & -0.30 \\
\hline 8 & 0.28 & 0.31 & 0.19 & -0.01 & 0.19 & -0.16 & 0.31 & 0.16 & 0.33 & -0.10 & -0.04 & -0.07 & 0.23 \\
\hline 12 & -0.02 & 0.19 & -0.22 & -0.02 & 0.01 & -0.06 & 0.08 & -0.01 & 0.06 & $\begin{array}{l}-0.03 \\
\end{array}$ & 0.04 & 0.01 & 0.07 \\
\hline 20 & -0.02 & 0.02 & -0.02 & -0.07 & 0.00 & 0.06 & 0.00 & 0.04 & -0.04 & 0.00 & -0.06 & -0.04 & -0.01 \\
\hline 40 & 0.00 & 0.01 & -0.01 & -0.01 & 0.00 & 0.00 & 0.00 & 0.00 & 0.00 & 0.00 & 0.00 & 0.00 & 0.00 \\
\hline \multicolumn{14}{|c|}{ Panel I: Fragility factor } \\
\hline & OR & OSN & OSP & LS & $A D$ & GFI & GDI & GTI & $\mathbf{P R}$ & MPS & TL & TS & TT \\
\hline 0 & 0.02 & 0.00 & 0.00 & -0.02 & -0.03 & 0.00 & 0.02 & -0.01 & 0.03 & 0.00 & -0.01 & 0.00 & -0.01 \\
\hline 2 & 0.01 & -0.01 & -0.01 & -0.03 & -0.01 & 0.01 & 0.00 & 0.01 & 0.00 & 0.00 & -0.03 & 0.01 & 0.01 \\
\hline 4 & -0.02 & -0.03 & 0.00 & 0.02 & 0.02 & -0.01 & -0.02 & 0.02 & -0.03 & 0.02 & -0.03 & -0.01 & 0.01 \\
\hline 6 & -0.02 & -0.04 & 0.00 & 0.03 & 0.01 & -0.03 & -0.03 & 0.01 & -0.02 & 0.01 & -0.01 & 0.01 & 0.00 \\
\hline 8 & -0.01 & -0.06 & 0.01 & 0.03 & -0.01 & -0.03 & -0.02 & $\begin{array}{l}0.01 \\
\end{array}$ & 0.00 & 0.01 & 0.00 & 0.01 & -0.02 \\
\hline 12 & -0.02 & -0.05 & 0.02 & 0.03 & -0.01 & -0.03 & -0.02 & 0.00 & -0.01 & 0.01 & 0.00 & 0.01 & -0.01 \\
\hline 20 & -0.02 & -0.06 & & 0.02 & -0.01 & -0.02 & -0.02 & 0.00 & -0.01 & 0.01 & -0.01 & 0.01 & -0.01 \\
\hline 40 & -0.02 & -0.06 & 0.02 & 0.02 & 0.00 & -0.02 & -0.02 & 0.00 & -0.02 & 0.01 & -0.01 & 0.01 & -0.01 \\
\hline
\end{tabular}

The table reports impulse responses for real activity (Panel A), real stock prices (Panel B), nominal stock market volatility (Panel C), SMB (Panel D), HML (Panel E), MOM (Panel F), PSL (Panel G), LEV (Panel H) and FRA (Panel I) at selected horizons (impact (0) and 2 to 40 quarters), relatively to various identified structural shocks: oil reserves (OR), flow oil supply (positive, OSP; negative, OSN), labor supply (LS), aggregate demand (AD), productivity (PR), global imbalance (GFI, GDI, GTI), monetary policy stance (MPS), term structure level (TL) and slope (TS), US terms of trade (TT). Figures in bold denote statistical significance at the $5 \%$ level. 
Table 2: Fama-French size-value portfolios, cross-sectional regressions

\begin{tabular}{|c|c|c|c|c|c|c|c|c|c|c|c|c|c|}
\hline \multicolumn{14}{|c|}{ Panel A: Non-filtered factors, US stock market return factor } \\
\hline & CAPM & CAPM-M & CAPM-P & CAPM-L & CAPM-F & CAPM-V & FF & FF-M & FF-P & FF-L & FF-F & FF-V & FF-A \\
\hline C & $\begin{array}{l}4.036^{*} \\
(0.834)\end{array}$ & $\begin{array}{l}3.676^{*} \\
(0.819) \\
\end{array}$ & $\begin{array}{l}3.261^{*} \\
(0.835) \\
\end{array}$ & $\begin{array}{l}5.157^{*} \\
(0.635) \\
\end{array}$ & $\begin{array}{l}3.675^{*} \\
(0.844) \\
\end{array}$ & $\begin{array}{l}2.630^{*} \\
(0.926) \\
\end{array}$ & $\begin{array}{l}5.208^{*} \\
(0.581) \\
\end{array}$ & $\begin{array}{l}4.664^{*} \\
(0.624)\end{array}$ & $\begin{array}{l}5.199 * \\
(0.597)\end{array}$ & $\begin{array}{l}5.679 * \\
(0.692) \\
\end{array}$ & $\begin{array}{l}5.122^{*} \\
(0.577)\end{array}$ & $\begin{array}{l}4.480^{*} \\
(0.635)\end{array}$ & $\begin{array}{l}5.957^{*} \\
(0.691)\end{array}$ \\
\hline Mkt & $\begin{array}{l}-1.606 \\
(0.897) \\
\end{array}$ & $\begin{array}{l}-1.916^{*} \\
(0.842)\end{array}$ & $\begin{array}{l}-0.975 \\
(0.900)\end{array}$ & $\begin{array}{c}-2.666^{*} \\
(0.897) \\
\end{array}$ & $\begin{array}{l}-1.701 \\
(0.897) \\
\end{array}$ & $\begin{array}{c}-0.450 \\
(0.901)\end{array}$ & $\begin{array}{l}-3.370^{*} \\
(0.896)\end{array}$ & $\begin{array}{l}-2.271^{*} \\
(0.897)\end{array}$ & $\begin{array}{l}-3.351^{*} \\
(0.897)\end{array}$ & $\begin{array}{l}-3.900^{*} \\
(0.797)\end{array}$ & $\begin{array}{l}-3.281^{*} \\
(0.896)\end{array}$ & $\begin{array}{l}-2.843^{*} \\
(0.896)\end{array}$ & $\begin{array}{l}-3.667^{*} \\
(0.918)\end{array}$ \\
\hline SMB & & & & & & & $\begin{array}{c}0.171 \\
(0.544) \\
\end{array}$ & $\begin{array}{c}0.223 \\
(0.544) \\
\end{array}$ & $\begin{array}{c}0.175 \\
(0.544) \\
\end{array}$ & $\begin{array}{c}-0.124 \\
(0.344) \\
\end{array}$ & $\begin{array}{c}0.026 \\
(0.543) \\
\end{array}$ & $\begin{array}{c}0.071 \\
(0.544) \\
\end{array}$ & $\begin{array}{c}0.079 \\
(0.547) \\
\end{array}$ \\
\hline HML & & & & & & & $\begin{array}{c}0.929 \\
(0.730) \\
\end{array}$ & $\begin{array}{c}0.786 \\
(0.730) \\
\end{array}$ & $\begin{array}{c}0.924 \\
(0.730) \\
\end{array}$ & $\begin{array}{l}1.276^{*} \\
(0.556) \\
\end{array}$ & $\begin{array}{c}0.878 \\
(0.730) \\
\end{array}$ & $\begin{array}{c}0.673 \\
(0.730) \\
\end{array}$ & $\begin{array}{l}1.666^{*} \\
(0.737)\end{array}$ \\
\hline MOM & & $\begin{array}{l}-1.817 \\
(1.079) \\
\end{array}$ & & & & & & $\begin{array}{c}1.132 \\
(0.899) \\
\end{array}$ & & & & & $\begin{array}{l}-1.163 \\
(0.924) \\
\end{array}$ \\
\hline PSL & & & $\begin{array}{l}5.194 * \\
(1.186) \\
\end{array}$ & & & & & & \begin{tabular}{|l|}
-1.575 \\
$(1.148)$ \\
\end{tabular} & & & & $\begin{array}{l}-0.040 \\
(1.163) \\
\end{array}$ \\
\hline LEV & & & & $\begin{array}{c}-0.030^{*} \\
(0.009) \\
\end{array}$ & & & & & & $\begin{array}{c}-0.043^{*} \\
(0.018)\end{array}$ & & & $\begin{array}{l}-0.108^{*} \\
(0.009)\end{array}$ \\
\hline FRA & & & & & $\begin{array}{c}-0.046^{*} \\
(0.020) \\
\end{array}$ & & & & & & $\begin{array}{c}-0.008 \\
(0.020) \\
\end{array}$ & & $\begin{array}{l}0.103^{*} \\
(0.020) \\
\end{array}$ \\
\hline FV & & & & & & $\begin{array}{c}-0.499^{*} \\
(0.120) \\
\end{array}$ & & & & & & $\begin{array}{l}-0.186 \\
(0.119) \\
\end{array}$ & $\begin{array}{l}-0.136 \\
(0.123) \\
\end{array}$ \\
\hline $\mathbf{R}^{2}$ & 0.174 & 0.324 & 0.312 & 0.225 & 0.438 & 0.442 & 0.516 & 0.520 & 0.516 & 0.598 & 0.541 & 0.562 & 0.757 \\
\hline$\overline{\mathbf{R}}^{2}$ & 0.109 & 0.262 & 0.249 & 0.154 & 0.387 & 0.391 & 0.447 & 0.424 & 0.455 & 0.517 & 0.449 & 0.465 & 0.636 \\
\hline \multicolumn{14}{|c|}{ Panel B: Filtered factors, US stock market return factor } \\
\hline & CAPM & CAPM-M & CAPM-P & CAPM-L & CAPM-F & CAPM-V & FF & FF-M & FF-P & FF-L & FF-F & FF-V & FF-A \\
\hline C & $\begin{array}{l}4.036^{*} \\
(1.828) \\
\end{array}$ & $\begin{array}{l}3.431^{*} \\
(0.764) \\
\end{array}$ & $\begin{array}{l}1.923 * \\
(0.754) \\
\end{array}$ & $\begin{array}{l}4.865^{*} \\
(0.639) \\
\end{array}$ & $\begin{array}{l}3.345^{*} \\
(0.918) \\
\end{array}$ & $\begin{array}{l}2.845^{*} \\
(0.938) \\
\end{array}$ & $\begin{array}{l}4.995^{*} \\
(0.580) \\
\end{array}$ & $\begin{array}{l}3.239^{*} \\
(0.673) \\
\end{array}$ & $\begin{array}{l}5.142^{*} \\
(0.623) \\
\end{array}$ & $\begin{array}{l}5.141^{*} \\
(0.555) \\
\end{array}$ & $\begin{array}{l}4.895^{*} \\
(0.589) \\
\end{array}$ & $\begin{array}{l}4.223^{*} \\
(0.616) \\
\end{array}$ & $\begin{array}{l}4.839^{*} \\
(0.653)\end{array}$ \\
\hline Mkt & $\begin{array}{l}-1.606 \\
(0.902) \\
\end{array}$ & $\begin{array}{l}-1.454 \\
(0.897) \\
\end{array}$ & $\begin{array}{c}0.584 \\
(0.904) \\
\end{array}$ & $\begin{array}{l}-2.392^{*} \\
(0.895) \\
\end{array}$ & $\begin{array}{l}-1.364 \\
(0.898) \\
\end{array}$ & $\begin{array}{c}-0.309 \\
(0.901) \\
\end{array}$ & $\begin{array}{l}-3.041^{*} \\
(0.896) \\
\end{array}$ & $\begin{array}{l}-1.058 \\
(0.896) \\
\end{array}$ & $\begin{array}{l}-3.550^{*} \\
(0.778) \\
\end{array}$ & $\begin{array}{l}-3.387^{*} \\
(0.897) \\
\end{array}$ & $\begin{array}{l}-3.019^{*} \\
(0.662) \\
\end{array}$ & $\begin{array}{l}-2.086^{*} \\
(0.673) \\
\end{array}$ & $\begin{array}{l}-2.649 * \\
(0.906) \\
\end{array}$ \\
\hline SMB & & & & & & & $\begin{array}{l}0.997^{*} \\
(0.276) \\
\end{array}$ & $\begin{array}{c}0.536 \\
(0.345) \\
\end{array}$ & $\begin{array}{l}0.999^{*} \\
(0.351) \\
\end{array}$ & $\begin{array}{c}0.755 \\
(0.401) \\
\end{array}$ & $\begin{array}{l}0.968^{*} \\
(0.375) \\
\end{array}$ & $\begin{array}{c}0.725 \\
(0.401) \\
\end{array}$ & $\begin{array}{l}1.032^{*} \\
(0.414) \\
\end{array}$ \\
\hline HML & & & & & & & $\begin{array}{c}0.764 \\
(0.608) \\
\end{array}$ & $\begin{array}{c}0.473 \\
(0.661) \\
\end{array}$ & $\begin{array}{l}1.100^{*} \\
(0.389) \\
\end{array}$ & $\begin{array}{c}0.961 \\
(0.699) \\
\end{array}$ & $\begin{array}{c}0.665 \\
(0.428) \\
\end{array}$ & $\begin{array}{c}0.513 \\
(0.390) \\
\end{array}$ & $\begin{array}{c}0.796 \\
(0.702) \\
\end{array}$ \\
\hline MOM & & $\begin{array}{l}-1.739^{*} \\
(0.814) \\
\end{array}$ & & & & & & $\begin{array}{l}2.770^{*} \\
(0.687) \\
\end{array}$ & & & & & $\begin{array}{l}-0.405 \\
(0.809) \\
\end{array}$ \\
\hline PSL & & & $\begin{array}{l}9.351^{*} \\
(1.080) \\
\end{array}$ & & & & & & $\begin{array}{l}-3.970^{*} \\
(0.843) \\
\end{array}$ & & & & $\begin{array}{l}2.836^{*} \\
(1.052) \\
\end{array}$ \\
\hline LEV & & & & $\begin{array}{c}-2.647^{*} \\
(0.826) \\
\end{array}$ & & & & & & $\begin{array}{l}-5.625^{*} \\
(0.817) \\
\end{array}$ & & & $\begin{array}{l}-6.048^{*} \\
(0.826) \\
\end{array}$ \\
\hline FRA & & & & & $\begin{array}{c}-0.063^{*} \\
(0.017) \\
\end{array}$ & & & & & & $\begin{array}{c}-0.003 \\
(0.022) \\
\end{array}$ & & $\begin{array}{l}0.066^{*} \\
(0.019) \\
\end{array}$ \\
\hline FV & & & & & & $\begin{array}{c}-0.729^{*} \\
(0.112) \\
\end{array}$ & & & & & & $\begin{array}{l}-0.409 * \\
(0.154) \\
\end{array}$ & $\begin{array}{c}0.025 \\
(0.116) \\
\end{array}$ \\
\hline $\mathbf{R}^{2}$ & 0.174 & 0.265 & 0.421 & 0.220 & 0.550 & 0.635 & 0.576 & 0.616 & 0.672 & 0.693 & 0.592 & 0.660 & 0.811 \\
\hline$\overline{\mathbf{R}}^{2}$ & 0.109 & 0.198 & 0.368 & 0.149 & 0.509 & 0.601 & 0.515 & 0.539 & 0.606 & 0.632 & 0.510 & 0.592 & 0.717 \\
\hline \multicolumn{14}{|c|}{ Panel C: Non-filtered factors, Global stock market return factor } \\
\hline & CAPM & CAPM-M & CAPM-P & CAPM-L & CAPM-F & CAPM-V & FF & FF-M & FF-P & FF-L & FF-F & FF-V & FF-A \\
\hline C & $\begin{array}{l}2.044^{*} \\
(0.661) \\
\end{array}$ & $\begin{array}{l}2.031^{*} \\
(0.652) \\
\end{array}$ & $\begin{array}{l}3.313^{*} \\
(0.723) \\
\end{array}$ & $\begin{array}{c}1.278 \\
(0.807) \\
\end{array}$ & $\begin{array}{l}2.613^{*} \\
(0.709) \\
\end{array}$ & $\begin{array}{c}1.188 \\
(0.769) \\
\end{array}$ & $\begin{array}{l}1.900^{*} \\
(0.840) \\
\end{array}$ & $\begin{array}{l}2.959^{*} \\
(0.653) \\
\end{array}$ & $\begin{array}{l}3.327^{*} \\
(0.553) \\
\end{array}$ & $\begin{array}{l}4.164^{*} \\
(0.568) \\
\end{array}$ & $\begin{array}{l}3.884^{*} \\
(0.428) \\
\end{array}$ & $\begin{array}{l}2.268^{*} \\
(0.765) \\
\end{array}$ & $\begin{array}{l}4.095^{*} \\
(0.479) \\
\end{array}$ \\
\hline Mkt & $\begin{array}{c}0.044 \\
(0.132) \\
\end{array}$ & $\begin{array}{c}0.038 \\
(0.133)\end{array}$ & $\begin{array}{c}0.087 \\
(0.133)\end{array}$ & $\begin{array}{c}0.225 \\
(0.132) \\
\end{array}$ & $\begin{array}{l}-0.196 \\
(0.133) \\
\end{array}$ & $\begin{array}{c}0.222 \\
(0.133)\end{array}$ & $\begin{array}{c}0.015 \\
(0.133)\end{array}$ & $\begin{array}{c}0.023 \\
(0.133) \\
\end{array}$ & $\begin{array}{l}-0.096 \\
(0.132)\end{array}$ & $\begin{array}{c}-0.630^{*} \\
(0.133)\end{array}$ & $\begin{array}{l}-0.695^{*} \\
(0.133)\end{array}$ & $\begin{array}{l}-0.201 \\
(0.133) \\
\end{array}$ & $\begin{array}{l}-0.031 \\
(0.136)\end{array}$ \\
\hline SMB & & & & & & & $\begin{array}{c}0.276 \\
(0.543) \\
\end{array}$ & $\begin{array}{c}0.326 \\
(0.544) \\
\end{array}$ & $\begin{array}{c}0.130 \\
(0.543) \\
\end{array}$ & $\begin{array}{c}0.014 \\
(0.545) \\
\end{array}$ & $\begin{array}{c}0.136 \\
(0.544) \\
\end{array}$ & $\begin{array}{c}0.412 \\
(0.544) \\
\end{array}$ & $\begin{array}{c}0.207 \\
(0.547) \\
\end{array}$ \\
\hline HML & & & & & & & $\begin{array}{c}1.409 \\
(0.730) \\
\end{array}$ & $\begin{array}{c}0.600 \\
(0.730) \\
\end{array}$ & $\begin{array}{c}1.273 \\
(0.730) \\
\end{array}$ & $\begin{array}{l}2.094^{*} \\
(0.733) \\
\end{array}$ & $\begin{array}{c}1.359 \\
(0.731) \\
\end{array}$ & $\begin{array}{c}0.955 \\
(0.730) \\
\end{array}$ & $\begin{array}{l}1.703^{*} \\
(0.740) \\
\end{array}$ \\
\hline MOM & & $\begin{array}{l}-0.167 \\
(0.897) \\
\end{array}$ & & & & & & $\begin{array}{l}2.336^{*} \\
(0.898) \\
\end{array}$ & & & & & $\begin{array}{l}-0.185 \\
(0.920) \\
\end{array}$ \\
\hline PSL & & & $\begin{array}{c}-6.079 * \\
(1.154)\end{array}$ & & & & & & $\begin{array}{l}-5.100 * \\
(1.156)\end{array}$ & & & & $\begin{array}{c}-0.351 \\
(1.175)\end{array}$ \\
\hline LEV & & & & $\begin{array}{l}0.030^{*} \\
(0.009) \\
\end{array}$ & & & & & & $\begin{array}{c}-0.077^{*} \\
(0.009) \\
\end{array}$ & & & $\begin{array}{l}-0.124^{*} \\
(0.010)\end{array}$ \\
\hline FRA & & & & & $\begin{array}{c}-0.077^{*} \\
(0.020) \\
\end{array}$ & & & & & & $\begin{array}{l}-0.058^{*} \\
(0.020)\end{array}$ & & $\begin{array}{l}0.141^{*} \\
(0.020)\end{array}$ \\
\hline FV & & & & & & $\begin{array}{c}-0.728^{*} \\
(0.120) \\
\end{array}$ & & & & & & $\begin{array}{l}-0.535^{*} \\
(0.119)\end{array}$ & $\begin{array}{c}0.002 \\
(0.125)\end{array}$ \\
\hline $\mathbf{R}^{2}$ & 0.005 & 0.005 & 0.140 & 0.073 & 0.252 & 0.303 & 0.357 & 0.500 & 0.423 & 0.504 & 0.456 & 0.444 & 0.752 \\
\hline$\overline{\mathbf{R}}^{2}$ & -0.038 & -0.086 & 0.062 & -0.011 & 0.183 & 0.239 & 0.265 & 0.400 & 0.308 & 0.405 & 0.347 & 0.333 & 0.628 \\
\hline
\end{tabular}


Table 2 (ctd): Fama-French size-value portfolios, cross-sectional regressions

\begin{tabular}{|c|c|c|c|c|c|c|c|c|c|c|c|c|c|}
\hline \multicolumn{14}{|c|}{ Panel D: Filtered factors, Global stock market return factor } \\
\hline & CAPM & CAPM-M & CAPM-P & CAPM-L & CAPM-F & CAPM-V & FF & FF-M & FF-P & FF-L & FF-F & FF-V & FF-A \\
\hline C & $\begin{array}{l}1.424^{*} \\
(0.549)\end{array}$ & $\begin{array}{l}2.342^{*} \\
(0.515)\end{array}$ & $\begin{array}{c}0.561 \\
(0.648)\end{array}$ & $\begin{array}{c}1.227 \\
(0.703)\end{array}$ & $\begin{array}{l}1.851^{*} \\
(0.558)\end{array}$ & $\begin{array}{l}1.441^{*} \\
(0.571)\end{array}$ & $\begin{array}{l}1.707^{*} \\
(0.497)\end{array}$ & $\begin{array}{l}2.403^{*} \\
(0.476)\end{array}$ & $\begin{array}{l}2.949^{*} \\
(0.782)\end{array}$ & $\begin{array}{l}2.121^{*} \\
(0.468)\end{array}$ & $\begin{array}{l}2.442^{*} \\
(0.448)\end{array}$ & $\begin{array}{l}1.965^{*} \\
(0.512)\end{array}$ & $\begin{array}{l}2.379 * \\
(0.507)\end{array}$ \\
\hline Mkt & $\begin{array}{l}0.211^{*} \\
(0.098) \\
\end{array}$ & $\begin{array}{l}0.291^{*} \\
(0.101) \\
\end{array}$ & $\begin{array}{l}0.094^{*} \\
(0.112) \\
\end{array}$ & $\begin{array}{l}0.322^{*} \\
(0.114) \\
\end{array}$ & $\begin{array}{c}-0.047 \\
(0.103) \\
\end{array}$ & $\begin{array}{c}-0.081 \\
(0.106) \\
\end{array}$ & $\begin{array}{c}0.046 \\
(0.087) \\
\end{array}$ & $\begin{array}{c}0.025 \\
(0.087) \\
\end{array}$ & $\begin{array}{c}0.132 \\
(0.096) \\
\end{array}$ & $\begin{array}{l}-0.164 \\
(0.087) \\
\end{array}$ & $\begin{array}{l}-0.333^{*} \\
(0.103) \\
\end{array}$ & $\begin{array}{l}-0.388^{*} \\
(0.103) \\
\end{array}$ & $\begin{array}{l}-0.170 \\
(0.113) \\
\end{array}$ \\
\hline SMB & & & & & & & $\begin{array}{l}0.828^{*} \\
(0.276) \\
\end{array}$ & $\begin{array}{l}0.893^{*} \\
(0.276) \\
\end{array}$ & $\begin{array}{l}0.793^{*} \\
(0.308) \\
\end{array}$ & \begin{tabular}{|l|}
$1.237^{*}$ \\
$(0.277)$ \\
\end{tabular} & $\begin{array}{l}1.139^{*} \\
(0.346)\end{array}$ & $\begin{array}{l}1.187^{*} \\
(0.347)\end{array}$ & $\begin{array}{l}0.881^{*} \\
(0.412)\end{array}$ \\
\hline HML & & & & & & & $\begin{array}{l}2.066^{*} \\
(0.608) \\
\end{array}$ & $\begin{array}{c}0.983 \\
(0.609) \\
\end{array}$ & $\begin{array}{l}2.029^{*} \\
(0.668) \\
\end{array}$ & $\begin{array}{l}2.411^{*} \\
(0.611) \\
\end{array}$ & $\begin{array}{c}1.117 \\
(0.662) \\
\end{array}$ & $\begin{array}{l}1.463^{*} \\
(0.662) \\
\end{array}$ & $\begin{array}{c}0.381 \\
(0.701) \\
\end{array}$ \\
\hline MOM & & $\begin{array}{l}3.990^{*} \\
(0.730) \\
\end{array}$ & & & & & & $\begin{array}{l}1.847^{*} \\
(0.616) \\
\end{array}$ & & & & & $\begin{array}{l}1.812^{*} \\
(0.797) \\
\end{array}$ \\
\hline PSL & & & $\begin{array}{l}8.266^{*} \\
(1.046) \\
\end{array}$ & & & & & & $\begin{array}{l}-4.176^{*} \\
(0.839) \\
\end{array}$ & & & & $\begin{array}{l}2.325^{*} \\
(1.038) \\
\end{array}$ \\
\hline LEV & & & & $\begin{array}{l}6.292^{*} \\
(0.838) \\
\end{array}$ & & & & & & $\begin{array}{l}-2.669^{*} \\
(0.746) \\
\end{array}$ & & & $\begin{array}{l}-2.756^{*} \\
(0.817) \\
\end{array}$ \\
\hline FRA & & & & & $\begin{array}{c}-0.079 * \\
(0.017) \\
\end{array}$ & & & & & & $\begin{array}{c}-0.023 \\
(0.017) \\
\end{array}$ & & $\begin{array}{l}0.050^{*} \\
(0.018) \\
\end{array}$ \\
\hline FV & & & & & & $\begin{array}{c}-0.743^{*} \\
(0.103)\end{array}$ & & & & & & $\begin{array}{l}-0.281^{*} \\
(0.103)\end{array}$ & $\begin{array}{c}-0.150 \\
(0.116) \\
\end{array}$ \\
\hline $\mathbf{R}^{2}$ & 0.107 & 0.449 & 0.274 & 0.402 & 0.505 & 0.506 & 0.535 & 0.659 & 0.590 & 0.697 & 0.598 & 0.691 & 0.779 \\
\hline$\overline{\mathbf{R}}^{2}$ & 0.068 & 0.399 & 0.208 & 0.348 & 0.459 & 0.461 & 0.469 & 0.591 & 0.508 & 0.637 & 0.517 & 0.629 & 0.669 \\
\hline
\end{tabular}

The Table reports the results of the estimation of Fama-MacBeth second-step cross-sectional regressions, using the Fama-French 25 size and value portfolios as test assets. The parameters reported refer to the intercept component (c), the market factor (MKT), and size (SMB), value (HML), momentum (MOM), stock market liquidity (PSL), leverage (LEV), financial fragility (FRA) and stock market volatility (FV) factors; $\mathbf{R}^{2}$ is the coefficient of determination and $\overline{\mathbf{R}}^{2}$ the adjusted coefficient of determination. The point estimate of the parameters is reported in the table, with Shenken's standard errors in round brackets; “*” denotes statistical significance at the $5 \%$ level. The specification employed are the CAPM model (CAPM); the CAPM model augmented with momentum (CAPM-M), stock market liquidity (CAPM-P), leverage (CAPM-L), financial fragility (CAPM-F) and risk aversion (CAPM-V); the Fama-French model (FF); the Fama-French model (FF) augmented with momentum (FF$M)$, stock market liquidity(FF-P), leverage (FF-L), financial fragility (FF-F), and risk aversion (FF-V); an 8-factor model including all the previous factors jointly (FF-A). In Panel $A$ and $C$ results for the standard case of actual factors, with US (A) and global stock market return factor (C), respectively, are reported. In Panel $B$ and $D$ results for the case of filtered factors, with US (B) and global stock market return factor (D), respectively, are reported. 

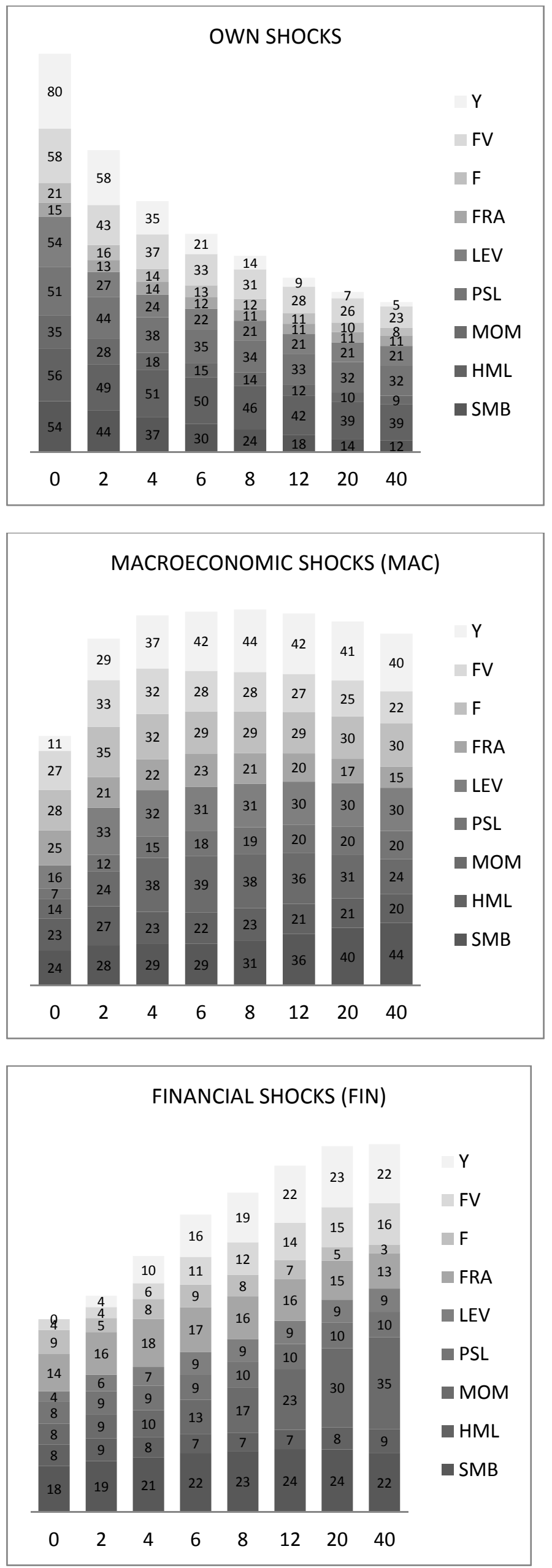

\section{RISK FACTORS SHOCKS (RF)}
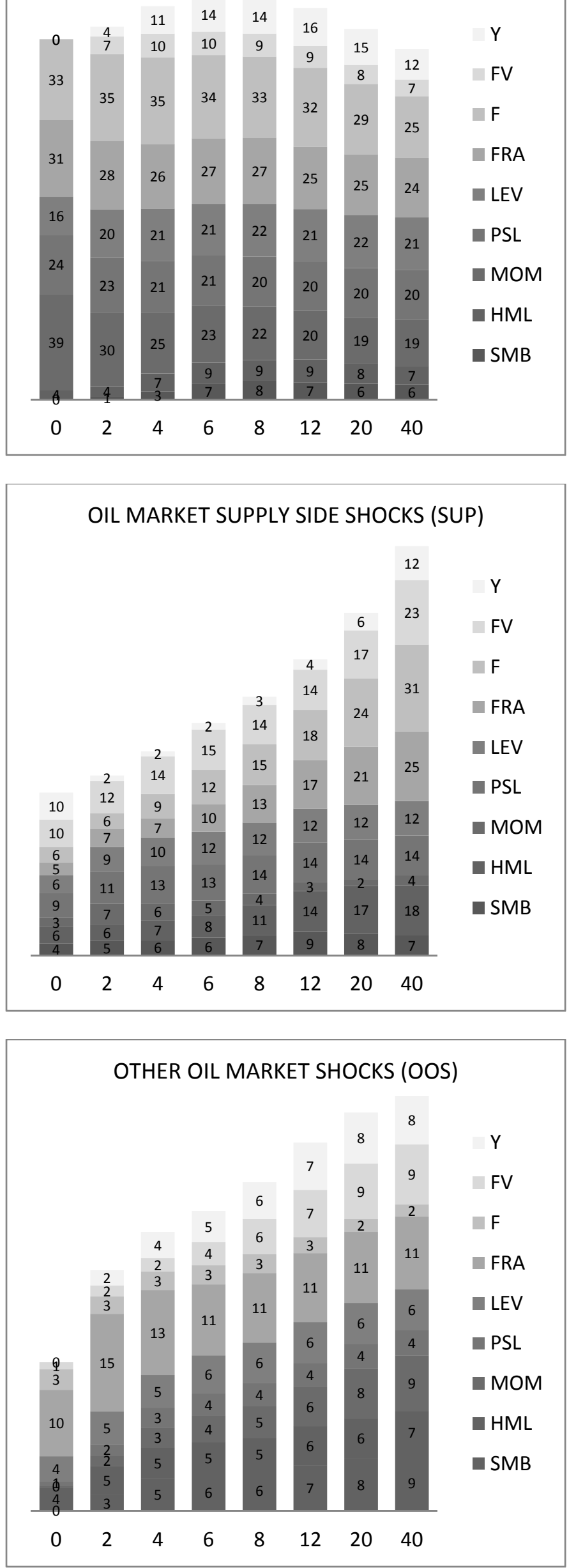

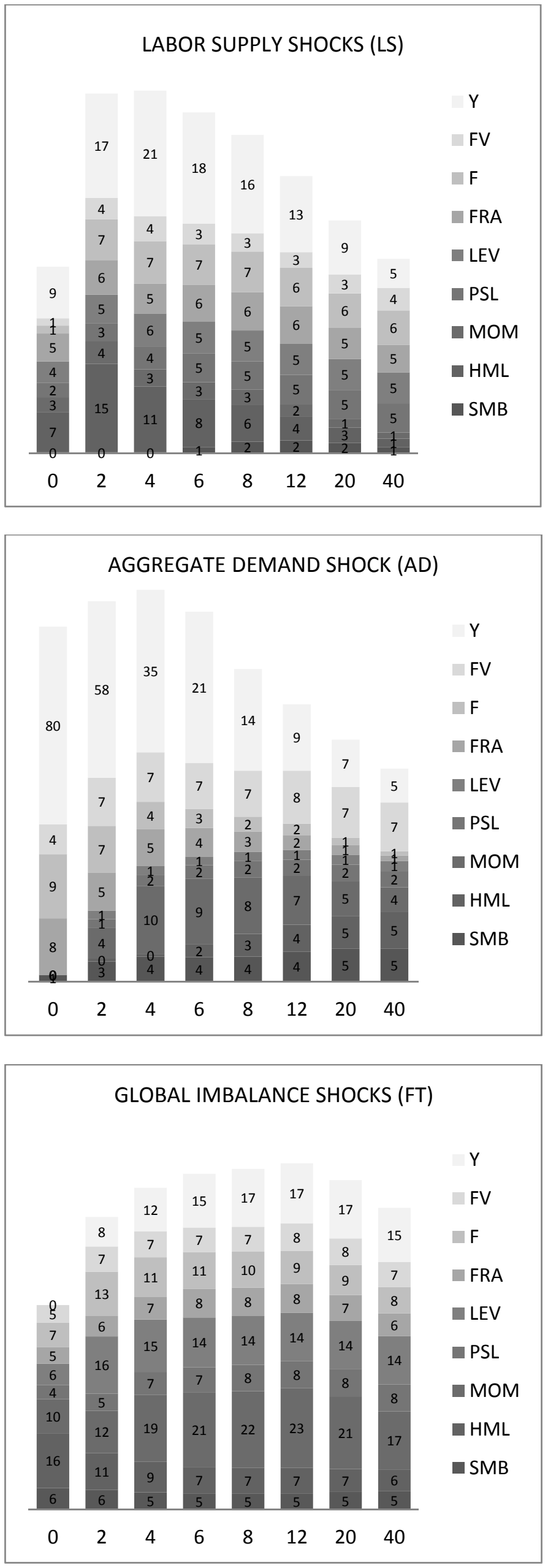

Figure 2: Forecast error variance decomposition, contribution of various categories of macroeconomic shocks (LS, AD, $F T, C l, P R)$ to real activity $(\mathrm{Y})$, stock market volatility (FV), stock market returns (F), fragility index (FRA), leverage (LEV), stock market liquidity (PSL), momentum (MOM), value (HML) and size (SMB) factors fluctuations at various horizons, from 1 quarter (1) to 10 years (40). 

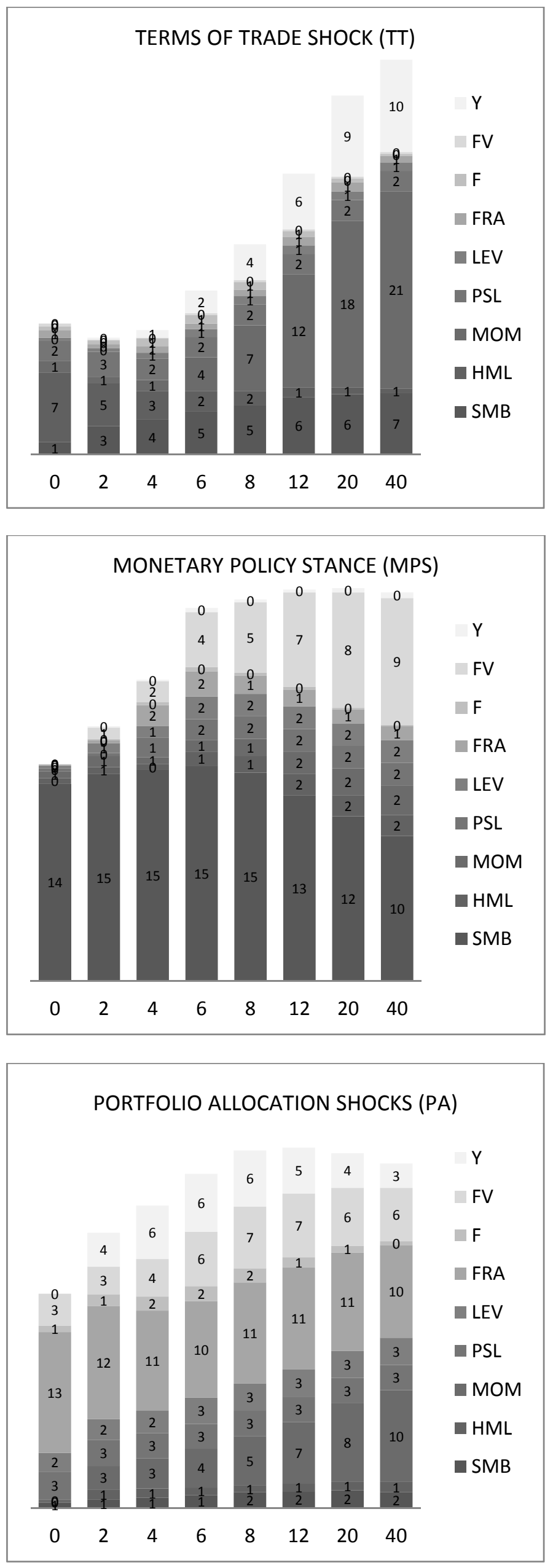

Figure 3: Forecast error variance decomposition, contribution of various categories of financial shocks (TT, MPS, PA, TL, TS) to real activity (Y), stock market volatility (FV), stock market returns (F), fragility index (FRA), leverage (LEV), stock market liquidity (PSL), momentum (MOM), value (HML) and size (SMB) factors fluctuations at various horizons, from 1 quarter (1) to 10 years (40).
TERM STRUCTURE LEVEL SHOCKS (TL)

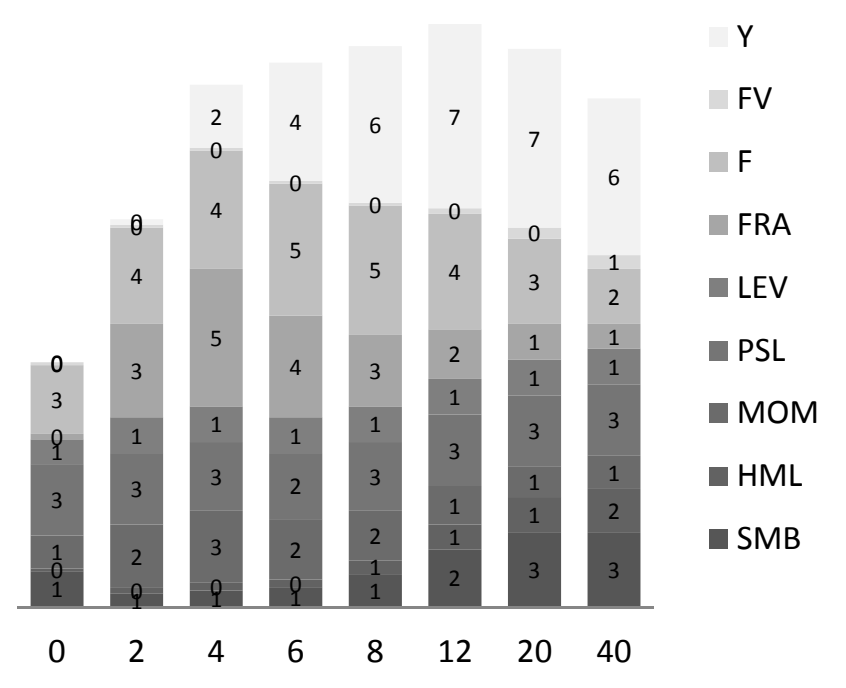

TERM STRUCTURE SLOPE SHOCKS (TS)

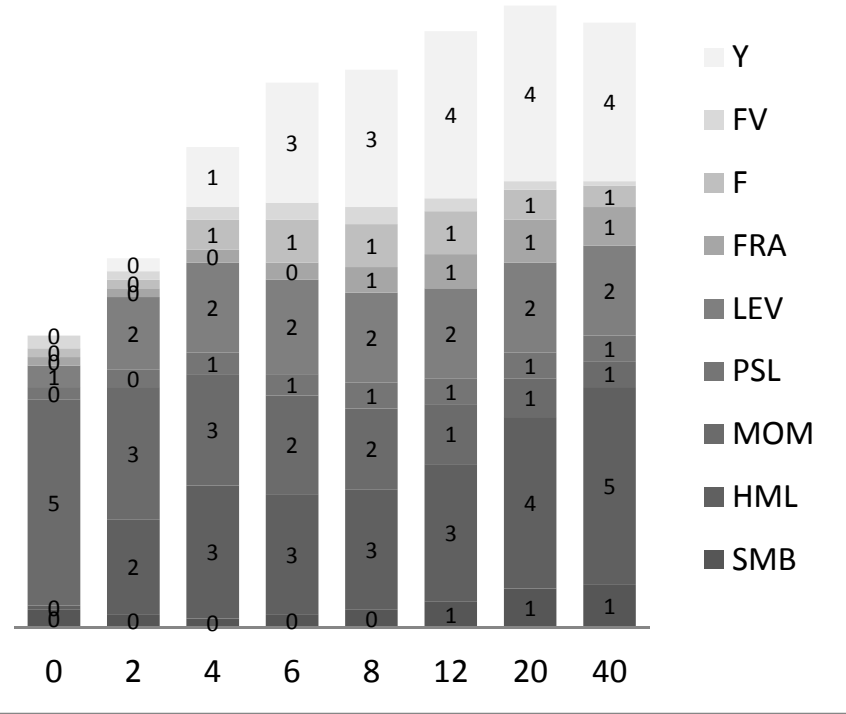




\title{
Appendix B (Online Appendix) for referee use only. \\ Insights on the global macro-finance interface: Structural sources of risk factors fluctuations and the cross-section of expected stock returns
}

\author{
Claudio Morana* \\ Università di Milano Bicocca (Milano, Italy), \\ CeRP-Collegio Carlo Alberto (Moncalieri, Italy),
}

December, 8, 2013

\begin{abstract}
In this Appendix, details concerning the identification of the global structural shocks are reported, as well as for the forecast errror variance decomposition analysis.

Keywords: macro-finance interface; risk factors; size, value, momentum, liquidity, and leverage effects; factor vector autoregressive model. JEL classification: G12, C22.
\end{abstract}

*Address for correspondence: Claudio Morana, Università di Milano-Bicocca, Dipartimento di Scienze Economiche, Metodi Quantitativi e Strategie d'Impresa, Piazza dell'Ateneo Nuovo 1, 20126, Milano, Italy. E-mail: claudio.morana@unimib.it. 


\section{Identification of structural shocks and se- lected impulse responses}

Three main sets of structural disturbances are identified by means of the assumed recursive structure, i.e., oil market, macroeconomic and financial shocks. Details for each category of shocks are reported below, where theoretical predictions are contrasted with the empirical evidence provided by impulse response analysis. For exposition purposes we refer to selected time horizons, i.e., very short-term (VST; within 2 quarters), short-term (ST; between 1 and 2 years), medium-term (MT; 3 to 5 years), and long-term (LT; 10-year horizon).

Impulse responses for various variables and shocks are reported in Table A1-A3. Results in each Panel and Table correspond to impulse responses of relevant variables to a given shock. For instance, Panel A in Table A1, reports impulse responses of oil reserves $(R)$, future basis $(F B)$, real oil price $(O P)$, nominal oil price volatility $(O V)$, real activity $(Y)$ and the price level $(N)$ to a 1 standard deviation oil reserves shocks $(O R)$.

\subsection{Oil market shocks}

The oil market structural disturbances are: oil market supply side shocks (oil reserves $(O R)$, flow oil supply (positive, OSP; negative, OSN), oil production mix $(O X)$ ); oil market demand side shocks (oil consumption and inventories preferences $(O C, O I)$ ); oil futures market speculative shocks (oil futures market-pressure $(O F P)$, residual oil futures market $(O F R))$; other oil price shocks (other real oil price $(O R P)$ and nominal oil price volatility $(O N V))$. Results are reported in Table A1, Panel A-L.

\subsubsection{Oil market supply side shocks}

A positive oil reserves $(O R$ ) shock (signaling a future downward shift in the flow oil supply schedule) drives the futures, and through a price discovery mechanism, the spot oil prices downward; empirically, $O R$ leads to a permanent increase in oil reserves $(0.39 \% \mathrm{VST} ; 1.29 \% \mathrm{ST} ; 1.66 \%)$, and to a very short-term contraction in the futures $(-1.90 \%$, futures basis) and spot real oil price $(-1.03 \%)$, as well as in nominal oil price volatility $(-0.13 \%$ VST; $0.55 \% \mathrm{ST} ;-0.75 \%$ LT). Consistent with lower oil price uncertainty and weaker user costs, precautionary savings and discretionary income effects, a shortto long-term positive effect on real activity can be noted $(0.23 \%$ ST; $0.44 \%$ LT). 
A negative $(O S N)$ (positive, $O S P$ ) flow oil supply shock (upward (downward) shift in the flow oil supply schedule) causes a negative (positive) correlation between oil production and the real oil price.

Empirically, $O S N$ leads to a permanent contraction in oil production ($0.21 \%$ VST; $-0.15 \% \mathrm{ST} ;-0.13 \% \mathrm{LT})$, increasing the real oil price $(3.26 \%)$ and nominal oil price volatility $(0.74 \%)$ in the very short-term. Consistent with higher user costs, precautionary savings and discretionary income effects, a stagflationary impact can be noted in the very short-term $(-0.11 \%$, real activity; $0.03 \%$ price level), yet not in the medium- to long-term $(0.62 \%$ and $0.03 \%$, respectively), due to the contraction in nominal oil price uncertainty $(-0.65 \%$ ST; $-1.02 \%$ LT).

Conversely, $O S P$ leads to a permanent increase in oil production $(0.41 \%$ VST; $0.42 \%$ ST; $0.36 \%$ LT) and a transitory contraction in the real oil price (-0.96\% VST; $1.85 \% \mathrm{ST})$, increasing nominal oil price volatility (0.82\% VST; $1 \% \mathrm{ST} ; 1.26 \% \mathrm{LT})$. While the impact on real activity is mostly not significant over the horizon investigated, consistent with increased nominal oil price uncertainty, some negative effects can be noted, particularly in the long-term (-0.19\% LT; $-0.05 \%$ VST).

A positive oil production mix shock $(O X)$ leads to a negative correlation between refineries output and the real oil price, consistent with a shift in the production mix favoring (relatively less expensive) medium and heavy sour crudes; empirically, $O X$ leads to a permanent increase in refineries output $(0.43 \%$ VST; $0.50 \% \mathrm{ST} ; 0.68 \% \mathrm{LT})$ and contraction in the real oil price (-2.07\% VST; $-1.25 \%$ ST; $-1.42 \%$ LT). Due to increased nominal oil price uncertainty $(0.65 \% \mathrm{VST} ; 0.58 \% \mathrm{ST} ; 0.52 \% \mathrm{LT})$, real activity contracts ($0.07 \%$ VST; $-0.21 \%$ ST and MT).

\subsubsection{Oil market demand side shocks}

Positive oil consumption $(O C)$ and inventories $(O I)$ preferences shocks, unrelated to macro-financial fundamentals, cause an upward (downward) shift in the flow (financial) oil demand function and therefore a positive (negative) correlation between oil consumption (inventories) and the real oil price.

Empirically, $O C$ leads to a permanent increase in global oil consumption (0.54\% VST; $0.59 \%$ ST $0.55 \%$ LT) and the real oil price $(2.79 \%$ VST; $3.54 \%$ ST; $3.27 \%$ LT), dampening nominal oil price volatility (-0.42 VST; $-0.37 \%$ ST; $-0.39 \%$ LT). Due to lower oil price uncertainty, the shock then leads to an increase in real activity (0.14\% VST; $0.27 \%$ ST; $0.22 \% \mathrm{LT})$.

Differently, $O I$ leads to a permanent increase in global oil inventories (0.50\% VST; $0.39 \% \mathrm{ST} ; 0.44 \% \mathrm{LT})$ and contraction in the real oil price (-0.98\% VST; $-0.66 \%$ ST; $-0.93 \%$ LT), also dampening nominal oil price 
volatility (-0.61\% VST; $-0.50 \%$ ST; $-0.56 \%$ LT). Through reduced oil price uncertainty, as well as lower user costs and precautionary savings, and higher discretionary income effects, the shock then leads to a permanent increase in real activity $(0.07 \%$ VST; $0.32 \%$ ST; $0.29 \%$ LT).

\subsubsection{Oil futures market speculative shocks}

Two oil futures market speculative shocks, unrelated to macro-financial, as well as physical oil market conditions, can be identified, i.e., an oil futures market-pressure shock (OFP) and a residual oil futures market shock $(O F R)$.

Consistent with the Theory of Normal Backwardation and Market Pressure Theory, a positive oil futures market-pressure shock $(O F P)$ causes a positive correlation between the excess supply for long (speculative) traders positions and the demand for short (hedging) positions (Working's T index, $W T$ ) and the oil futures prices; as price discovery occurs first in the futures market, to spill over to the spot market, a positive correlation with the spot oil price is also imparted by $O F P$; empirically, $O F P$ leads to a contemporaneous increase in the Working's T index $(0.72 \% ; 0.73 \% \mathrm{LT})$, the futures basis $(0.24 \%$; $0.10 \% \mathrm{MT})$ and the real oil price $(0.36 \%$; $0.59 \% \mathrm{LT})$, dampening nominal oil price volatility (-0.43\% VST; $-0.27 \% \mathrm{ST} ;-0.20 \% \mathrm{LT})$. Consistent with higher user costs, precautionary savings and discretionary income effects, a contraction in real activity can be noted (-0.03\% VST; $-0.15 \%$ ST and LT);

To the residual oil futures market shock $(O F R)$, which is net of the contemporaneous effect of traders positions (Working-T index) as well, we do not provide an economic interpretation; empirically, $O F R$ leads to a contemporaneous increase in the futures basis $(4.36 \%)$ and the real oil price $(0.30 \%$; $2.67 \% \mathrm{ST} ; 2.39 \% \mathrm{LT})$, dampening nominal oil price volatility $(-0.21 \%$ VST; $-0.13 \%$ ST; $-0.11 \%$ LT). Due to lower oil price uncertainty, $O F R$ then leads to an increase in real activity (0.08\% VST; $0.13 \% \mathrm{ST} ; 0.09 \% \mathrm{LT})$.

\subsubsection{Other oil price shocks}

To the other real oil price $(O R P)$ and nominal oil price volatility $(O N V)$ shocks, unrelated to macro-financial, as well as physical and futures oil market conditions, we do not attach an economic interpretation. Consistent with various mechanisms explaining the transmission of oil price shocks to the macroeconomy, i.e., discretionary income, precautionary savings, operating costs and uncertainty effects, the latter disturbances exercise recessionary effects, i.e., cause a negative correlation between oil price fluctuations and 
real activity.

Empirically, a positive other real oil price shock (ORP) leads to a permanent increase in the real oil price (3.73\% VST; $2.64 \% \mathrm{ST} ; 2.95 \%$, LT) and nominal oil price volatility $(0.22 \% \mathrm{VST} ; 0.18 \% \mathrm{ST} ; 0.21 \% \mathrm{LT})$, and a contraction in real activity $(-0.05 \%$ VST; $-0.21 \% \mathrm{ST}$ and LT); similarly for a positive other nominal oil price volatility shock $(O N V)$, yielding a permanent increase in nominal oil price volatility $(1.28 \% \mathrm{VST} ; 1.14 \% \mathrm{ST} ; 1.19 \%$ LT) and the real oil price (1.79\% ST; $1.05 \%$ LT), and a medium to long-term contraction in real activity $(-0.14 \%)$.

\subsection{Macroeconomic structural shocks}

The macroeconomic structural disturbances are labor market shocks (labor demand $(L D)$ and supply $(L S)$ ); aggregate demand shocks $(A D)$; productivity shocks $(P R)$; core inflation shocks $(C I)$; global imbalance shocks (global (GFI), US (GDI) and ex-US global (GTI) saving rate). Results are reported in Table A 2, Panel A-H.

\subsubsection{Labor market shocks}

A positive labor supply shock ( $L S$, upward shift in the labor supply schedule) induces a negative correlation between employment and the real wage; empirically, $L S$ has an opposite contemporaneous impact on employment $(0.24 \%)$ and the real wage $(-0.16 \%)$, building up monotonically as the horizon increases ( $1.33 \%$ and $-0.70 \% \mathrm{ST} ; 1.31 \%$ and $-1.30 \% \mathrm{LT})$, leading to a contraction in the unemployment rate as well (-0.41\% VST; $-0.92 \% \mathrm{ST}$; $0.58 \% \mathrm{LT})$; through the short-run production function, a positive impact on real activity $(0.43 \% \mathrm{VST} ; 0.60 \% \mathrm{ST} ; 0.18 \% \mathrm{MT})$ can then be noted. $L S$ might also be understood in terms of a positive factor shares shock, as in Lettau and Ludvigson (2011), boosting stock prices (0.37\% VST; 0.34\% ST; $0.47 \%$ LT), while depressing real wages.

A negative labor demand shock ( $L D$, downward shift in the labor demand schedule) causes a positive correlation between employment and the real wage; empirically, $L D$ leads to a $-0.10 \%$ contraction in employment in the very short-term $(-0.08 \% \mathrm{ST})$, a $0.28 \%$ contemporaneous increase in the unemployment rate $(0.32 \% \mathrm{ST} ; 0.35 \% \mathrm{LT})$ and to a delayed contraction in the real wage (-0.10 ST; $-0.33 \% \mathrm{LT})$; through the short-run production function, a negative impact on real activity is found as well $(-0.14 \%$ VST; $-0.08 \%$ $\mathrm{ST} ;-0.17 \% \mathrm{LT})$. 


\subsubsection{Aggregate demand and productivity shocks}

A positive aggregate demand shock ( $A D$, upward shift in the aggregate demand schedule) induces a positive correlation between output and the price level; empirically, $A D$ has a positive contemporaneous impact on real activity $(0.41 \%)$ and the price level $(0.02 \%)$, the former effect being strongest in the very short- $(0.67 \%)$ than in the short- to long-term $(0.59 \%$ to $0.28 \%)$. A positive impact can also be noted on housing ( $0.02 \% \mathrm{VST})$ and stock prices (0.23\% VST; $0.13 \%$ MT and LT).

A positive productivity shock ( $P R$, rightward shift in the long-run aggregate supply schedule) causes a permanent increase in output, negatively affecting or without impacting on the price level; empirically, $P R$ yields a negative correlation between real activity $(0.04 \%)$ and the price level $(-0.01 \%)$ in the very short-term; the effect of the shock on real activity builds up over time, being strongest in the long- $(0.85 \%)$ than in the short-term $(0.67 \%)$. $P R$ also causes a negative correlation between aggregate output and stock prices. The latter effect is consistent with a Shumpeterian view of innovation as a process of creative destruction (Kogan et al., 2012); while shareholder wealth increases at the innovator firm, due to booming profits determined by the adoption of the new technology, shareholder wealth destruction occurs at the innovator's competitor firms, which fail to fully adopt the new technology: hence, a positive linkage between productivity shocks and stock prices can be posited at the firm level, yet a negative linkage at the aggregate market level, as the aggregate market return is a weighted average of heterogeneous and mostly negatively correlated individual firm's stock returns. The countercyclical impact may also follow the opposite effect $P R$ exercises on future cashflows (increasing) and the pricing kernel, i.e., consumption and hours worked (decreasing); if $P R$ is sufficiently persistent, the pricing kernel effect dominates the cash flow effect, depressing asset prices (Canova and De Nicolò, 1995). Empirically, the negative impact on real stock prices builds up over time, being strongest in the long- $(-0.63 \%)$ than in the short-term $(-0.27 \%)$. $P R$ also leads to an increase in (housing) wealth $(0.28 \%$, VST; $0.63 \%, \mathrm{ST} ; 0.96 \%, \mathrm{LT})$ and in real wages $(0.66 \%$, VST; $0.86 \%$, ST; $1.58 \%$, LT), consistent with Lettau and Ludvigson (2011).

\subsubsection{Core inflation shock}

A positive core inflation shock (CI, upward shift in the short-term Phillips curve) induces a positive correlation between the price level and the unemployment rate in the short-term, being neutral in the long-term; empirically, $C I$ yields a positive permanent impact on the price level $(0.07 \%$ VST; $0.05 \%$ 
ST and LT); consistent with a vertical long-run Phillips curve, the shock is long-run output (real activity) neutral, positively affecting the unemployment rate in the short- to medium-term only ( $0.19 \%$ ST; $0.15 \% \mathrm{MT})$.

\subsubsection{Global imbalance shocks}

A positive global fiscal imbalance shock is a negative global saving rate shock $(G F I)$; as predicted by the neoclassical growth model, this leads to a downward shift in gross investment and to a contraction in the steady-state real capital and output levels; the latter also decline over the transition process; empirically, GFI yields a permanent increase in the global public consumption to GDP ratio $(0.59 \%$ VST; $0.86 \% \mathrm{ST} ; 0.59 \% \mathrm{LT})$, as well as a permanent contraction in real stock prices (-0.29\% VST; $-0.34 \%$ ST; $-0.26 \%$ LT), i.e., in the market valuation of installed capital, and real activity $(-0.25 \%$ VST; $-0.7 \%$ ST; $-0.5 \%$ LT). An increase in the short-term rate can also be noted (4 b.p. VST).

Similarly, a positive US fiscal imbalance shock is a negative US saving rate shock $(G D I)$; due to the driving role of the US for the global economy, the contraction in the US steady-state real capital and output levels determined by $G D I$ is then expected to lead to a contraction in world steady-state real capital and output levels. Empirically, GDI yields a permanent increases in the US fiscal deficit to GDP ratio (0.40\% VST; $0.18 \% \mathrm{ST} ; 0.15 \% \mathrm{LT})$ and the short-term rate ( 6 b.p. VST; 4 b.p. LT), and contraction in real stock prices $(-0.31 \%$ VST; $-0.25 \% \mathrm{ST} ;-0.43 \% \mathrm{LT})$, as well in global real activity in the short-term (-0.23\% VST; $-0.13 \%$ ST; $0.21 \%$ LT).

A positive US trade imbalance shock (GTI) is a positive saving glut shock, which can be associated with the ongoing capital flows from emerging countries to the US, since early 1980s. ${ }^{1}$ Consistent with Bernanke $(2005)^{2}$, the shock leads to the diversion of savings from countries with relative higher productivity (fast growing emerging countries) to the US, driving down the global real interest rate; empirically, GTI leads to a permanent increase in the US trade deficit to GDP ratio (0.23\% VST; $0.27 \%$ ST; $0.29 \%$ LT), ap-

\footnotetext{
${ }^{1}$ Japan in the 1980s and early 1990s, oil producer and emerging Asia economies since the mid 1990s, and China more recently.

${ }^{2}$ Higher ex-US global savings, servicing the growing US trade deficit, can be explained on the basis of increased savings and reserves accumulation in emerging Asia economies, following the 1997-1998 financial crisis, also determined by their export-led growth policies cum undervaluation; aging population in industrialized countries, requiring higher savings to provide to the needs of a growing retired population; the increase in oil prices, leading to trade balance surpluses in oil exporting countries. According to Caballero et al. (2008), the saving glut is also compatibile with the shortage of strores of values affecting less developed economies.
} 
preciation of the US\$ (-0.05\% VST; $-0.22 \%$ ST; $-0.19 \%$ LT), and contraction in the real short-term interest rate (-11 b.p. VST; -5 b.p. ST and LT); real stock prices decline in the short-term (-0.05\% VST, $-0.13 \%$ ST, $0.15 \%$ LT), as well as real activity also in the long-term (-0.03\% VST, $-0.30 \% \mathrm{ST},-0.37 \%$ LT).

\subsection{Financial structural shocks}

The financial structural disturbances are monetary policy stance shocks (MPS); term structure level $(T L)$ and slope (TS) shocks; US terms of trade shocks $(T T)$; portfolio allocation/preferences shocks (stocks $(P F)$, housing $(P H)$, non-energy commodities $(P M)$ and gold $(P G))$; revisions in expectations about the state of the investment opportunity set (size $(S Z)$, value $(V L)$, momentum $(M M)$, stock market liquidity $(S L)$ and financial leverage $(L V)$ ), risk aversion and risk appetite $(R A V, R A P)$ shocks. Results are reported in Table A3, Panel A-Q.

\subsubsection{Monetary policy shocks}

A positive monetary policy stance/excess liquidity shock (MPS) induces a negative correlation between overall liquidity and interest rates; through various channels, i.e., interest rate, asset prices, credit, the shock is then transmitted to real activity; empirically, MPS yields a liquidity effect, causing a permanent increase in excess liquidity (0.33\% VST; $0.50 \% \mathrm{ST} ; 0.62 \% \mathrm{LT})$ and contraction in the real short-term interest rate (-4 b.p. VST; -6 b.p. ST; -7 b.p. LT). Consistent with the expectation hypothesis of the term structure of interest rates a contraction in the long-term interest rate can also be noted (-9 b.p. VST; -2 b.p. ST; -3 b.p. LT) ${ }^{3}$. The dynamic response of real activity and asset prices is consistent with a boom-bust cycle: in fact, $M P S$ triggers an increase in real activity $(0.02 \%$, not significant), the price level $(0.01 \%)$, real stock prices $(0.03 \%)$ and financial leverage $(0.24 \%)$ in the very short-term turning into a contraction in the short-term (real activity: $-0.09 \%$; $-0.14 \%$ LT; real stock prices: $-0.09 \%$; financial leverage: $-0.48 \%$ ); an increase in stock market uncertainty is however triggered at any horizon.

\footnotetext{
${ }^{3}$ The responses for the real long-term interest rate $(L R)$ are obtained from the responses of the real term spread $(T S)$ and short-term interest rate $(S R)$, as $T S=L R-S R$, i.e., $L R=T S+S R$.
} 


\subsubsection{Term structure shocks}

A positive term structure level shock $(T L)$ upward shifts the whole term structure of interest rates; empirically, $T L$ leads to a permanent increase in the real short- and long-term interest rates (17 b.p. and 16 b.p. VST, respectively; 13 b.p. and 9 b.p. LT). Due to the smaller increase in the longthan in the short-term rate, the term spread contracts (-1 b.p. VST; -4 b.p. ST and LT); as the term spread tends to be lower near business cycle peaks (Fama and French, 1989), its contraction is then consistent with the increase in real activity $(0.06 \%$ VST; $0.51 \% \mathrm{ST} ; 0.37 \% \mathrm{LT})$ triggered/signalled by the shock. Also consistent with a current/expected improved macroeconomic outlook is the increase in real stock (0.12\% VST; 0.31\% ST; $0.21 \%$ LT) and housing $(0.04 \%$ VST; $0.52 \%$ ST; $0.40 \% \mathrm{LT})$ prices, as well as the contraction in real gold prices $(-0.65 \% \mathrm{VST} ;-0.51 \% \mathrm{MT})$.

A positive term structure slope shock $(T S)$ tilts upward the term structure of interest rates; empirically, $T S$ leads to a permanent increase in the long-term interest rate (23 b.p. VST; 18 b.p. ST; 19 b.p. LT), leaving (mostly) unaffected the real short-term rate (1 b.p. LT), therefore increasing the term spread (26 b.p. VST; 18 b.p. ST and LT). As the increase in the term spread is not associated with a contraction in the real short-term rate, the increase in real activity $(0.07 \% \mathrm{VST} ; 0.36 \% \mathrm{ST} ; 0.31 \% \mathrm{LT})$ triggered/signalled by the shock is consistent with current/expected improved macroeconomic conditions, as well as with perceived inflation risk (the price level increases $0.01 \%$ VST-ST; $0.02 \%$ MT-LT); similarly the increase in real stock (0.04\% VST; $0.16 \%$ ST; $0.12 \%$ LT) and housing (0.04\% VST; $0.26 \%$ $\mathrm{ST} ; 0.16 \% \mathrm{LT})$ prices, as well as the contraction in real gold prices $(-0.42 \%$ VST; $-0.85 \%$ ST; $-0.87 \%$ LT) caused by the shock.

\subsubsection{US terms of trade shock}

A negative US terms of trade shock $(T T)$ causes a depreciation of the US\$ exchange rate; empirically, TT leads to a permanent depreciation of the US\$ exchange rate index $(0.47 \% \mathrm{VST} ; 0.72 \% \mathrm{ST} ; 0.84 \% \mathrm{LT})$ and a short- to longterm contraction in the US trade deficit to GDP ratio $(-0.10 \%)$; a negative short- to long-term impact on real activity $(-0.45 \% \mathrm{ST} ;-0.56 \% \mathrm{LT})$ can also be noted, consistent with the contraction in US import and its negative impact on aggregate demand.

\subsubsection{Portfolio allocation shocks}

Positive stocks $(P F)$, housing $(P H)$, non-energy commodities $(P M)$ and gold $(P G)$ portfolio allocation/preference shocks lead to an increase in the 
demand of the corresponding asset and in its price, unrelated to global macrofinancial and oil market developments, triggering portfolio reallocation across assets classes and impacting, through wealth/Tobin's $Q$ effects, on real activity as well.

Empirically, a positive stocks preference shock $(P F)$ leads to a permanent increase in real stock prices $(0.23 \%$ VST; $0.13 \% \mathrm{ST}$ and LT), as well as a transitory short-term increase in housing $(0.06 \%$; -0.11 LT) and Treasury bill and bond prices (the short- and long-term real interest rates contracts -1 b.p. (VST) and -3 b.p., respectively). PF also leads to a permanent increase in non energy commodities (0.25\% VST; $0.29 \%$ ST; $0.38 \%$ LT), oil (0.61\% VST; $0.98 \%$ ST; $1.14 \%$ LT) and gold (0.37\% ST; $1.05 \%$ LT) prices.

Similarly, a positive housing preference shock $(P H)$ leads to a permanent increase in real housing prices (0.40\% VST; $0.74 \% \mathrm{ST} ; 0.47 \% \mathrm{LT})$, a transitory short-term increase in Treasury bill and bond prices (the real shortand long-term rates contract -4 b.p. and -7 b.p, respectively), as well as in real stock prices $(0.12 \%$ VST; $0.17 \%$ ST; $0.08 \% \mathrm{MT})$; a permanent increase in oil (2.32\% ST and LT), non energy commodities (1.12\% VST; $1.01 \%$ ST; $0.95 \%$ LT) and gold (1.69\% VST; $1.56 \%$ ST; $1.94 \%$ LT) prices.

Differently, a positive non-energy commodities preference shock $(P M)$ leads to a permanent increase in real non-energy commodities prices $(1.64 \%$ VST; $2.14 \%$ ST; $2.09 \%$ LT), as well as in stock (0.06\% VST), gold $(0.75 \%$ VST; $1.27 \%$ ST and LT) and oil (0.79\% VST; $0.34 \%$ ST $0.32 \%$ LT) prices, yet depressing housing (-0.04\% VST; 0.09\% ST; -0.13\% LT) and Treasury bills and bonds (the real short- and long-term rates increase 3 b.p. ST) prices.

Moreover, a positive gold preference shock $(P G)$ leads to a permanent increase in real gold prices $(2.47 \% \mathrm{VST} ; 3.61 \% \mathrm{ST} ; 3.93 \% \mathrm{LT})$, as well as in non-energy commodities (0.75\% VST; $0.92 \%$ ST and LT) and oil (0.97\% VST; $1.52 \%$ ST; $1.34 \%$ LT) prices, yet depressing stock (-0.06\% ST), housing $(-0.04 \%$ VST; $0.12 \%$ ST; $-0.26 \%$ LT) and Treasury bills and bonds (the real short- and long-term rates increase 1 b.p. VST; 2 b.p. and 4 b.p. ST, respectively; 5 b.p. LT, long-term rate only) markets.

Overall the findings show that a shift in investors preferences toward stocks and/or housing also leads to increased demand and prices for any other asset class; differently, a shift in investors preferences toward commodities tend to depress other asset classes, particularly less risky assets, i.e., housing and Treasury bills and bonds, as well as stocks ( $P G$ only). Finally, through wealth, Tobin's q and financial accelerator mechanics ${ }^{4}, P F$ and $P H$ only

\footnotetext{
${ }^{4}$ Financial accelerator effects may be generated through both firms and households spending decision; households and firms can borrow posting their equities as collateral; changes in asset prices then affect net worth and therefore spending, not only through wealth or Tobin's Q effects, but also, by changing their external finance premium, i.e.,
} 
trigger a short to long-term increase in real activity $(0.08 \%$ and 0.19 VST, respectively; $0.12 \%$ and $0.39 \% \mathrm{ST} ; 0.21 \% \mathrm{PH}$, LT); a positive effect on real activity is also yield by $P M$ and $P G$, yet in the very short-term only $(0.06 \%)$.

\subsubsection{Revisions in expectations and risk aversion/risk appetite shocks}

Size and value shocks A positive size shock $(S Z)$ causes a positive correlation between $S M B$ and real activity. As small firms are more vulnerable than large firms to changing credit conditions, being poorly collateralized and having limited access to external capital markets (Gertler and Gilchrist, 1994), improving (worsening) credit/macroeconomic conditions might be associated with higher (lower) profitability of small than large stocks, i.e., with a higher contemporaneous return on $S M B$. A positive (negative) $S M B$ can be expected during expansions (recessions) (Hahn and Lee, 2006; Petkova, 2006), a positive size shock $(S Z)$ then revealing expectations of favorable changes in the investment opportunity set.

Similarly, a positive value shock $(V L)$ causes a positive correlation between $H M L$ and real activity. As firms with high book-to-market ratios are likely to suffer from a higher debt burden than low book-to-market firms, and therefore more vulnerable to changes in the monetary policy stance and interest rates, value stocks are more strongly exposed to cyclical news on future economic activity than growth stocks (Koijen et al., 2012); moreover, value stocks are more strongly correlated with consumption growth during recessions (Lettau and Ludvigson, 2001) and do worse when the expected aggregate stock market return declines (Campbell and al., 2012). Improving (worsening) economic conditions might then be associated with higher (lower) profitability of value than growth stocks, i.e., with a higher contemporaneous return on $H M L$ on average. A positive (negative) $H M L$ can be expected during expansions (recessions) (Hahn and Lee, 2006; Petkova, 2006; Koijen et al., 2012), a positive value shock ( $V L)$ then revealing expectations about favorable changes in the investment opportunity set.

Empirically, $S Z$ leads to a permanent increase in $S M B(3.08 \%$ VST; $1.36 \% \mathrm{ST} ; 1.74 \% \mathrm{LT})$, while $V L$ in $H M L(3.81 \% \mathrm{VST} ; 4.16 \% \mathrm{ST} ; 3.87 \%$ LT), pointing to larger profitability of small than large stocks and value than growth stocks, respectively; both shocks (trigger) signal an expansion in real activity (SMB: $0.19 \%$ VST and MT; $0.49 \% \mathrm{ST} ; H M L: 0.18 \% \mathrm{ST} ; 0.41 \%$ LT). ${ }^{5}$

their cost of credit.

${ }^{5}$ The finding is consistent with the evidence of forecasting power of $S M B$ and $H M L$ for US GDP growth, as well as for other industrialized countries (Liew and Vassalou, 2000; 
Coherently, a tightening in the monetary policy stance can be noted, as excess liquidity contracts $(S Z$ : $-0.18 \% \mathrm{VST} ; V L:-0.07 \% \mathrm{VST} ;-0.27 \% \mathrm{ST}$; $-0.49 \%$ LT), the real short-term rate increases ( $S Z: 5$ b.p. ST; 3 b.p. MT; $V L: 1$ b.p. MT; 2 b.p. LT), while the term spread falls (SZ: -3 b.p. VST; -12 b.p. ST; -9 b.p. LT; $V L:-4$ b.p. VST and ST; -8 b.p. LT).

Favorable revisions in expectations about the investment opportunity set are also revealed by the portfolio shift toward riskier assets triggered by both shocks. For instance, both shocks lead to higher housing ( $S Z$ : $0.22 \%$ VST; 0.54\% ST; $0.43 \%$ MT; VL: $0.03 \%$ VST; $0.31 \%$ ST; $0.58 \%$ LT), non-energy commodities (SZ:1.35\% VST; $1.96 \% \mathrm{ST} ; 2.08 \mathrm{LT}$; $V L: 1.15 \%$ VST; $1.61 \%$ ST; $1.33 \%$ LT), and Treasury bond prices (long-term rate: -5 b.p. VST; -10 b.p. ST; -9 b.p. LT, following SZ; -4 b.p. VST and ST; -7 b.p. LT, following $V L$ ), while Treasury bill prices contract (short-term rate: 5 b.p. ST, following $S Z ; 2$ b.p. LT, following $V L)$.

Also, while $S Z$ leads to higher stock (0.54\% VST; $0.61 \%$ ST; $0.71 \%$ LT) and gold $(1.28 \% \mathrm{VST} ; 1.37 \% \mathrm{ST} ; 2.72 \% \mathrm{LT})$ prices, $V L$ triggers a contraction in the price of both assets $(F:-0.17 \% \mathrm{VST} ;-0.31 \% \mathrm{ST} ;-0.49 \% \mathrm{LT} ; G:-0.40 \%$ VST; $-0.64 \%$ MT; $-1.59 \%$ LT). Moreover, $S Z$ leads to higher oil prices in the medium- to long-term $(0.93 \% \mathrm{LT} ;-1.98 \% \mathrm{ST})$ and $V L$ in the very short-term (1.03\% VST; $-1.18 \%$ ST).

Momentum shocks A positive momentum shock ( $M M)$ may cause both a positive or negative correlation between $M O M$ and real activity. As the return on momentum strategies might be related to the state of the business cycle, being positive (negative) during expansionary (contractionary) phases (Chordia and Shivakumar, 2002; Liu and Zhang, 2008) and following periods of upward (downward) market-wide movements (Cooper et al., 2004), when also financial leverage (Adrian et al., 2012) ${ }^{6}$ and stock market liquidity increase (decrease) (Pastor and Stambaugh, 2003), a positive (negative) MOM can be expected during expansions (recessions). A positive momentum shock $(M M)$ might then reveal expectations of favorable changes in the investment opportunity set.

Yet, firms with stronger fundamentals may be expected to outperform firms with weaker fundamentals during economic downturn; if fundamentals are persistent and reflected in stock returns, positive momentum should be observed also during recessions. A positive momentum shock $(M M)$ might

Lettau and Ludvigson, 2001), as well with the view that investors hold large and growth stocks when the economy is in a bad state, shifting to small and and value stocks when expectations of future economic growth improve (Liew and Vassalou, 2000).

${ }^{6}$ According to Adrian et al. (2012) momentum is procyclical, being eroded when falling asset prices and worsening credit conditions force financial institutions into deleveraging. 
then also induce a negative correlation between $M O M$ and real activity, revealing expectations of unfavorable changes in the investment opportunity set. Empirically, the latter pattern is found to be relevant. ${ }^{7}$

Empirically, a positive momentum shock $(M M)$, leading to a permanent increase in $M O M(3.50 \mathrm{VST} ; 2.36 \% \mathrm{ST} ; 2.31 \% \mathrm{LT})$, might be associated with a negative outlook on the investment opportunity set, signalling an incoming contraction in real activity $(-0.07 \%$ VST; $-0.23 \%$ ST and LT) and the ensuing expansion in the monetary policy stance, as excess liquidity increases $(0.09 \%$ VST; $0.14 \% \mathrm{ST}$ ) and the real short-term rate contracts in the short- to longterm (-1 b.p.). Due to the contraction in Treasury bond prices (the long-term rate increases 5 b.p. VST; 7 b.p. ST and LT), the term spread also increases (4 b.p. VST; 7 b.p. ST; 8 b.p. LT).

Consistent with the expectations of unfavorable changes in the investment opportunity set, $M M$ triggers portfolio rebalancing favoring Treasury bills (flight to safety), as real stock (-0.12\% VST; -0.16\% ST; -0.08\% LT), housing (-0.06\% VST; -0.29\% ST; -0.27\% LT), non-energy commodities (-0.21\% VST; $-0.99 \%$ ST; $-0.90 \%$ LT), and Treasury bond prices contract (long-term rate: 5 b.p. VST; 7 b.p. ST and LT), while Treasury bill (short-term rate: -1 b.p. ST and LT) and gold prices (0.17\% VST; not reported) increase; an increase in the real oil price can however be noted (1.04\% VST; $0.89 \% \mathrm{ST}$; $0.55 \%$ LT; not reported).

Stock market liquidity shocks A positive stock market liquidity shock $(S L)$ causes a positive correlation between $P S L$ and real activity. As improving economic conditions lead to a reduction in investors' risk aversion and to portfolio rebalancing towards riskier assets, higher stock market liquidity, pointing to increased investment in stocks (risky assets), signals an expected improvement in the economic outlook. Hence, a high (low) PSL can be expected during expansions (recessions), a positive stock market liquidity shock $(S L)$ revealing expectations of favorable changes in the investment opportunity set.

Empirically, a positive stock market liquidity shock $(S L)$ leads to a transitory increase in $P S L(6.3 \% \mathrm{VST})$, signaling an incoming short-term increase in real activity $(0.07 \% \mathrm{VST} ; 0.11 \% \mathrm{ST})$ and tightening in the monetary policy stance, as excess liquidity contracts $(-0.06 \% \mathrm{VST} ;-0.09 \% \mathrm{ST})$ and the real short-term rate increases (1 b.p. VST; 2 b.p. ST), while the term spread

\footnotetext{
${ }^{7}$ Chordia and Shivakumar (2002), based on NBER chronology, find that, over the period 1926-1994, the return on momentum strategies is positive in each of the ten expansionary phases, albeit statistically significant only in four cases; positive in six out of the nine recessionary episodes, yet statistically significant in only one case.
} 
contracts (-2 b.p. ST).

Consistent with the improved macroeconomic outlook, as well as with increased stock market participation, $S L$ leads to portfolio rebalancing favoring stocks over other risky and safe assets; in fact, real stock prices increases $(0.11 \%$ VST; $0.15 \%$ ST; $0.19 \%$ LT), while Treasury bills and bonds prices contract (short- and long-term rates: 1 b.p. VST; 2 b.p. ST); similarly housing (-0.07\% VST; $-0.30 \% \mathrm{ST}, \mathrm{LT})$, non-energy commodities (-0.70\% VST; $-1.03 \%$ ST; $-0.82 \%$ LT) and gold (-0.59\% VST; $-1.14 \%$ ST; $-0.77 \%$ LT; not reported) prices; differently an increase in the real oil price can be noted (1.48\% VST; $0.87 \%$ ST; $0.65 \%$ LT; not reported).

Leverage shocks A positive leverage shock $(L V)$ may cause both a positive and negative correlation between $L E V$ and real activity. As leverage of financial intermediaries is procyclical, i.e., increasing in boom phases and contracting during recessions (Adrian and Shin, 2010; Adrian et al., 2012), it is negatively related to risk aversion; then, $L E V$ can be expected to be high during expansions and low during recessions. Hence, an unexpected increase in leverage might reveal favorable changes to the investment opportunity set.

Yet, consistent with recent events, excessive leverage may enhance financial fragility, leading to financial crises, credit crunches and deep real effects. A positive leverage shock $(L V)$ might then also reveal expectations of unfavorable changes in the investment opportunity set. As shown below, the latter pattern is found empirically relevant.

Empirically, a positive leverage shock $(L V)$, leading to a contemporaneous increase in $L E V(3.78 \%)$, might be associated with a negative outlook on the investment opportunity set, signalling an incoming contraction in real activity (-0.10\% ST; $-0.34 \%, \mathrm{ST} ;-0.19 \%$ LT) and credit supply (excess liquidity contracts $-0.09 \% \mathrm{ST} ;-0.31 \% \mathrm{LT})$.

Consistent with bust dynamics and the expectation of unfavorable changes in the investment opportunity set, a generalized decline in asset prices is triggered by $L V$, as real stock (-0.19\% VST; $-0.29 \% \mathrm{ST} ;-0.26 \% \mathrm{LT})$, housing (-0.09\% VST; -0.29\% ST; -0.40\% LT), non-energy commodities (-0.45\% VST; $-0.75 \%$ ST; $-0.49 \%$ LT), oil (-1.84\% VST; $-2.0 \%$ ST; $-2.16 \%$ LT; not reported), Treasury bond (long-term rate: 5 b.p. VST; 10 b.p. ST; 8 b.p. LT) and gold (-0.49\% VST; $-0.61 \%$ ST; $-0.58 \%$ LT; not reported) prices contract; while also Treasury bill prices contract in the short-term (short-term rate: 3 b.p.), portfolio rebalancing favoring Treasury bills (flight to safety) occurs in the medium-term (short-term rate: -1 b.p. MT). 
Risk aversion and appetite shocks A positive risk aversion shock $(R A V)$, i.e., an increase in risk aversion, causes a negative correlation between $F V$ and real activity. As higher (lower) economic uncertainty may be expected during recessions, higher (lower) volatility in future fundamentals and discount rates, and therefore higher (lower) stock market uncertainty can be expected during economic downturn (Schwert, 1989a,b; Hamilton and Susmel, 1994; Hamilton and Lin, 1996; Beltratti and Morana, 2006). Moreover, worsening (improving) economic conditions lead to an increase (decrease) in risk aversion by investors (Fama and French, 1989; Cochrane, 2007). Then, FV can be expected to be low (high) during expansions (recessions), a positive risk aversion shock $(R A V)$ signaling unfavorable revisions in expectations in the investment opportunity set.

Empirically, $R A V$ leads to a permanent increase in stock market volatility ( $0.60 \%$ VST; $0.36 \%$ ST; $0.28 \%$ LT), signaling an incoming contraction in real activity (-0.08\% VST) and loosening in the monetary policy stance, as excess liquidity increases $(0.12 \% \mathrm{VST} ; 0.30 \% \mathrm{LT})$, while the real short-term rate contracts ( -5 b.p. ST); similarly the term spread, due to the contraction in the real long-term rate as well (-15 b.p. ST; -10 b.p. LT).

The latter pattern can also be understood in the light of an unexpected uncertainty increase, as higher uncertainty, by negatively affecting investment and aggregate demand, exercises recessionary effects, which might be lessened/sterilized through an expansionary monetary policy.

Moreover, consistent with worsening macroeconomic conditions, $R A V$ causes portfolio rebalancing, favoring safer over riskier assets, in the very short-term; in fact, stock prices (-0.26\% VST), oil (-0.97\% VST; not reported) and non-energy commodity prices contract (-0.35\% VST), while Treasury bills and bonds prices (short-term rate: -5 b.p. ST; long-term rate: -15 b.p. ST; -10 b.p. LT), as well as housing (0.04\% VST; $0.56 \%$ ST; $0.45 \%$ LT) and gold $(0.35 \%$ VST; not reported) prices increase.

Conversely, a positive risk appetite shock $(R A P)$ causes a positive correlation between $F R A$ and real activity. As credit risk is countercyclical, when the economic outlook improves (worsens) the cost of external financing for borrowers decrease (increase) (Bernanke and Gertler, 1989). Moreover, as raising (falling) asset prices during economic upturn (downturn) drive up (down) financial institutions' balance sheets and leverage, and the value of the collateral borrowers can post, leading to higher (lower) lending and borrowing ability, credit is procyclical over the business cycle (Bernanke, 1983).

The Bagliano-Morana fragility/credit risk index $(F R A)$ might then be expected to be low (high) during expansions (recessions). Yet, a positive risk appetite shock $(R A P)$, by pointing to increased willingness of investors to bear credit risk, signals the expectations of favorable changes in the invest- 
ment opportunity set. ${ }^{8}$

Empirically, $R A P$ leads to a permanent increase in $F R A$ (4 b.p. VST, ST and LT), signaling an incoming short- to medium-term increase in real activity $(0.06 \% \mathrm{ST} ; 0.04 \% \mathrm{MT})$ and stronger credit flow to the economy (excess liquidity: $0.03 \% \mathrm{ST}$; $0.11 \% \mathrm{LT}$ ); a temporary increase in the term spread (1 b.p. VST), determined by the increase in the long-term rate at an unchanged short-term rate, is also found..$^{9}$

Moreover, consistent with the improved macroeconomic outlook, a generalized increase in asset prices is triggered by $R A P$, as stock $(0.03 \%$ VST; $0.07 \%$ ST; $0.08 \%$ LT), housing (0.01\% VST; $0.05 \%$ ST and MT), oil ( $0.22 \%$ ST; not reported), non-energy commodities (0.06\% VST) and Treasury bill and bond prices (short- and long-term rate: -1 b.p. ST) increase, while gold prices fall (-0.12\% VST; $-0.28 \% \mathrm{ST} ;-0.32 \% \mathrm{MT}$; not reported).

\section{References}

[1] Adrian, T., Etula, E., Muir, T., 2012. Financial intermediaries and the cross-section of asset returns. Federal Reserve Bank of New York Staff Report, no. 464, July 2010, revised (The Journal of Finance, forthcoming).

[2] Adrian, T., Shin, H.S., 2010. Liquidity and leverage. Journal of Financial Intermediation 19, 418-437.

[3] Beltratti, A., Morana, C., 2006. Breaks and persistency: Macroeconomic causes of stock market volatility. Journal of Econometrics 131, 151-177.

[4] Bernanke, B.S., 1983. Nonmonetary effects of the financial crises in the propagation of the Great Depression. American Ecnomic Review 73, 256-277.

[5] Bernanke, B.S., Gertler, M., 1989. Agency costs, net worth, and business fluctuations. American Economic Review 79, 14-31.

\footnotetext{
${ }^{8}$ Due to ordering, the idiosyncratic fragility index shock is contemporaneously orthogonal to oil market, macro and financial conditions, as well as to the information contained in the other risk factors; it therefore contains residual information about credit risk conditions unrelated to contemporaneous signals provided by all the other variables in the system.

${ }^{9}$ The latter finding is broadly consistent with the evidence of forecasting power of the default spread, one of the components of $F R A$, for future GDP growth over short horizons (Lettau and Ludvigson, 2001).
} 
[6] Bernanke, B.S., 2005. The global saving glut and the U.S. current account deficit. Remarks by Governor Ben S. Bernanke at the Sandridge Lecture, Virginia Association of Economists, Richmond, Virginia, March, 10, 2005.

[7] Caballero, R.J., Farhi, E., Gourinchas, P.O., 2008. An equilibrium model of global imbalances and low interest rates. American Economic Review 98, 358-393.

[8] Campbell, J.Y., Giglio, S., Polk, C., Turley, R., 2012. An intertemporal CAPM with stochastic volatility. NBER Working Paper Series, no.18411.

[9] Canova, F., De Nicolò, G., 1995. Stock returns and real activity: A structural approach. European Economic Review 39, 981-1015.

[10] Chordia, T, Shivakumar, L., 2002. Momentum, business cycle and time varying expected returns. Journal of Finance 57, 985-1019.

[11] Cochrane, J.H., 2007. Financial markets and the real economy. In Mehra, R. (Ed.), Handbook of the Equity Premium. Elsevier, UK, 237-325.

[12] Cooper, M.J., Gutierrez JR., R.C., Hamed, A., 2004. Market states and momentum. The Journal of Finance LIX, 1345-1365.

[13] Fama, E.F., French, K.R., 1989. Business conditions and expected returns on stocks and bonds. Journal of Financial Economics 25, 23-49.

[14] Gertler, M., Gilchrist, S., 1994, Monetary policy, business cycle, and the behavior of small manufacturing firms. Quarterly Journal of Economics 109, 309-340.

[15] Hamilton, J.D., Susmel, R., 1994. Autoregressive conditional heteroskedasticity and changes in regime. Journal of Econometrics 64, 307333.

[16] Hamilton, J.D., Lin, 1996. Stock market volatility and the business cycle. Journal of Applied Econometrics 11, 573-593.

[17] Hahn, J., Lee, H., 1996. Yield spreads as alternative risk factors for size and book-to-market. The Journal of Financial and Quantitative Analysis 41, 245-269. 
[18] Kogan, L., Papanikolaou, D., Seru, A., Stoffman, N., 2012. Technological innovation, resource allocation, and growth. NBER Working Paper, no. 17769 .

[19] Koijen, R.S.J, Lustig, H., Van Nieuwerburgh, S., 2012. The cross-section and time series of stock and bond returns. CEPR Discussion Papers no. 9024 .

[20] Liew, J., Vassalou, M., 2000. Can book-to-market, size and momentum be risk factors that predict economic growth. Journal of Financial Economics 57, 221-245.

[21] Liu, X.L., Zhang, L., 2008. Momentum profits, factor pricing, and macroeconomic risk. The Review of Financial Studies 21, 2417-2448.

[22] Lettau, M., Ludvigson, S., 2001. Resurrecting the (C)CAPM: A crosssectional test when risk premia are time-varying. Journal of Political Economy 109, 1238-1287.

[23] Lettau, M., Ludvigson, S., 2011. Shocks and crashes. NBER Working Paper Series, no. 16966.

[24] Pastor, L., Stambaugh, R.F., 2003. Liquidity risk and expected stock returns. Journal of Political Economy 11, 642-685.

[25] Petkova, R., 2006. Do the Fama-French factors proxy for innovations in predictive variables? Journal of Finance 61, 581-612.

[26] Schwert, G.W., 1989a. Why does stock market volatility change over time? The Journal of Finance XLIV, 1115-1153.

[27] Schwert, G.W., 1989b. Business cycles, financial crises and stock volatility. Carnegie-Rochester Conference Series on Public Policy 31, 83-125. 
Table A1: Identification of oil market structural shocks: Empirical responses of selected variable for congruence evaluation with theoretical effects of structural shocks

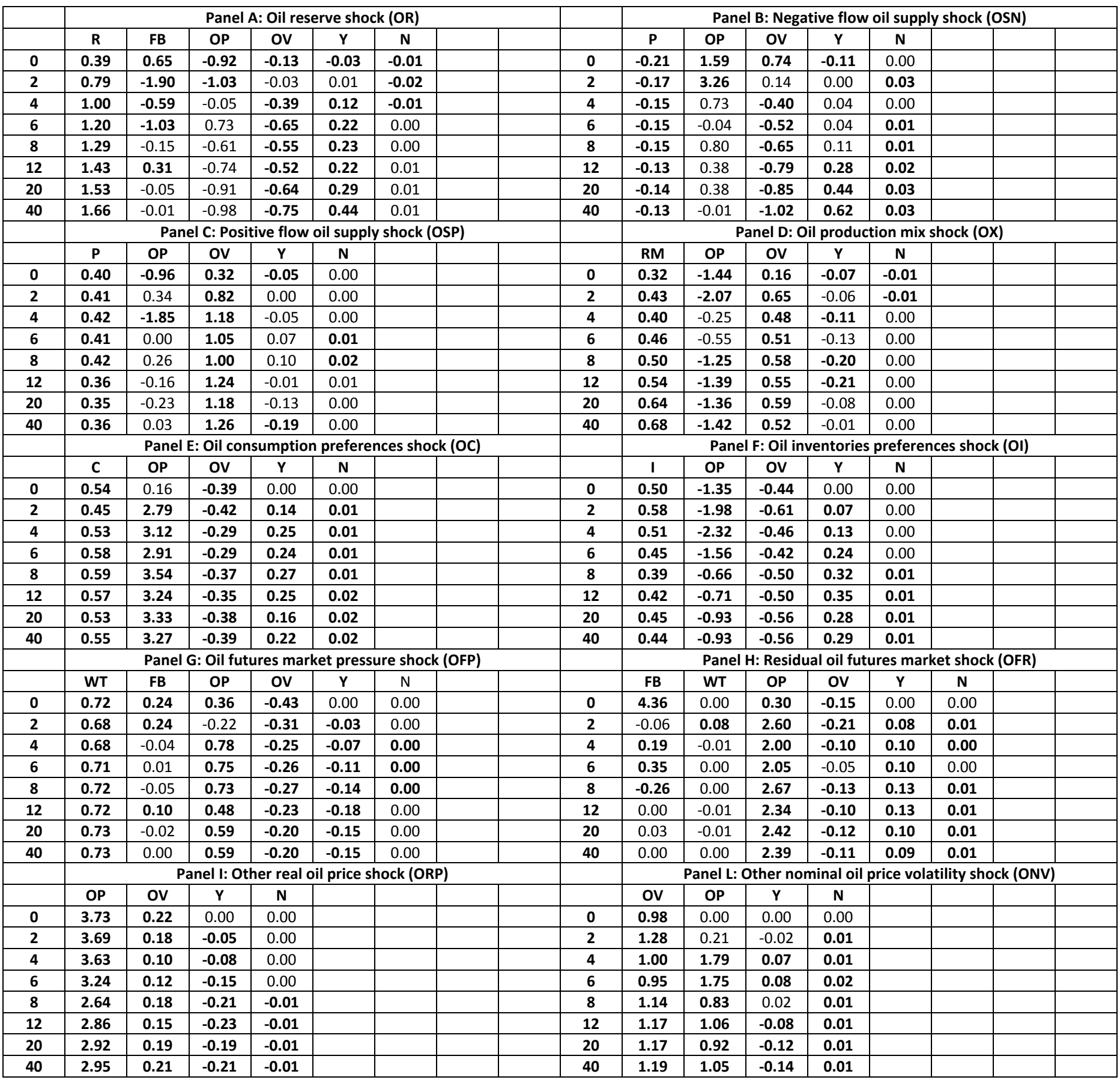

Each Panel in the Table reports impulse responses of selected variables to a given oil market shock, i.e., oil reserves (OR, Panel A), flow oil supply (positive, OSP, Panel B; negative, OSN, Panel C), oil production mix (OX, Panel D), oil consumption and inventories preferences (OC, Panel E; OI, Panel F), oil futures market-pressure (OFP, Panel G), residual oil futures market (OFR, Panel H), other real oil price (ORP, Panel I) and nominal oil price volatility (ONV, Panel L). The variables of interest are oil reserves $(R)$, oil production $(P)$, refineries margins (RF), oil consumption and inventories $(C, I)$, Working-T index (WT), oil futures market basis (FB), real oil price (OP), nominal oil price volatility (OV), real activity $(\mathrm{Y})$, core inflation $(\mathrm{N})$. Figures in bold denote statistical significance at the $5 \%$ level. 
Table A2: Identification of macroeconomic structural shocks: Empirical responses of selected variable for congruence evaluation with theoretical effects of structural shocks

\begin{tabular}{|c|c|c|c|c|c|c|c|c|c|c|c|c|c|c|c|}
\hline & \multicolumn{8}{|c|}{ Panel A: Labor supply shock (LS) } & \multicolumn{7}{|c|}{ Panel B: (Negative) Labor demand shock (LD) } \\
\hline & $\mathbf{E}$ & $\mathbf{W}$ & $\mathbf{U}$ & $\mathbf{Y}$ & $\mathbf{F}$ & $\mathbf{H}$ & $\mathbf{N}$ & & $\mathbf{U}$ & $\mathbf{w}$ & $\mathbf{E}$ & $\mathbf{Y}$ & $\mathbf{F}$ & $\mathbf{H}$ & $\mathbf{N}$ \\
\hline 0 & 0.24 & -0.16 & -0.10 & 0.13 & 0.09 & 0.13 & -0.02 & 0 & 0.28 & 0.03 & 0.00 & -0.07 & 0.11 & -0.07 & -0.04 \\
\hline 2 & 0.57 & -0.40 & -0.41 & 0.43 & 0.37 & 0.35 & 0.01 & 2 & 0.40 & 0.04 & -0.10 & -0.14 & 0.19 & 0.01 & -0.03 \\
\hline 4 & 0.94 & -0.52 & -0.74 & 0.62 & 0.32 & 0.48 & 0.00 & 4 & 0.37 & -0.01 & -0.08 & -0.08 & 0.30 & -0.03 & -0.03 \\
\hline 6 & 1.17 & -0.60 & -0.85 & 0.64 & 0.35 & 0.54 & 0.01 & 6 & 0.31 & -0.09 & -0.04 & -0.06 & 0.29 & -0.12 & -0.03 \\
\hline 8 & 1.33 & -0.70 & -0.92 & 0.60 & 0.34 & 0.53 & 0.01 & 8 & 0.32 & -0.10 & -0.01 & -0.08 & 0.28 & -0.16 & -0.04 \\
\hline 12 & 1.38 & -0.90 & -0.84 & 0.43 & 0.33 & 0.36 & 0.02 & 12 & 0.34 & -0.15 & -0.01 & -0.12 & 0.34 & -0.14 & -0.04 \\
\hline 20 & 1.23 & -1.10 & -0.58 & 0.18 & 0.37 & 0.09 & 0.01 & 20 & 0.31 & -0.24 & 0.06 & -0.12 & 0.39 & -0.08 & -0.04 \\
\hline \multirow[t]{3}{*}{40} & 1.31 & -1.30 & -0.58 & 0.14 & 0.47 & 0.04 & 0.01 & 40 & 0.35 & -0.33 & 0.07 & -0.17 & 0.42 & -0.15 & -0.04 \\
\hline & \multicolumn{8}{|c|}{ Panel C: Aggregate demand shock (AD) } & \multicolumn{7}{|c|}{ Panel D: Productivity shock (PR) } \\
\hline & $\mathbf{Y}$ & $\mathbf{N}$ & $\mathbf{F}$ & $\mathbf{H}$ & $\mathbf{W}$ & & & & $\mathbf{Y}$ & $\mathbf{N}$ & $\mathbf{F}$ & $\mathbf{H}$ & $\mathbf{W}$ & & \\
\hline 0 & 0.41 & 0.02 & 0.23 & 0.02 & -0.10 & & & 0 & 0.00 & 0.00 & -0.22 & 0.14 & 0.40 & & \\
\hline 2 & 0.67 & 0.02 & 0.23 & -0.02 & -0.31 & & & 2 & 0.04 & -0.01 & -0.27 & 0.28 & 0.66 & & \\
\hline 4 & 0.59 & 0.02 & 0.12 & -0.01 & -0.31 & & & 4 & 0.26 & 0.00 & -0.17 & 0.48 & 0.77 & & \\
\hline 6 & 0.39 & 0.01 & 0.07 & 0.05 & -0.22 & & & 6 & 0.56 & 0.01 & -0.14 & 0.58 & 0.77 & & \\
\hline 8 & 0.32 & 0.02 & 0.13 & 0.10 & -0.21 & & & 8 & 0.67 & 0.02 & -0.27 & 0.63 & 0.86 & & \\
\hline 12 & 0.29 & 0.02 & 0.12 & 0.01 & -0.25 & & & 12 & 0.66 & 0.02 & -0.40 & 0.80 & 1.12 & & \\
\hline 20 & 0.28 & 0.02 & 0.13 & -0.05 & -0.23 & & & 20 & 0.70 & 0.02 & -0.55 & 0.79 & 1.33 & & \\
\hline \multirow[t]{3}{*}{40} & 0.29 & 0.02 & 0.13 & -0.04 & -0.22 & & & 40 & 0.85 & 0.02 & -0.63 & 0.96 & 1.58 & & \\
\hline & \multicolumn{8}{|c|}{ Panel E: Core inflation shock (CI) } & \multicolumn{7}{|c|}{ Panel F: (Negative) Global saving rate shock (GFI) } \\
\hline & $\mathbf{N}$ & $\mathbf{U}$ & $\mathbf{Y}$ & $\mathbf{E}$ & & & & & $\mathbf{G}$ & $\mathbf{F}$ & $\mathbf{Y}$ & SR & & & \\
\hline 0 & 0.07 & 0.00 & 0.00 & 0.00 & & & & 0 & 0.34 & -0.15 & 0.00 & 0.04 & & & \\
\hline 2 & 0.06 & -0.01 & -0.08 & -0.04 & & & & 2 & 0.59 & -0.29 & -0.25 & 0.04 & & & \\
\hline 4 & 0.05 & 0.05 & -0.16 & -0.10 & & & & 4 & 0.80 & -0.34 & -0.49 & 0.03 & & & \\
\hline 6 & 0.05 & 0.15 & -0.23 & -0.21 & & & & 6 & 0.88 & -0.33 & -0.63 & 0.01 & & & \\
\hline 8 & 0.05 & 0.19 & -0.24 & -0.30 & & & & 8 & 0.86 & -0.34 & -0.70 & 0.00 & & & \\
\hline 12 & 0.04 & 0.15 & -0.15 & -0.34 & & & & 12 & 0.70 & -0.30 & -0.65 & -0.01 & & & \\
\hline 20 & 0.05 & 0.04 & -0.01 & -0.28 & & & & 20 & 0.54 & -0.22 & -0.47 & -0.01 & & & \\
\hline \multirow[t]{3}{*}{40} & 0.05 & 0.02 & 0.01 & -0.30 & & & & 40 & 0.59 & -0.26 & -0.50 & 0.00 & & & \\
\hline & \multicolumn{8}{|c|}{ Panel G: (Negative) US saving rate shock (GDI) } & \multicolumn{7}{|c|}{ Panel H: Saving glut shock (GTI) } \\
\hline & Fd & $\mathbf{F}$ & $\mathbf{Y}$ & SR & & & & & Td & $\mathbf{F}$ & $\mathbf{Y}$ & SR & & & \\
\hline 0 & 0.40 & -0.12 & 0.00 & 0.04 & & & & 0 & 0.16 & -0.05 & 0.00 & -0.11 & & & \\
\hline 2 & 0.18 & -0.31 & -0.23 & 0.06 & & & & 2 & 0.23 & -0.06 & -0.03 & 0.00 & & & \\
\hline 4 & 0.20 & -0.19 & -0.13 & 0.01 & & & & 4 & 0.22 & -0.13 & -0.17 & -0.01 & & & \\
\hline 6 & 0.17 & -0.20 & -0.03 & 0.02 & & & & 6 & 0.22 & -0.09 & -0.30 & -0.04 & & & \\
\hline 8 & 0.18 & -0.25 & 0.01 & 0.04 & & & & 8 & 0.27 & 0.01 & -0.30 & -0.05 & & & \\
\hline 12 & 0.16 & -0.28 & 0.08 & 0.04 & & & & 12 & 0.29 & 0.05 & -0.32 & -0.05 & & & \\
\hline 20 & 0.16 & -0.38 & 0.13 & 0.04 & & & & 20 & 0.29 & 0.12 & -0.29 & -0.04 & & & \\
\hline 40 & 0.15 & -0.43 & 0.21 & 0.04 & & & & 40 & 0.29 & 0.15 & -0.37 & -0.04 & & & \\
\hline
\end{tabular}

Each Panel in the Table reports impulse responses of selected variables to a given macroeconomic shock, i.e., labor supply (LS; Panel A) and demand (LD, Panel B), aggregate demand ( $A D$, Panel $C$ ), productivity (PR, Panel D), core inflation ( $C l$, Panel E), global saving rate (GFI, Panel F), US saving rate (GDI, Panel G) and ex-US global saving rate (GTI, Panel $\mathrm{H})$. The variables of interest are real activity $(\mathrm{Y})$, excess public consumption $(\mathrm{G})$, US\$ exchange rate return index $(\mathrm{X})$, core inflation $(\mathrm{N})$, excess liquidity (L), employment (E), unemployment rate (U), real wage (W), real stock prices (F), real short term rate (SR). Figures in bold denote statistical significance at the $5 \%$ level. 
Table A3: Identification of financial structural shocks: Empirical responses of selected variable for congruence evaluation with theoretical effects of structural shocks

\begin{tabular}{|c|c|c|c|c|c|c|c|c|c|c|c|c|c|c|c|c|c|}
\hline & \multicolumn{8}{|c|}{ Panel A: Monetary policy stance shock (MPS) } & & \multicolumn{8}{|c|}{ Panel B: Term structure level shock (TL) } \\
\hline & $\mathrm{L}$ & SR & TS & $\mathbf{Y}$ & $\mathbf{N}$ & $\mathbf{F}$ & LEV & FV & & SR & TS & $\mathrm{Y}$ & $\mathbf{N}$ & $\mathbf{F}$ & H & GD & FV \\
\hline 0 & 0.29 & -0.03 & -0.01 & 0.00 & 0.00 & 0.03 & 0.24 & 0.01 & 0 & 0.17 & -0.01 & 0.00 & 0.00 & 0.12 & 0.04 & -0.65 & 0.03 \\
\hline 2 & 0.33 & -0.04 & -0.05 & 0.02 & 0.01 & 0.02 & 0.24 & 0.12 & 2 & 0.11 & 0.01 & 0.06 & 0.01 & 0.23 & 0.23 & -0.14 & -0.04 \\
\hline 4 & 0.51 & -0.03 & 0.01 & -0.06 & 0.00 & -0.09 & -0.24 & 0.18 & 4 & 0.11 & -0.02 & 0.28 & 0.01 & 0.30 & 0.38 & 0.10 & -0.02 \\
\hline 6 & 0.54 & -0.07 & 0.04 & -0.09 & 0.00 & -0.04 & -0.48 & 0.25 & 6 & 0.12 & -0.02 & 0.44 & 0.01 & 0.31 & 0.47 & 0.15 & -0.04 \\
\hline 8 & 0.50 & $\mid-0.06$ & 0.04 & -0.07 & 0.00 & -0.03 & -0.10 & 0.23 & 8 & 0.13 & -0.04 & 0.51 & 0.02 & 0.28 & 0.52 & 0.01 & 0.00 \\
\hline 12 & 0.53 & \begin{tabular}{|l|}
-0.06 \\
\end{tabular} & 0.04 & -0.11 & 0.00 & -0.04 & -0.03 & 0.27 & 12 & 0.14 & -0.06 & 0.49 & 0.03 & 0.24 & 0.54 & -0.51 & 0.04 \\
\hline 20 & 0.56 & \begin{tabular}{|l|}
-0.06 \\
\end{tabular} & 0.04 & -0.10 & 0.00 & 0.02 & 0.00 & 0.26 & 20 & 0.14 & -0.04 & 0.34 & 0.02 & 0.19 & 0.39 & -0.24 & 0.08 \\
\hline \multirow[t]{3}{*}{40} & 0.62 & \begin{tabular}{|l|}
-0.07 \\
\end{tabular} & 0.04 & -0.14 & 0.00 & 0.04 & 0.00 & 0.28 & 40 & 0.13 & -0.04 & 0.37 & 0.02 & 0.21 & 0.40 & -0.18 & 0.07 \\
\hline & \multicolumn{8}{|c|}{ Panel C: Term structure slope shock (TS) } & & \multicolumn{8}{|c|}{ Panel D: US terms of trade shock (TT) } \\
\hline & TS & SR & $\mathbf{Y}$ & $\mathbf{N}$ & $\mathbf{F}$ & $\mathrm{H}$ & GD & FV & & $\mathbf{x}$ & $\mathrm{Td}$ & $\mathbf{Y}$ & & & & & \\
\hline 0 & 0.23 & 0.17 & 0.00 & 0.00 & 0.04 & 0.03 & -0.42 & 0.04 & 0 & 0.47 & 0.00 & 0.00 & & & & & \\
\hline 2 & 0.26 & 0.11 & 0.07 & 0.01 & 0.04 & 0.04 & -0.15 & 0.00 & 2 & 0.59 & 0.01 & 0.02 & & & & & \\
\hline 4 & 0.22 & 0.11 & 0.22 & 0.01 & 0.18 & 0.10 & -0.07 & -0.09 & 4 & 0.61 & -0.04 & -0.17 & & & & & \\
\hline 6 & 0.18 & 0.12 & 0.34 & 0.01 & 0.14 & 0.15 & -0.59 & -0.06 & 6 & 0.67 & -0.08 & -0.34 & & & & & \\
\hline 8 & 0.18 & 0.13 & 0.36 & 0.01 & 0.16 & 0.21 & -0.85 & -0.0 & 8 & 0.72 & -0.10 & -0.45 & & & & & \\
\hline 12 & 0.17 & 0.14 & 0.40 & 0.02 & 0.16 & 0.26 & -1.05 & -0.02 & 12 & 0.78 & -0.11 & -0.54 & & & & & \\
\hline 20 & 0.18 & 0.14 & 0.30 & 0.02 & 0.10 & 0.16 & -0.97 & 0.0 & 20 & 0.84 & -0.10 & -0.54 & & & & & \\
\hline \multirow[t]{3}{*}{40} & 0.18 & 0.13 & 0.31 & 0.02 & 0.12 & 0.16 & -0.87 & 0.02 & 40 & .84 & -0.10 & -0.56 & & & & & \\
\hline & \multicolumn{8}{|c|}{ Panel E: Stocks preferences shock (PF) } & & \multicolumn{8}{|c|}{ Panel F: Housing preferences shock (PH) } \\
\hline & $\mathbf{F}$ & $\mathrm{H}$ & SR & TS & $\mathbf{M}$ & OP & GD & $\mathbf{Y}$ & & $\mathrm{H}$ & $\mathbf{F}$ & SR & TS & $\mathbf{M}$ & OP & GD & $\mathbf{Y}$ \\
\hline 0 & 0.35 & 0.00 & 0.00 & 0.00 & 0.00 & 0.00 & -0.15 & 0.00 & 0 & 0.40 & 0.03 & 0.00 & 0.00 & 0.21 & -0.87 & 1.26 & 0.00 \\
\hline 2 & 0.43 & 0.06 & -0.01 & -0.02 & 0.25 & 0.61 & 0.15 & 0. & 2 & 0.57 & 0. & -0.04 & 0 & 1.12 & 0.73 & 1.69 & 0.19 \\
\hline 4 & 0.44 & 0.07 & 0.00 & -0.03 & 0.43 & 0.82 & 0.31 & 0. & 4 & 0.68 & 0.16 & -0.03 & -0.02 & 1.32 & 1.89 & 1.98 & 0.34 \\
\hline 6 & 0.43 & 0.07 & 0.01 & -0.03 & 0.34 & 0.75 & 0.31 & 0.1 & 6 & 0.73 & 0.17 & -0.01 & -0.04 & 1.29 & 2.40 & 1.72 & 0.40 \\
\hline 8 & 0.44 & 0.06 & 0.00 & -0.02 & 0.29 & 0.98 & 0.37 & 0. & 8 & 0.74 & 0.14 & 0.01 & -0. & 1 & 2.32 & 1.56 & 0.39 \\
\hline 12 & 0.45 & 0.00 & 0.00 & -0.02 & 0.29 & 1.27 & 0.50 & 0.0 & 12 & 0.66 & 0.08 & 0.01 & -0. & 0 & .61 & 1.53 & 0.29 \\
\hline 20 & 0.48 & \begin{tabular}{|l|}
-0.08 \\
\end{tabular} & 0.00 & -0.01 & 0.33 & 1.07 & 0.82 & -0.01 & 20 & 0.44 & 0.04 & -0.01 & -0.01 & 0.91 & 2.24 & 2.00 & 0.16 \\
\hline \multirow[t]{3}{*}{40} & 0.51 & \begin{tabular}{|l|}
-0.11 \\
\end{tabular} & 0.00 & -0.01 & 0.38 & 1.14 & 1.05 & -0.03 & 40 & 0.47 & 0.07 & -0.01 & -0.02 & 0.95 & 2.32 & 1.94 & 0.21 \\
\hline & \multicolumn{8}{|c|}{ Panel G: Non-energy commodities preferences shock (PM) } & & & & nel $\mathrm{H}$ : & old pre & erence & hock (P & & \\
\hline & M & $\mathbf{F}$ & H & SR & TS & OP & GD & $\mathbf{Y}$ & & GD & $\mathbf{F}$ & H & SR & TS & M & OP & $\mathbf{Y}$ \\
\hline 0 & 1.64 & 0.06 & 0.00 & 0.00 & 0.00 & 0.00 & 0.58 & 0.00 & $\mathbf{0}$ & 2.47 & 0.00 & 0.00 & 0.00 & 0.00 & 0.00 & 0.00 & 0.00 \\
\hline 2 & 2.14 & 0.03 & -0.04 & 0.01 & -0.03 & 0.79 & 0.75 & 0.06 & 2 & 2.80 & 0.00 & -0.04 & 0.01 & .00 & .75 & 0.97 & 0.06 \\
\hline 4 & 2.04 & \begin{tabular}{|l|}
-0.04 \\
\end{tabular} & -0.08 & 0.03 & -0.01 & -0.13 & 1.01 & 0.01 & 4 & 3.26 & -0.06 & -0.09 & 0.02 & 0.02 & .77 & 0.51 & 0.00 \\
\hline 6 & 1.98 & \begin{tabular}{|l|}
-0.06 \\
\end{tabular} & $\begin{array}{l}-0.08 \\
\end{array}$ & 0.02 & 0.01 & -0.13 & 1.11 & -0.04 & 6 & 3.44 & -0.03 & -0.09 & 0.01 & 0.04 & .76 & 0.78 & 0.00 \\
\hline 8 & 2.09 & -0.03 & -0.09 & 0.01 & 0.02 & 0.34 & 1.27 & -0.03 & 8 & 3.61 & 0.01 & -0.12 & 0.00 & 0.04 & 0.92 & 1.52 & 0.02 \\
\hline 12 & 2.16 & \begin{tabular}{|l|l|} 
\\
\end{tabular} & -0.13 & 0.01 & 0.01 & 0.36 & 1.33 & -0.02 & 12 & 3.58 & 0.00 & -0.17 & 0.01 & 0.03 & 0.86 & 1.28 & 0.01 \\
\hline 20 & 2.16 & \begin{tabular}{|l|}
-0.03 \\
\end{tabular} & -0.13 & 0.01 & 0.01 & 0.37 & 1.31 & -0.01 & 20 & 3.80 & 0.01 & -0.23 & 0.01 & 0.04 & 0.89 & 1.33 & -0.04 \\
\hline 40 & 2.14 & -0.04 & -0.13 & 0.01 & 0.01 & 0.32 & 1.27 & -0.01 & 40 & 3.93 & 0.04 & -0.26 & 0.00 & 0.05 & 0.92 & 1.34 & \begin{tabular}{|l|l|}
-0.06 \\
\end{tabular} \\
\hline & & & & el I: Siz & shock & & & & & & & & L: Val & e shock & (VL) & & \\
\hline & SMB & $Y$ & $\mathbf{L}$ & $F$ & H & SR & TS & $\mathbf{M}$ & & HML & $Y$ & $\mathbf{L}$ & $F$ & $\mathrm{H}$ & SR & TS & $M$ \\
\hline 0 & 3.08 & 0.00 & 0.00 & 0.33 & 0.00 & 0.00 & 0.00 & 0.44 & 0 & 3.81 & 0.00 & 0.00 & -0.10 & 0.00 & 0.00 & 0.00 & 0.74 \\
\hline 2 & 2.71 & 0.19 & -0.18 & 0.54 & 0.22 & -0.02 & -0.03 & 1.35 & 2 & 3.57 & -0.03 & -0.07 & -0.17 & 0.03 & 0.01 & -0.04 & 1.15 \\
\hline 4 & 2.01 & 0.45 & -0.25 & 0.65 & 0.36 & -0.01 & -0.13 & 2.60 & 4 & 4.38 & 0.03 & -0.15 & -0.25 & 0.14 & 0.01 & -0.05 & 1.18 \\
\hline 6 & 1.43 & 0.49 & 0.03 & 0.56 & 0.45 & 0.05 & -0.15 & 2.11 & 6 & 3.99 & 0.07 & -0.20 & -0.31 & 0.23 & 0.00 & -0.04 & 1.43 \\
\hline 8 & 1.36 & 0.47 & 0.27 & 0.61 & 0.54 & 0.02 & -0.12 & 1.96 & 8 & 4.16 & 0.18 & -0.27 & -0.31 & 0.31 & 0.00 & -0.04 & 1.61 \\
\hline 12 & 1.40 & 0.48 & 0.44 & 0.65 & 0.43 & 0.03 & -0.13 & 2.03 & 12 & 3.88 & 0.32 & -0.34 & -0.34 & 0.43 & 0.01 & -0.06 & 1.61 \\
\hline 20 & 1.60 & 0.19 & 0.65 & 0.63 & 0.16 & 0.02 & -0.10 & 1.92 & 20 & 3.90 & 0.36 & -0.36 & -0.43 & 0.53 & 0.01 & -0.08 & 1.34 \\
\hline 40 & 1.74 & 0.15 & 0.72 & 0.71 & 0.09 & 0.02 & -0.09 & 2.08 & 40 & 3.87 & 0.41 & -0.49 & -0.49 & 0.58 & 0.02 & -0.08 & 1.33 \\
\hline & & & anel $M$ & Mome & um sh & (MM & & & & & Par & $\mathrm{N}: \mathrm{St}$ & 8 mark & liquid & s shock & (SL) & \\
\hline & MOM & $Y$ & L & $F$ & $\mathrm{H}$ & SR & TS & $M$ & & PSL & $Y$ & L & $F$ & $\mathrm{H}$ & SR & TS & $M$ \\
\hline 0 & 3.50 & 0.00 & 0.00 & -0.12 & 0.00 & 0.00 & 0.00 & -0.21 & 0 & 6.34 & 0.00 & 0.00 & 0.11 & 0.00 & 0.00 & 0.00 & -0.09 \\
\hline 2 & 2.51 & \begin{tabular}{|l|}
-0.07 \\
\end{tabular} & 0.09 & -0.16 & -0.06 & 0.01 & 0.04 & -0.66 & 2 & -0.18 & 0.07 & -0.06 & 0.10 & -0.07 & 0.01 & 0.00 & -0.70 \\
\hline 4 & 2.42 & \begin{tabular}{|l|}
-0.17 \\
\end{tabular} & 0.14 & -0.16 & -0.14 & 0.00 & 0.07 & -1.04 & 4 & -0.39 & 0.11 & -0.09 & 0.15 & -0.18 & 0.02 & -0.02 & -0.60 \\
\hline 6 & 2.15 & \begin{tabular}{|l|l|}
-0.19 \\
\end{tabular} & 0.06 & -0.11 & -0.22 & -0.01 & 0.07 & -0.93 & 6 & -0.19 & 0.04 & -0.05 & 0.09 & -0.27 & 0.02 & -0.01 & \begin{tabular}{|c|c|}
-0.86 \\
\end{tabular} \\
\hline 8 & 2.36 & $\mid-0.23$ & 0.03 & -0.13 & -0.29 & 0.00 & 0.07 & -0.99 & 8 & 0.02 & -0.03 & 0.00 & 0.08 & -0.31 & 0.02 & 0.00 & -1.03 \\
\hline 12 & 2.17 & \begin{tabular}{|l|}
-0.30 \\
\end{tabular} & 0.00 & -0.12 & -0.31 & -0.01 & 0.08 & -1. & 12 & 0.01 & -0.04 & -0.06 & 0.13 & -0.35 & 0.00 & 0.02 & \begin{tabular}{|l|l|}
-0.83 \\
\end{tabular} \\
\hline 20 & 2.29 & \begin{tabular}{|l|}
-0.22 \\
\end{tabular} & -0.06 & -0.09 & -0.27 & -0.01 & 0.08 & -0.8 & 20 & 0.01 & -0.01 & -0.06 & 0.18 & -0.27 & 0.00 & 0.01 & -0.80 \\
\hline 40 & 2.31 & \begin{tabular}{|l|}
-0.23 \\
\end{tabular} & -0.03 & -0.08 & -0.27 & -0.01 & 0.08 & -0.90 & 40 & 0.00 & -0.05 & 0.01 & 0.19 & -0.30 & 0.00 & 0.01 & $\begin{array}{l}-0.82 \\
\end{array}$ \\
\hline
\end{tabular}


Table A3 (ctd): Identification of financial structural shocks: Empirical responses of selected variable for congruence evaluation with theoretical effects of structural shocks

\begin{tabular}{|c|c|c|c|c|c|c|c|c|c|c|c|c|c|c|c|c|c|}
\hline & \multicolumn{8}{|c|}{ Panel O: Leverage shock (LV) } & & \multicolumn{8}{|c|}{ Panel P: Risk aversion shock (RAV) } \\
\hline & LEV & $\mathbf{Y}$ & $\mathbf{L}$ & $\mathbf{F}$ & $\mathbf{H}$ & SR & TS & $\mathbf{M}$ & & FV & $\mathbf{Y}$ & $\mathbf{L}$ & $\mathbf{F}$ & $\mathbf{H}$ & SR & TS & $\mathbf{M}$ \\
\hline 0 & 3.78 & 0.00 & 0.00 & -0.10 & 0.00 & 0.00 & 0.00 & -0.03 & 0 & 0.57 & 0.00 & 0.00 & -0.26 & 0.00 & 0.00 & 0.00 & -0.35 \\
\hline 2 & -0.26 & -0.10 & 0.02 & -0.19 & -0.09 & 0.02 & 0.03 & -0.45 & 2 & 0.60 & -0.08 & 0.12 & -0.18 & 0.04 & -0.01 & 0.01 & -0.05 \\
\hline 4 & 0.11 & -0.24 & 0.06 & -0.28 & -0.23 & 0.03 & 0.05 & -0.75 & 4 & 0.42 & 0.00 & 0.04 & -0.03 & 0.25 & -0.05 & -0.01 & -0.06 \\
\hline 6 & -0.23 & -0.31 & 0.00 & -0.27 & -0.32 & 0.00 & 0.09 & -0.72 & 6 & 0.31 & 0.14 & -0.02 & 0.07 & 0.44 & -0.02 & -0.08 & 0.07 \\
\hline 8 & -0.01 & -0.34 & -0.09 & -0.29 & -0.40 & 0.00 & 0.10 & -0.63 & 8 & 0.26 & 0.18 & 0.02 & 0.09 & 0.56 & -0.01 & -0.13 & 0.04 \\
\hline 12 & 0.01 & -0.31 & -0.24 & -0.27 & -0.41 & -0.01 & 0.11 & -0.42 & 12 & 0.34 & 0.13 & 0.25 & 0.03 & 0.66 & 0.01 & -0.14 & -0.35 \\
\hline 20 & 0.05 & -0.17 & -0.32 & -0.23 & -0.25 & 0.00 & 0.08 & -0.39 & 20 & 0.40 & 0.00 & 0.34 & -0.04 & 0.44 & 0.00 & -0.10 & -0.34 \\
\hline \multirow[t]{3}{*}{40} & 0.00 & -0.19 & -0.31 & -0.26 & -0.24 & 0.00 & 0.08 & -0.49 & 40 & 0.38 & 0.03 & 0.30 & 0.00 & 0.45 & 0.00 & -0.10 & -0.23 \\
\hline & \multicolumn{8}{|c|}{ Panel Q: Risk appetite shock (RAP) } & & & & & & & & & \\
\hline & FRA & $\mathbf{Y}$ & $\mathbf{L}$ & $\mathbf{F}$ & $\mathbf{H}$ & SR & TS & M & & & & & & & & & \\
\hline 0 & 0.04 & 0.00 & 0.00 & 0.00 & 0.00 & 0.00 & 0.00 & 0.00 & & & & & & & & & \\
\hline 2 & 0.04 & 0.00 & 0.01 & 0.03 & 0.01 & 0.00 & 0.01 & 0.06 & & & & & & & & & \\
\hline 4 & 0.04 & 0.03 & 0.00 & 0.05 & 0.03 & -0.01 & 0.00 & 0.04 & & & & & & & & & \\
\hline 6 & 0.04 & 0.06 & 0.00 & 0.07 & 0.05 & -0.01 & -0.01 & 0.07 & & & & & & & & & \\
\hline 8 & 0.04 & 0.06 & 0.03 & 0.06 & 0.05 & 0.00 & -0.01 & 0.03 & & & & & & & & & \\
\hline 12 & 0.04 & 0.04 & 0.08 & 0.06 & 0.05 & 0.00 & -0.01 & -0.05 & & & & & & & & & \\
\hline 20 & 0.04 & 0.01 & 0.10 & 0.06 & 0.02 & 0.00 & -0.01 & -0.03 & & & & & & & & & \\
\hline 40 & 0.04 & 0.01 & 0.11 & 0.08 & 0.01 & 0.00 & 0.00 & 0.00 & & & & & & & & & \\
\hline
\end{tabular}

Each Panel in the Table reports impulse responses of selected variables to a given financial shock, i.e., monetary policy stance (MPS, Panel A), term structure level (TL, Panel B) and slope (TS, Panel C), US terms of trade shocks (TT, Pane D), stocks (PF, Panel E), housing (PH, Panel F), non-energy commodities (PM, Panel G) and gold (PG, Panel H) preferences, size (SZ, Panel I), value (VL, Panel L), momentum (MM, Panel M), stock market liquidity (SL, Panel N) and financial leverage (LV, Panel O), risk aversion and risk appetite (RAV, Panel P; RAP, Panel Q). The variables of interest are excess liquidity (L), real short term rate (SR) and term spread (TS), real housing prices $(H)$, real stock prices $(F)$, US\$ exchange rate index $(X)$, real activity $(Y)$, core inflation (N), real oil prices (OP), real non-energy commodities prices (M), real gold prices (GD), stock market volatility (FV), Fama-French size and value factors (SMB, HML), Carhart momentum factor (MOM), Pastor-Stambaugh stock market liquidity factor (PSL), Adrian-Etula-Muir leverage factor (LEV), Bagliano-Morana fragility index (FRA). Figures in bold denote statistical significance at the 5\% level. 
Real activity $(Y)$

\begin{tabular}{|c|c|c|c|c|c|c|c|c|c|c|c|c|c|c|c|c|c|c|c|c|c|c|c|c|c|c|c|c|c|c|c|c|c|}
\hline \multicolumn{34}{|c|}{ Real activity $(\mathrm{Y})$} \\
\hline & OR & \begin{tabular}{|l|} 
OSN \\
\end{tabular} & OSP & ox & LS & LD & AD & GFI & GDI & GTI & $\mathrm{Cl}$ & PR & OC & MPS & $\mathrm{TL}$ & TS & PH & $T T$ & RAV & SZ & $\mathrm{VL}$ & MM & $S L$ & LV & OFP & OFR & Ol & ORP & \begin{tabular}{|l|} 
ONV \\
\end{tabular} & PM & $\mathrm{PF}$ & PG & \begin{tabular}{|l|} 
RAP \\
\end{tabular} \\
\hline 0 & 0.3 & 5.8 & 1.0 & 2.5 & 8.5 & 2.1 & 79.9 & 0.0 & 0.0 & 0.0 & 0.0 & 0.0 & 0.0 & 0.0 & 0.0 & 0.0 & 0.0 & 0.0 & 0.0 & 0.0 & 0.0 & 0.0 & 0.0 & 0.0 & $\begin{array}{l}0.0 \\
\end{array}$ & 0.0 & 0.0 & $\begin{array}{l}0.0 \\
\end{array}$ & 0.0 & 0.0 & 0.0 & 0.0 & 0.0 \\
\hline 2 & 0.1 & 0.8 & 0.2 & 0.8 & 17.2 & 2.9 & 58.4 & 4.5 & 3.8 & 0.1 & 0.4 & 0.1 & 1.5 & 0.1 & 0.2 & 0.3 & 2.6 & 0.2 & 0.4 & 2.2 & 0.0 & 0.3 & 0.4 & 0.7 & 0.1 & 0.4 & 0.3 & 0.1 & 0.0 & 0.3 & 0.4 & 0.2 & 0.0 \\
\hline 4 & 0.4 & 0.4 & 0.2 & 0.8 & 20.7 & 1.4 & 35.4 & 9.3 & 2.4 & 0.7 & 0.9 & 1.8 & 2.4 & 0.1 & 2.3 & 1.4 & 4.5 & 0.8 & 0.3 & 7.4 & 0.1 & 1.0 & 0.5 & 2.0 & 0.2 & 0.5 & 0.7 & 0.2 & 0.1 & 0.2 & 0.9 & 0.1 & 0.0 \\
\hline 6 & 1.1 & 0.3 & 0.2 & 0.8 & \begin{tabular}{|l|}
18.3 \\
\end{tabular} & 0.8 & 21.4 & 12.1 & 1.3 & 1.9 & 1.4 & 5.8 & 2.3 & 0.3 & 4.3 & 2.8 & 5.2 & 2.4 & 0.5 & 8.8 & 0.1 & 1.2 & $\begin{array}{l}0.3 \\
\end{array}$ & 2.9 & 0.3 & 0.4 & 1.2 & 0.5 & 0.2 & 0.1 & 0.8 & $\begin{array}{l}0.1 \\
\end{array}$ & 0.1 \\
\hline 12 & 1.4 & 0.9 & 0.2 & 1.3 & 12.5 & $\begin{array}{l}0.5 \\
\end{array}$ & 9.4 & 13.8 & 0.6 & 2.7 & 1.3 & 10.9 & 2.2 & 0.2 & 6.7 & \begin{tabular}{|l|}
3.9 \\
\end{tabular} & 4.3 & 5.9 & 0.8 & 8 & 1.4 & 1.9 & $\begin{array}{l}0.2 \\
\end{array}$ & 3.2 & 0.6 & 0.5 & 2.8 & 1.1 & 0.2 & $\begin{array}{l}0.1 \\
\end{array}$ & 0.5 & 0.0 & 0.1 \\
\hline 20 & 1.9 & 2.9 & 0.3 & 1.1 & 8.9 & $\begin{array}{l}0.5 \\
\end{array}$ & 6.7 & 13.1 & 0.6 & 2.9 & $\begin{array}{l}0.9 \\
\end{array}$ & 14.5 & 1.7 & 0.3 & 6.5 & 4.1 & 3.2 & 8.6 & 0.6 & 6.2 & 2.9 & 2.1 & $\begin{array}{l}0.1 \\
\end{array}$ & 2.8 & 0.8 & 0.5 & 3.2 & 1.4 & 0.3 & 0.0 & 0.3 & $\begin{array}{l}0.1 \\
\end{array}$ & 0.1 \\
\hline 40 & 3.8 & 7.1 & 0.7 & 0.6 & 4.8 & 0.6 & 4.8 & 11.1 & 0.8 & 3.5 & 0.4 & 19.1 & 1.5 & 0.4 & 5.7 & 3.7 & 2.4 & 9.8 & 0.3 & 3.5 & 4.4 & 2 & $\begin{array}{l}0.1 \\
\end{array}$ & 2.1 & 0.8 & 0.4 & 3.1 & 1.4 & 0.4 & 0.0 & 0.2 & $\begin{array}{l}0.1 \\
\end{array}$ & 0.0 \\
\hline \multicolumn{34}{|c|}{ Real stock prices (F) } \\
\hline & OR & OSN & OSP & ox & LS & LD & AD & GFI & GDI & GTI & $\mathrm{Cl}$ & PR & oc & MPS & $\mathrm{TL}$ & TS & $\mathrm{PH}$ & $T$ & RAV & Sz & $\mathrm{VL}$ & MM & SL & LV & OFP & OFR & ol & ORP & ONV & PM & PF & PG & RAP \\
\hline 2 & 3.6 & 0.8 & 0.9 & 0.3 & 6.7 & 2.0 & 6.6 & 5.5 & 6.6 & 0.5 & 0.7 & 6.4 & 0.6 & 0.1 & 3.5 & 0.2 & 0.8 & 0.4 & 5.7 & 21.6 & 2.5 & 2.0 & 1.5 & 2.1 & 0.4 & 0.1 & 0.8 & 0.7 & 0.1 & 0.3 & 15.9 & 0.0 & 0.0 \\
\hline 4 & 2.3 & 4.3 & 1.8 & 0.2 & 7.0 & 3.8 & 3.9 & 6.0 & 4.6 & 0.6 & 1.4 & 4.3 & 0.7 & 0.2 & 4.3 & 0.7 & 1.2 & 0.8 & 3.0 & 22.9 & 2.9 & 1.8 & 1.5 & 3.2 & 0.4 & 0.1 & 0.4 & 0.8 & 0.6 & 0.2 & 14.0 & 0.1 & 0.1 \\
\hline 6 & 1.8 & 6.5 & 3.8 & 0.2 & 6.7 & 4.3 & 2.7 & 6.2 & 3.7 & 0.6 & 2.0 & 3.2 & 0.7 & 0.3 & 4.8 & 1.0 & 1.3 & 0.9 & 2.1 & 21.8 & 3.9 & 1.4 & 1.2 & 3.6 & 0.3 & 0.1 & 0.4 & 0.7 & 0.8 & 0.2 & 12.8 & 0.1 & 0.1 \\
\hline 8 & 2.0 & 7.6 & 4.9 & 0.2 & 6.7 & 4.3 & 2.1 & 6.3 & 3.4 & 0.5 & 2.4 & 3.2 & 0.8 & 0.2 & 4.7 & 1.0 & 1.2 & 0.8 & 1.6 & 21.1 & 4.2 & 1.3 & 0.9 & 3.8 & 0.3 & 0.0 & 0.3 & 0.6 & 0.8 & 0.2 & 12.1 & 0.1 & 0.2 \\
\hline 12 & 3.1 & 9.4 & 5.1 & 0.3 & 6.3 & 4.5 & 1.6 & 5.7 & 3.4 & 0.3 & 2.7 & 4.3 & 0.7 & 0.2 & 4.2 & 1.0 & 0.9 & 0.6 & 1.1 & 20.8 & 4.6 & 1.1 & 0.8 & 3.7 & 0.3 & 0.0 & 0.2 & 0.6 & 0.7 & 0.1 & 11.2 & 0.1 & 0.2 \\
\hline 20 & 4.9 & 13.7 & 5.4 & 0.4 & 5.6 & 5.2 & 1.0 & 4.2 & 3.9 & 0.4 & 2.7 & 6.7 & 0.4 & 0.1 & 3.1 & 0.7 & 0.5 & 0.4 & 0.6 & 18.2 & 5.2 & 0.8 & 0.9 & 2.9 & 0.2 & 0.0 & 0.1 & 0.6 & 0.7 & 0.1 & 10.0 & 0.0 & 0.2 \\
\hline 40 & 6.3 & 18.4 & 5.9 & 0.5 & 5.7 & 5.1 & 0.6 & 2.7 & 4.4 & 0.4 & 2.6 & 8.6 & 0.2 & 0.1 & 2.0 & 0.5 & 0.3 & 0.2 & 0.3 & 15.3 & 5.9 & 0.4 & 1.0 & 2.2 & 0.1 & 0.0 & 0.1 & 0.7 & 0.8 & 0.1 & 8.3 & 0.0 & 0.1 \\
\hline \multicolumn{34}{|c|}{ Stock market volatility (FV) } \\
\hline & OR & OSN & OSP & $0 x$ & LS & LD & AD & GFI & GDI & GTI & $\mathrm{Cl}$ & PR & OC & MPS & $\mathrm{TL}$ & TS & PH & $\pi T$ & RAV & SZ & $\mathrm{VL}$ & MM & $S \mathrm{~L}$ & LV & OFP & OFR & Ol & ORP & \begin{tabular}{|l|} 
ONV \\
\end{tabular} & PM & $\mathrm{PF}$ & PG & \begin{tabular}{|l|} 
RAP \\
\end{tabular} \\
\hline 0 & 6.2 & 1.0 & 0.0 & 2.6 & 1.2 & 3.2 & 4.2 & 0.8 & 0.4 & 8.9 & $\begin{array}{ll}1.1 \\
\end{array}$ & 7.4 & 1.1 & 0.0 & 0.1 & 0.3 & 3.4 & 0.3 & 57.6 & 0.0 & 0.0 & 0.0 & 0.0 & 0.0 & 0.0 & 0.0 & 0.0 & 0.0 & 0.0 & 0.0 & 0.0 & 0.0 & 0.0 \\
\hline 2 & 9.1 & 0.4 & 0.5 & 1.5 & 3.5 & 1.8 & 6.8 & 0.4 & 1.9 & 5.8 & 0.4 & 12.2 & 1.2 & 0.8 & 0.1 & 0.2 & 2.6 & \begin{tabular}{ll|}
0.1 \\
\end{tabular} & 42.7 & 5.9 & 0.2 & 0.7 & 0.3 & 0.1 & 0.0 & \begin{tabular}{|l|}
0.1 \\
\end{tabular} & 0.2 & 0.0 & 0.1 & 0.0 & 0.3 & 0.0 & 0.0 \\
\hline 8 & 4.9 & 4.4 & 0.5 & 4.1 & 3.0 & 3.1 & 6.5 & 0.5 & 1.7 & 4.9 & 0.2 & 7.7 & 3.1 & 5.0 & 0.1 & 0.4 & 5.2 & 0.2 & 31.4 & 5.9 & 0.5 & 0.8 & 0.7 & 1.6 & 0.1 & 1.2 & 0.5 & 0.1 & 0.5 & 0.4 & 0.3 & 0.7 & 0.0 \\
\hline 12 & 3.9 & 3.9 & 0.8 & 5.8 & 2.6 & 2.6 & 7.5 & 0.4 & 2.0 & 5.3 & 0.2 & 6.1 & 4.7 & 6.7 & 0.2 & 0.3 & 5.2 & 0.2 & 28.4 & 4.5 & 0.8 & 0.7 & 1.3 & 1.6 & 0.1 & 1.4 & 0.7 & 0.1 & 0.4 & 0.3 & 0.4 & 0.8 & 0.0 \\
\hline 20 & 3.0 & 4.4 & $\begin{array}{l}1.7 \\
\end{array}$ & 8.2 & 3.1 & 2.1 & 7.2 & 0.4 & 2.4 & 5.3 & $\begin{array}{l}0.5 \\
\end{array}$ & 4.0 & 5.6 & 8.2 & 0.4 & $\begin{array}{l}0.2 \\
\end{array}$ & 4.1 & \begin{tabular}{l|l}
0.2 \\
\end{tabular} & 26.0 & 3.0 & 1.5 & 0.5 & 1.5 & 1.2 & 0.1 & 1.7 & 1.0 & 0.0 & 0.3 & 0.3 & 0.8 & $\begin{array}{l}1.1 \\
\end{array}$ & 0.0 \\
\hline 40 & 3.1 & 6.6 & 2.9 & 10.5 & 3.7 & 1.4 & 6.9 & 0.3 & 3.0 & $\begin{array}{l}4.4 \\
\end{array}$ & 0.8 & 2.0 & 6.1 & 9.0 & 0.5 & $\begin{array}{ll}0.1 \\
\end{array}$ & 2.9 & 0.2 & 22.5 & 1.8 & 2.3 & 0.4 & 1.7 & $\begin{array}{l}0.7 \\
\end{array}$ & 0.0 & 1.9 & 1.2 & 0.0 & 0.2 & 0.2 & 1.2 & 1.4 & 0.1 \\
\hline \multicolumn{34}{|c|}{ Size factor (SMB) } \\
\hline & OR & OSN & OSP & ox & LS & LD & $A D$ & GFI & GDI & GTI & $\mathrm{Cl}$ & PR & OC & MPS & $\mathrm{TL}$ & TS & PH & TT & RAV & Sz & $\mathrm{VL}$ & MM & SL & LV & OFP & OFR & ol & ORP & \begin{tabular}{|l|} 
ONV \\
\end{tabular} & PM & PF & PG & RAP \\
\hline 0 & 3.0 & 0.1 & 1.0 & 0.1 & 0.2 & 1.2 & 1.0 & 0.7 & 0.0 & 5.4 & 0.0 & 15.4 & 0.2 & 14.0 & 1.3 & 0.4 & 0.6 & 1.3 & 0.1 & 53.9 & 0.0 & 0.0 & 0.0 & 0.0 & 0.0 & 0.0 & 0.0 & 0.0 & 0.0 & 0.0 & 0.0 & 0.0 & 0.0 \\
\hline 2 & 1.7 & 1.4 & 1.5 & 0.4 & 0.2 & 3.2 & 2.9 & 0.7 & 0.6 & 4.3 & 0.1 & 16.0 & 1.4 & 14.7 & 0.5 & 0.3 & 0.7 & 3.0 & 0.6 & 43.9 & 0.1 & 0.2 & 0.2 & 0.0 & 0.0 & 0.5 & 0.3 & 0.1 & 0.2 & 0.0 & 0.1 & 0.0 & 0.0 \\
\hline 4 & 1.1 & 1.7 & 2.3 & 0.3 & 0.2 & 2.6 & 3.6 & 0.9 & 1.4 & 2.6 & 0.4 & 17.2 & 1.5 & 15.0 & 0.6 & 0.2 & 0.5 & 3.7 & 2.1 & 36.7 & 0.2 & 0.4 & 0.5 & 0.1 & 0.0 & 0.9 & 1.4 & 0.6 & 0.8 & 0.1 & 0.3 & 0.2 & 0.0 \\
\hline 6 & 0.9 & 2.4 & 2.7 & 0.3 & 1.0 & 2.1 & 3.5 & 0.7 & 1.7 & 2.2 & 0.5 & 17.4 & 1.1 & 15.3 & 0.7 & 0.3 & 0.4 & 4.6 & 4.2 & 29.9 & 0.2 & 0.9 & 1.1 & 0.1 & 0.1 & $\begin{array}{ll}1.0 \\
\end{array}$ & 2.2 & 0.7 & 0.8 & 0.2 & 0.6 & 0.2 & 0.0 \\
\hline 8 & 0.7 & 2.8 & 3.4 & 0.3 & 1.9 & $\begin{array}{ll}2.8 \\
\end{array}$ & 3.6 & 0.6 & 1.6 & 2.3 & 0.4 & 19.0 & 0.9 & 14.8 & 1.2 & 0.4 & 0.4 & 5.2 & 4.8 & 24.2 & 0.1 & 1.2 & 1.3 & $\begin{array}{l}0.1 \\
\end{array}$ & 0.2 & $\begin{array}{ll}1.0 \\
\end{array}$ & 3.0 & 0.8 & 0.6 & $\begin{array}{l}0.2 \\
0.2\end{array}$ & 0.8 & 0.3 & 0.0 \\
\hline 12 & 0.9 & 2.9 & 4.6 & 0.3 & 2.1 & 1.4 & 4.3 & 0.5 & 1.1 & 3.0 & 0.3 & 23.0 & 0.7 & 13.2 & 2.1 & 0.6 & 0.6 & \begin{tabular}{|l|}
6.1 \\
\end{tabular} & 4.2 & 17.8 & 0.2 & 1.4 & 1.1 & 0.1 & 0.2 & \begin{tabular}{|l|}
0.9 \\
\end{tabular} & 3.8 & 1.0 & 0.5 & 0.2 & 0.8 & 0.3 & 0.0 \\
\hline 20 & 1.4 & 1.9 & 4.5 & 0.2 & 1.7 & 0.8 & 4.7 & 0.4 & 0.7 & 3.9 & 0.3 & 27.5 & 0.8 & 11.7 & 2.7 & 0.9 & 0.7 & 6.4 & 3.5 & 13.7 & 0.4 & 1.7 & 0.7 & $\begin{array}{l}0.1 \\
\end{array}$ & 0.3 & \begin{tabular}{|l|}
0.9 \\
\end{tabular} & 4.4 & 1.4 & 0.5 & 0.2 & 0.7 & 0.3 & 0.0 \\
\hline 40 & 2.4 & 1.1 & 3.4 & 0.2 & 1.0 & $\begin{array}{l}0.4 \\
\end{array}$ & $\begin{array}{l}4.7 \\
\end{array}$ & 0.3 & 0.4 & 4.6 & 0.5 & 31.7 & 0.9 & 10.3 & 2.7 & $\begin{array}{l}1.0 \\
\end{array}$ & $\begin{array}{l}0.7 \\
\end{array}$ & 6.5 & 3.1 & 11.9 & 0.8 & 1.8 & 0.4 & 0. & 0.2 & 0.8 & 4.6 & 1.7 & 0.7 & 0.2 & 0.5 & 0.3 & 0.0 \\
\hline \multicolumn{34}{|c|}{ Value factor (HML) } \\
\hline & OR & OSN & OSP & ox & LS & LD & AD & GFI & GDI & GTI & $\mathrm{Cl}$ & PR & OC & MPS & TL & TS & $\mathrm{PH}$ & $T T$ & RAV & SZ & $\mathrm{VL}$ & MM & SL & LV & OFP & OFR & Ol & ORP & \begin{tabular}{|l|l} 
ONV \\
\end{tabular} & PM & PF & PG & \begin{tabular}{|l|} 
RAP \\
\end{tabular} \\
\hline 0 & 0.3 & 0.1 & 1.5 & 3.9 & 6.5 & 0.2 & 0.0 & 7.1 & 8.2 & 0.2 & 0.4 & 0.0 & 3.5 & $\begin{array}{l}0.4 \\
\end{array}$ & 0.1 & $\begin{array}{l}0.1 \\
\end{array}$ & 0.1 & \begin{tabular}{|l|}
7.4 \\
\end{tabular} & 2.4 & 1.3 & 56.4 & 0.0 & 0.0 & 0.0 & 0.0 & \begin{tabular}{|l|}
0.0 \\
\end{tabular} & 0.0 & 0.0 & 0.0 & 0.0 & 0.0 & 0.0 & 0.0 \\
\hline 2 & 0.9 & 0.5 & 0.6 & 4.0 & \begin{tabular}{|l}
14.5 \\
\end{tabular} & 0.5 & 0.4 & 7.5 & 2.7 & 0.3 & 0.9 & 0.4 & 3.6 & 0.5 & 0.2 & 2.2 & 0.7 & 4.6 & 2.2 & 1.0 & 49.4 & 0.0 & 0.9 & 0.0 & 0.1 & 0.5 & 0.3 & 0.1 & 0.1 & 0.1 & 0.0 & 0.2 & 0.0 \\
\hline 4 & 0.9 & 0.6 & 0.5 & 4.8 & \begin{tabular}{|l}
10.8 \\
\end{tabular} & 1.3 & 0.3 & 5.6 & 2.6 & 0.5 & $\begin{array}{l}0.7 \\
\end{array}$ & 0.7 & 2.3 & 0.4 & 0.3 & $\begin{array}{l}3.1 \\
\end{array}$ & 0.6 & 3.0 & 1.5 & 1.4 & 50.8 & 0.1 & 4.1 & $\begin{array}{l}0.1 \\
\end{array}$ & 0.1 & 1.0 & 0.4 & 0.1 & 0.7 & $\begin{array}{l}0.1 \\
\end{array}$ & 0.0 & $\begin{array}{l}0.3 \\
\end{array}$ & 0.0 \\
\hline 6 & 1.7 & 1.7 & 0.5 & 4.2 & 7.9 & 2.1 & 1.8 & 4.4 & 2.5 & 0.5 & 0.5 & 2.2 & 1.6 & 1.0 & 0.3 & 2.8 & 0.4 & 2.1 & 1.4 & 2.3 & 49.6 & 0.3 & 4.4 & $\begin{array}{l}0.1 \\
\end{array}$ & 0.1 & \begin{tabular}{|l|}
1.7 \\
\end{tabular} & $\begin{array}{l}0.4 \\
\end{array}$ & 0.1 & 1.0 & $\begin{array}{l}0.1 \\
\end{array}$ & 0.1 & 0.2 & 0.0 \\
\hline 8 & 2.2 & 3.7 & 1.0 & 3.8 & 6.0 & 2.7 & 3.2 & 3.5 & 3.3 & 0.6 & $\begin{array}{l}0.4 \\
\end{array}$ & 3.1 & 1.2 & 1.2 & 0.5 & 2.8 & 0.3 & $\begin{array}{l}1.5 \\
\end{array}$ & 1.8 & 1.8 & 46.3 & 0.2 & 4.5 & $\begin{array}{l}0.1 \\
\end{array}$ & 0.1 & 2.0 & 0.8 & 0.1 & 0.8 & $\begin{array}{l}0.1 \\
\end{array}$ & 0.1 & $\begin{array}{l}0.2 \\
\end{array}$ & 0.0 \\
\hline 12 & 3.5 & 5.9 & 2.2 & 2.9 & 3.9 & 2.6 & 3.8 & 2.6 & 3.9 & 0.8 & 0.3 & 3.1 & 1.1 & 1.5 & 0.9 & 3.2 & 0.2 & 1.0 & 2.8 & 1.3 & 41.7 & 0.2 & 5.0 & 0.1 & 0.2 & 2.3 & 1.5 & 0.2 & 0.8 & 0.1 & 0.3 & 0.2 & 0.0 \\
\hline
\end{tabular}


Momentum factor (MOM)

\begin{tabular}{|c|c|c|c|c|c|c|c|c|c|c|c|c|c|c|c|c|c|c|c|c|c|c|c|c|c|c|c|c|c|c|c|c|c|}
\hline \multicolumn{34}{|c|}{ Momentum factor (MOM) } \\
\hline & OR & OSN & OSP & OX & LS & LD & AD & GFI & GDI & GTI & Cl & PR & OC & MPS & TL & TS & PH & $\pi$ & RAV & SZ & VL & MM & SL & LV & OFP & OFR & OI & ORP & ONV & PM & PF & PG & RAP \\
\hline 0 & 1.5 & 1.1 & 0.5 & 0.3 & 2.5 & 0.4 & 0.0 & 2.4 & 3.3 & 4.1 & 1.1 & 0.0 & 0.4 & 0.5 & 1.2 & 4.8 & 0.2 & 1.2 & 0.7 & 22.0 & 16.7 & 35.2 & 0.0 & 0.0 & 0.0 & 0.0 & 0.0 & 0.0 & 0.0 & 0.0 & 0.0 & 0.0 & 0.0 \\
\hline 2 & 1.1 & 1.9 & 4.0 & 0.4 & 3.7 & 0.2 & 4.4 & 1.5 & 3.5 & 7.0 & 0.5 & 3.6 & 0.4 & 0.8 & 2.3 & 3.1 & 2.0 & 0.6 & 2.2 & 11.4 & 14.0 & 27.5 & 2.1 & 0.1 & 0.3 & 0.0 & 0.1 & 0.2 & 0.6 & 0.1 & 0.1 & 0.4 & 0.1 \\
\hline 4 & 1.3 & 1.6 & 3.1 & 0.3 & 2.8 & 0.1 & 9.7 & 1.0 & 9.0 & 9.0 & 0.3 & 5.7 & 1.4 & 0.5 & 2.6 & 2.6 & 1.9 & 1.2 & 5.3 & 5.7 & 8.4 & 18.0 & 5.0 & 0.1 & 0.7 & 0.0 & 0.1 & 0.3 & 0.6 & 0.1 & 0.4 & 0.7 & 0.1 \\
\hline 6 & 1.0 & 1.2 & 2.8 & 0.2 & 2.8 & 0.6 & 9.3 & 1.4 & 10.1 & 9.9 & 0.3 & 4.9 & 2.1 & 0.8 & 2.2 & 2.3 & 1.9 & 3.6 & 5.7 & 4.0 & $\begin{array}{ll}6.7 \\
\end{array}$ & 15.2 & 6.7 & 0.1 & 1.0 & 0.1 & 0.1 & 0.4 & 0.4 & 0.1 & 0.6 & 1.5 & 0.0 \\
\hline 12 & 0.6 & 0.7 & 1.5 & 0.3 & 2.1 & 1.3 & 6.9 & 2.7 & 9.9 & 10.1 & 0.2 & 2.5 & 3.2 & 1.6 & 1.4 & $\begin{array}{l}1.4 \\
\end{array}$ & 2.3 & 12.0 & 4.1 & 2.5 & 4.5 & 12.3 & 8.6 & 0.1 & 2.1 & 0.1 & 0.1 & 0.4 & 0.2 & 0.3 & 0.6 & 3.4 & 0.0 \\
\hline 20 & 0.5 & 0.8 & 0.9 & 0.2 & 1.4 & 1.5 & 5.0 & 2.8 & 8.2 & 9.7 & 0.2 & 1.8 & 4.5 & 1.9 & 1.1 & $\begin{array}{l}0.9 \\
\end{array}$ & 3.3 & 17.7 & 3.7 & 2.6 & 3.0 & 10.4 & 9.2 & 0.1 & 2.6 & 0.1 & 0.1 & 0.3 & 0.2 & 0.4 & 0.4 & 4.4 & 0.0 \\
\hline 40 & 0.8 & 1.8 & 0.8 & 0.2 & 1.0 & 1.4 & 3.5 & 2.1 & 6.2 & 8.3 & 0.4 & 1.6 & 5.1 & 2.1 & 1.2 & 0.6 & 4.0 & 20.9 & 4.2 & 4.1 & 1.5 & 9.3 & 9.3 & 0.1 & 2.8 & 0.2 & 0.1 & 0.3 & 0.2 & 0.5 & 0.2 & 5.2 & 0.0 \\
\hline \multicolumn{34}{|c|}{ Stock market liquidity factor (PSL) } \\
\hline & OR & OSN & OSP & ox & LS & LD & AD & GFI & GDI & GTI & $\mathrm{Cl}$ & PR & oc & MPS & $\mathrm{TL}$ & TS & $\mathrm{PH}$ & $\pi$ & RAV & Sz & VL & MM & SL & LV & OFP & OFR & OI & ORP & ONV & PM & PF & PG & RAP \\
\hline 2 & 5.1 & 3.8 & 2.3 & 0.2 & 3.0 & 0.9 & 1.2 & 1.0 & 1.7 & 2.2 & 0.2 & 1.4 & 1.1 & 0.2 & 2.6 & 0.4 & 2.6 & 2.7 & 8.6 & 10.5 & 1.5 & 2.0 & 43.9 & 0.0 & 0.0 & 0.1 & 0.5 & 0.1 & 0.0 & 0.1 & 0.0 & 0.0 & 0.0 \\
\hline 4 & 4.7 & 5.9 & 2.2 & 0.4 & 3.7 & 0.9 & 1.5 & 1.4 & 2.6 & 2.6 & 0.8 & 1.8 & 1.7 & 1.4 & 2.5 & 0.5 & 2.5 & 2.3 & 7.8 & 9.3 & 2.3 & 1.7 & 37.8 & 0.0 & 0.1 & 0.3 & 0.5 & 0.1 & 0.4 & 0.1 & 0.0 & 0.1 & 0.0 \\
\hline 6 & 4.7 & 5.6 & 2.2 & 0.6 & 4.7 & \begin{tabular}{ll|}
1.1 \\
\end{tabular} & 1.9 & 1.7 & 2.5 & 2.9 & 1.2 & 2.0 & 1.8 & 1.5 & 2.4 & $\begin{array}{ll}0.5 \\
\end{array}$ & 2.3 & 2.2 & 8.0 & 8.6 & 2.3 & 1.6 & 35.3 & 0.1 & 0.1 & 0.3 & 0.5 & 0.3 & 0.5 & 0.1 & 0.1 & 0.1 & 0.0 \\
\hline 8 & 4.6 & 6.3 & 2.1 & 0.6 & 4.6 & 1.2 & 2.3 & 1.6 & 2.9 & 3.0 & 1.2 & 2.2 & 1.9 & 1.6 & 2.5 & 0.6 & 2.3 & 2.2 & 7.8 & 8.3 & 2.5 & 1.6 & 33.8 & 0.1 & 0.1 & 0.3 & 0.6 & 0.3 & 0.5 & 0.1 & 0.1 & 0.1 & 0.0 \\
\hline 12 & 4.6 & 6.4 & 2.4 & 0.8 & 4.8 & 1.3 & 2.3 & 1.6 & 3.0 & 3.0 & 1.2 & 2.3 & 1.9 & 1.6 & 2.6 & $\begin{array}{ll}0.6 \\
\end{array}$ & 2.3 & 2.2 & 7.6 & 8.4 & 2.4 & 1.6 & 32.7 & 0.1 & 0.1 & 0.3 & 0.7 & 0.3 & 0.5 & 0.1 & 0.1 & 0.1 & 0.0 \\
\hline 20 & 4.6 & 6.4 & 2.5 & 0.8 & 4.8 & 1.3 & 2.3 & 1.7 & 3.0 & 3.0 & 1.2 & 2.3 & 1.9 & 1.6 & 2.6 & $\begin{array}{l}0.6 \\
\end{array}$ & 2.3 & 2.2 & 7.6 & 8.5 & 2.4 & 1.6 & 32.3 & 0.2 & 0.1 & 0.3 & 0.6 & 0.3 & 0.5 & 0.1 & 0.1 & 0.2 & 0.0 \\
\hline 40 & 4.6 & 6.4 & 2.5 & 0.8 & 4.8 & 1.3 & 2.3 & 1.7 & 3.0 & 3.0 & 1.2 & 2.3 & 1.9 & 1.6 & 2.6 & $\begin{array}{ll}0.6 \\
\end{array}$ & 2.3 & 2.2 & 7.6 & 8.5 & 2.4 & 1.6 & 32.3 & 0.2 & 0.1 & 0.3 & 0.6 & 0.3 & 0.6 & 0.1 & 0.1 & 0.2 & 0.0 \\
\hline \multicolumn{34}{|c|}{ Leverage factor (LEV) } \\
\hline & OR & OSN & OSP & ox & LS & LD & $A D$ & GFI & GDI & GTI & $\mathrm{Cl}$ & PR & OC & MPS & $\mathrm{TL}$ & TS & PH & $\pi$ & RAV & Sz & VL & MM & SL & LV & OFP & OFR & OI & ORP & ONV & PM & PF & PG & RAP \\
\hline 0 & 3.7 & 0.1 & 2.2 & 0.4 & 3.5 & 0.9 & 0.0 & 0.0 & 1.1 & 5.0 & 2.2 & 3.4 & 3.9 & 0.2 & 0.9 & 0.5 & 2.0 & 0.3 & 12.1 & 2.2 & 0.2 & 0.7 & 0.5 & 53.8 & 0.0 & 0.0 & 0.0 & 0.0 & 0.0 & 0.0 & 0.0 & 0.0 & 0.0 \\
\hline 2 & 4.3 & 0.3 & 4.0 & 0.4 & 4.7 & 1.9 & 1.2 & 0.6 & 10.5 & 5.2 & 1.6 & 7.4 & 4.5 & 0.7 & 1.3 & 1.7 & 1.4 & 0.4 & 13.4 & 3.2 & 1.1 & 1.0 & 1.0 & 26.8 & 0.1 & 0.1 & 0.2 & 0.1 & 0.2 & 0.4 & 0.3 & 0.0 & 0.2 \\
\hline 8 & 4.8 & 2.3 & 4.1 & 0.7 & 5.1 & 1.9 & 1.3 & 0.6 & 9.1 & 4.2 & 1.7 & 6.5 & 4.1 & 1.6 & 1.3 & 2.1 & 1.2 & 0.9 & 14.1 & 3.6 & 1.4 & 1.0 & 1.3 & 21.3 & 0.1 & 0.5 & 0.7 & 0.3 & 0.6 & 0.5 & 0.5 & 0.7 & 0.2 \\
\hline 12 & 4.8 & 2.6 & 4.1 & 0.7 & 5.1 & 2.0 & 1.4 & 0.6 & 9.0 & 4.2 & 1.7 & 6.4 & 4.2 & 1.6 & 1.3 & 2.1 & 1.2 & 0.9 & 14.0 & 3.6 & 1.4 & 1.0 & 1.4 & 20.9 & 0.1 & 0.5 & 0.7 & 0.3 & 0.6 & 0.5 & 0.5 & 0.7 & 0.2 \\
\hline 20 & 4.8 & 2.7 & 4.2 & 0.7 & 5.1 & 2.0 & 1.4 & 0.7 & 8.9 & 4.2 & 1.7 & 6.4 & 4.2 & 1.6 & 1.3 & 2.1 & 1.2 & 0.9 & 14.0 & 3.6 & 1.4 & 1.0 & 1.4 & 20.7 & 0.1 & 0.5 & 0.7 & 0.3 & 0.6 & 0.5 & 0.5 & 0.7 & 0.2 \\
\hline 40 & 4.8 & 2.7 & 4.2 & 0.7 & 5.1 & 2.0 & 1.4 & 0.7 & 8.9 & 4.2 & 1.7 & 6.3 & 4.2 & 1.6 & 1.3 & 2.1 & 1.2 & 0.9 & 13.9 & 3.7 & 1.4 & 1.0 & 1.4 & 20.7 & 0.1 & 0.5 & 0.7 & 0.3 & 0.6 & 0.5 & 0.5 & 0.7 & 0.2 \\
\hline \multicolumn{34}{|c|}{ Financial fragility index (FRA) } \\
\hline & OR & OSN & OSP & ox & LS & LD & AD & GFI & GDI & GTI & $\mathrm{Cl}$ & PR & oc & MPS & $\mathrm{TL}$ & TS & $\mathrm{PH}$ & $\pi$ & RAV & Sz & VL & MM & SL & LV & OFP & OFR & OI & ORP & ONV & PM & PF & PG & RAP \\
\hline 0 & 4.4 & 0.2 & 0.0 & 0.0 & 4.6 & 0.0 & 8.0 & 0.1 & 3.2 & 1.4 & 1.2 & 6.1 & 1.6 & 0.0 & 0.2 & 0.2 & 1.6 & 0.8 & 15.8 & 0.1 & 13.9 & 1.5 & 0.0 & 0.0 & 0.1 & 5.0 & 0.9 & 0.1 & 2.7 & 10.6 & 0.2 & 0.6 & 15.0 \\
\hline 2 & 3.6 & 0.7 & 0.5 & $\begin{array}{l}1.7 \\
\end{array}$ & 5.7 & 1.4 & 5.4 & 0.9 & 4.0 & 0.9 & 0.8 & 2.4 & 3.7 & 0.2 & $\begin{array}{l}3.4 \\
\end{array}$ & 0.2 & 1.1 & 0.4 & 6.4 & 0.5 & 16.2 & 2. & 2.2 & 0.3 & 0. & 5.3 & 0.5 & 0.9 & 4.8 & 9.7 & 0.1 & 1.1 & 12.7 \\
\hline 4 & 3.1 & 1.9 & 0.5 & 1.3 & 4.9 & 1.1 & 5.2 & 0.8 & 4.0 & 1.7 & 0.8 & 3.2 & 3.8 & 1.5 & 5.0 & $\begin{array}{ll}0.3 \\
\end{array}$ & 1.7 & 0.7 & 4.8 & 0.5 & \begin{tabular}{|l|l}
15.7 \\
\end{tabular} & 1.9 & 3.2 & 0.3 & 0.1 & 4.1 & 0.8 & 0.8 & 3.7 & 7.9 & 0.3 & 0.8 & 13.5 \\
\hline 6 & 3.2 & 5.3 & 0.4 & 1.1 & 6.0 & 1.0 & 4.1 & 1.9 & 4.9 & 1.3 & 0.6 & 3.4 & 3.1 & 1.8 & 3.7 & $\begin{array}{ll}0.4 \\
\end{array}$ & 2.9 & 0.6 & 4.2 & 4.0 & 12.8 & 1. & 4.2 & 0.3 & 0. & 2. & 1.4 & 0.6 & 3.0 & 6.0 & 0.9 & 0.6 & 12.2 \\
\hline 8 & 2.5 & 9.6 & 0.5 & 0.8 & 6.3 & 1.1 & 2.9 & 2.7 & 4.2 & 1.2 & 0.5 & 2.5 & 3.0 & 1.3 & 2.6 & 0.6 & 3.9 & 0.7 & 3.1 & 7.3 & 11.1 & 1.0 & 4.3 & 0.4 & 0.2 & 2.4 & 1.8 & 0.5 & 3.0 & 5.4 & 1.2 & 0.4 & 11.2 \\
\hline 12 & 1.9 & 13.1 & 1.4 & 0.9 & 6.2 & 1.1 & 2.1 & 3.8 & 3.5 & 0.9 & 0.5 & 1.7 & 3.0 & 1.2 & 1.8 & $\begin{array}{ll}0.8 \\
\end{array}$ & 4.3 & 0.9 & 2.1 & 8.8 & 9.2 & 0.7 & 4.1 & 0.5 & 0.3 & 1.9 & 2.3 & 0.4 & 3.0 & 5.0 & 1.3 & 0.3 & 11.0 \\
\hline 20 & 2.0 & 16.4 & 1.6 & 0.9 & 5.2 & 1.2 & 1.4 & 3.9 & 2.9 & 0.6 & 0.4 & 1.4 & 3.4 & 1.0 & 1.3 & 1.0 & 4.1 & 1.0 & 1.4 & 9.8 & 8.5 & 0.5 & 4.3 & 0.5 & 0.3 & 1.5 & 2.6 & 0.3 & 2.9 & 4.9 & 1.3 & 0.2 & 11.2 \\
\hline 40 & 2.2 & 20.2 & 1.8 & $\begin{array}{l}0.7 \\
\end{array}$ & 4.5 & 1.3 & 0.8 & 3.3 & 2.8 & 0.3 & 0.2 & 1.5 & 4.1 & 1.0 & $\begin{array}{l}0.9 \\
\end{array}$ & $\begin{array}{ll}0.9 \\
\end{array}$ & 3.8 & 0.7 & 0.8 & 9.9 & 8.4 & 0.3 & 4.6 & 0.4 & 0.3 & 1.3 & 2.5 & 0.3 & 2.9 & 4.6 & 1.3 & 0.1 & 11.1 \\
\hline
\end{tabular}

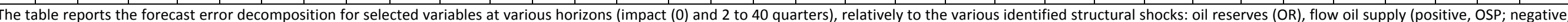

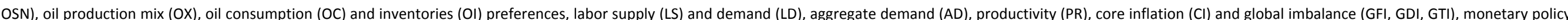

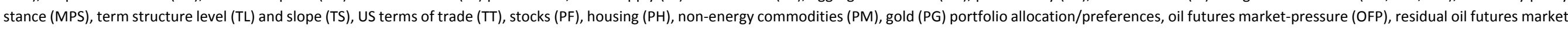

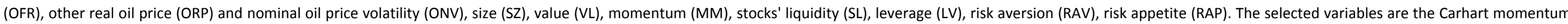
(MOM), Pastor-Stambaugh stocks' liquidity (PSL), Adrian-Etula-Muir leverage (LEV) and Bagliano-Morana fragility (FRA) factors. 